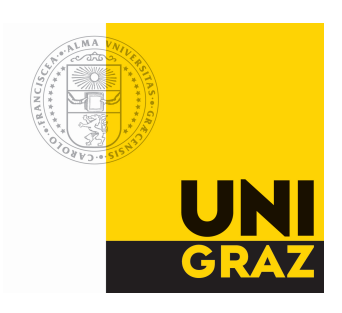

\title{
MATHEMATICAL MODEL FOR SOLUTE KINETICS AND BODY COMPOSITION IN HEMODIALYSIS PATIENTS
}

\section{Dissertation}

zur Erlangung des akademischen Grades

Doktor der Naturwissenschaften

vorgelegt von

\section{Rashida Hussain}

an der Naturwissenschaftlichen Fakultät

der Karl-Franzens-Universität Graz

Betreuer:

Em.Univ.-Prof. Dr. Franz Kappel

Institut für Mathematik und Wissenschaftliches Rechnen

Heinrichstrasse 36, A 8010 Graz

Karl-Franzens-Universität Graz

Graz, April 2012 
Copyright by Rashida Hussain 2012 All Rights reserved 


\section{Contents}

$\begin{array}{lll}1 & \text { Introduction } & 1\end{array}$

$\begin{array}{lll}2 & \text { Human kidney And Dialysis } & 7\end{array}$

$2.1 \quad$ Anatomy of Kidney $\ldots \ldots \ldots \ldots$. . . . . . . 7

$2.2 \quad$ Kidney Function $\ldots \ldots \ldots \ldots \ldots$

$2.2 .1 \quad$ Nephron as a Functional Unit. . . . . . . . . 11

$2.2 .2 \quad$ Uraemic Syndrome. . . . . . . . . . . . . . 13

$2.2 .3 \quad$ Renal Replacement Therapies . . . . . . . . . 13

$2.2 .4 \quad$ Kidney Transplantation . . . . . . . . . . . . 14

$2.2 .5 \quad$ Peritoneal Dialysis . . . . . . . . . . . . . 14

$2.3 \quad$ Hemodialysis . . . . . . . . . . . . . . . 15

$2.3 .1 \quad$ Properties of Fluids in Hemodialysis . . . . . . 16

$2.3 .2 \quad$ Blood Characteristic . . . . . . . . . . . . 16

$2.3 .3 \quad$ Dialysis Fluid Characteristics . . . . . . . . . 18

$2.3 .4 \quad$ Membrane Properties . . . . . . . . . . . 19

$2.3 .5 \quad$ Basic Transport Phenomena . . . . . . . . . 21

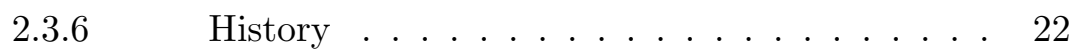

\begin{tabular}{lll}
\hline 3 & Body Composition & 28
\end{tabular}

$3.1 \quad$ Body Composition Definition . . . . . . . . . . 28

$3.2 \quad$ Body Composition Model . . . . . . . . . . . . . . . . . . . 29 
$3.2 .1 \quad$ Atomic Model . . . . . . . . . . . . . . . . 30

3.2 .2 Molecular Model . . . . . . . . . . . . . . . . . 31

$3.2 .3 \quad$ Cellular Model . . . . . . . . . . . . . . . . . . 32

$3.2 .4 \quad$ Tissue system Model . . . . . . . . . . . . . . . 33

$3.2 .5 \quad$ Multi-compartment Model . . . . . . . . . . 34

$3.3 \quad$ Method for Body Composition Assessment . . . . . . . . 35

$3.3 .1 \quad$ Underwater Weighing(UWW) . . . . . . . . 35

3.3 .2 Dilution Method . . . . . . . . . . . . . . . 36

$3.3 .3 \quad$ Dual Energy x-ray Absorptiometry(DEXA) . . 38

$3.3 .4 \quad$ Computed Tomography (CT) . . . . . . . . . . 41

$3.3 .5 \quad$ Magnetic Resonance Imaging(MRI) . . . . . . 42

$3.3 .6 \quad$ Neutron Activation Analysis . . . . . . . . 43

$3.3 .7 \quad$ Bioelectric Impedance Analysis _ . . . . . . . 43

3.3 .8 Other Measurement Methods . . . . . . . . . 46

\begin{tabular}{lll}
\hline 4 & Model & 47
\end{tabular}

$4.1 \quad$ The Model . . . . . . . . . . . . . . . . . . . . . . . . 47

$4.2 \quad$ Data Acquisition $\ldots \ldots \ldots \ldots \ldots \ldots$

$4.2 .1 \quad$ Study Population . . . . . . . . . . . . . 51

$4.2 .2 \quad$ Magnetic Resonance Imaging (MRI) . . . . . . 51

4.2 .3 Dilution Methods . . . . . . . . . . . . . 52

$4.2 .4 \quad$ Multi-frequency Bio-impedance Spectroscopy . 52

$4.3 \quad$ Numerical Simulation of Model $\ldots \ldots \ldots$. . . . . . . . 54

$4.3 .1 \quad$ Parameters . . . . . . . . . . . . . . . . . . . 54

$4.3 .2 \quad$ Simulations . . . . . . . . . . . . . . . 55

$4.4 \quad$ Conclusion . . . . . . . . . . . . . . . . . . . . . . . . 58

$5 \quad$ Sensitivity Analysis and Parameter Identification 59

$5.1 \quad$ Classical Sensitivities . . . . . . . . . . . . . . . . . . 59

5.2 Parameter Identification $\ldots \ldots \ldots \ldots$. . . . . . . 67 
5.3 Different Combinations of Parameters . . . . . . . . . . . . 68

5.4 Conclusion . . . . . . . . . . . . . . . . . 85

\begin{tabular}{|lr}
\hline 6 & Remarks and Perspectives \\
\hline
\end{tabular}

\begin{tabular}{ll}
\hline References & 93
\end{tabular} 


\section{List of Symbols and}

\section{Abbreviations}

Symbols

$\theta$

$\theta_{0}$

$\varepsilon$

$\xi$

$\Xi$

$J(\theta)$

$\mathbb{R}^{p}$

$\hat{\Theta}\left(\theta_{0}\right)$

$\mathcal{F}\left(\theta_{0}\right)$

$S(\theta)$

$s(\theta)$

$T$

CRF

CRRT

parameter vector

nominal parameter vector

error in measurement

measurement

measurement vector

least square function

parameter space

estimator of $\theta_{0}$

neighborhood of $\theta_{0}$

Fisher information matrix at $\theta_{0}$

sensitivity matrix

sensitivity function

end time point

\section{Abbreviations}

Acute renal failure

Chronic renal failure

Continuous renal replacement therapy 


$\begin{array}{ll}\text { ERSD } & \text { End-stage renal disease } \\ \text { TBW } & \text { Total body weight } \\ \text { FFM } & \text { Fat free mass } \\ \text { ARF } & \text { Generalized Sensitivity Functions } \\ \text { CSF } & \text { Classical Sensitivity Functions } \\ \text { GLS } & \text { Generalized Least Squares } \\ \text { ECV } & \text { Extracellular volume } \\ \text { ICV } & \text { Intracellular volume } \\ \text { UWW } & \text { Under water weighing } \\ \text { CT } & \text { Computed tomography } \\ \text { BMI } & \text { Body mass Index } \\ \text { MRI } & \text { Magnetic resonance imaging } \\ \text { NTA } & \text { Neutron activation analysis }\end{array}$




\section{List of Figures}

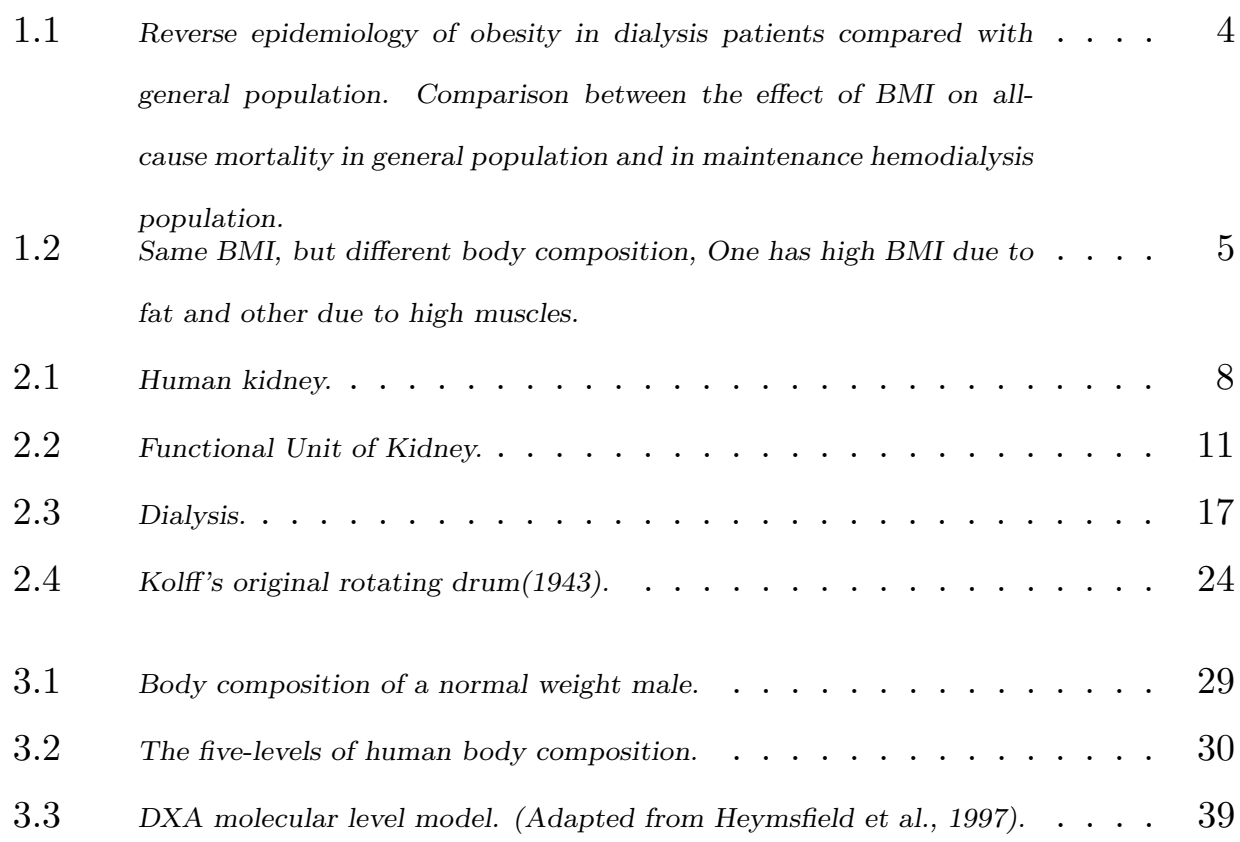

$4.1 \quad$ Structure of the model. . . . . . . . . . . . . . . . . . . . . . . . . 47

\begin{tabular}{|ll|ll}
\hline 4.2 & Uremic toxin concentration in all the four OM,MT,AT,E compart- & $\ldots$ & \\
& ments for all 6 patients.
\end{tabular} 


\begin{tabular}{|c|c|c|c|c|}
\hline 4.5 & $\begin{array}{l}\text { Uremic toxin concentration in the extracellular compartments for all } \\
6 \text { patients with average toxin production rates } G \text { and individual clear- } \\
\text { ance rates } k_{\text {clear. }}\end{array}$ & & & \\
\hline 5.1 & Sensitivity with respect to rate constant $k_{\mathrm{E}, \mathrm{AT}}$ for all 6 patients. & & & \\
\hline 5.2 & Sensitivity with respect to rate constant $k_{\mathrm{E}, \mathrm{OM}}$ for all 6 patients. & & & \\
\hline 5.3 & with respect to rate constant $k_{\mathrm{E}, \mathrm{MT}}$ for all 6 patients. & & & \\
\hline 5.4 & Sensitivity with respect to ra & & & \\
\hline 5.5 & Sensitivity with respect to rate constant $k_{\text {clear }}$ for all 6 patients. & & & \\
\hline 5.6 & Sensitivity of $C_{\mathrm{E}}$ with respect to $k_{\mathrm{E}, \mathrm{MT}}, k_{\mathrm{E}, \mathrm{AT}}, k_{\mathrm{E}, \mathrm{OM}}$ for all 6 patients. & & & \\
\hline 5.7 & $\begin{array}{l}\text { Sensitivity of } C_{\mathrm{E}} \text { with respect to all parameters } k_{\mathrm{E}, \mathrm{MT}}, k_{\mathrm{E}, \mathrm{AT}}, k_{\mathrm{E}, \mathrm{OM}} \text {, } \\
k_{\text {clear }} \text { and } G \text { for all } 6 \text { patients. }\end{array}$ & & & \\
\hline 5.8 & $\begin{array}{l}\text { Estimation of } k_{\text {clear }} \text { and } G \text { for Patients } 1-6 \text { with } \sigma=0.01 \text {, and } 7 \\
\text { measurements during dialysis, for } C_{O M} \text {. }\end{array}$ & . & & \\
\hline 5.9 & $\begin{array}{l}\text { Estimation of } k_{\text {clear }} \text { and } G \text { for all } 6 \text { patients with } \sigma=0.01 \text {, and } 7 \\
\text { measurements during dialysis, for } C_{M T} \text {. }\end{array}$ & . & & \\
\hline 5.10 & $\begin{array}{l}\text { Estimation of } k_{\text {clear }} \text { and } G \text { for all } 6 \text { patients with } \sigma=0.01 \text {, and } 7 \\
\text { measurements during dialysis, for } C_{A T} \text {. }\end{array}$ & . & & \\
\hline .11 & $\begin{array}{l}\text { Estimation of } k_{\text {clear }} \text { and } G \text { for all } 6 \text { patients with } \sigma=0.01 \text {, and } 7 \\
\text { measurements during dialysis, when measurements are taken in extra- } \\
\text { cellular compartment. }\end{array}$ & • & & \\
\hline .12 & $\begin{array}{l}\text { Estimation of } k_{E, O M}, k_{E, M T} \text {, and } k_{E, A T} \text { for all six patients with } \\
\sigma=0.01 \text {, and } 7 \text { measurements during dialysis. }\end{array}$ & . & & \\
\hline 5.13 & $\begin{array}{l}\text { Estimation of } k_{E, O M}, k_{E, M T} \text {, and } k_{E, A T} \text { for all six patients } \sigma=0.01 \text {, } \\
\text { and } 7 \text { measurements during dialysis. }\end{array}$ & & & \\
\hline 5.14 & $\begin{array}{l}\text { Estimation of } k_{E, O M}, k_{E, M T} \text {, and } k_{E A T} \text { for all six patients with } \\
\sigma=0.01 \text {, and } 7 \text { measurements during dialysis in the organ mass com- } \\
\text { partment. }\end{array}$ & • & & \\
\hline 5.15 & $\begin{array}{l}\text { Estimation of } k_{E, O M}, k_{E, M T} \text {, and } k_{E, A T} \text { for all six patients with } \\
\sigma=0.01 \text {, and } 7 \text { measurements during dialysis. }\end{array}$ & . & & \\
\hline 5.16 & $\begin{array}{l}\text { Estimation of } k_{E, A T}, k_{\text {clear }}, G \text { for Patient } 4 \text { with } \sigma=0.01 \text {, and } 7 \\
\text { measurements during dialysis. }\end{array}$ & . & & \\
\hline 5.17 & $\begin{array}{l}\text { Estimation of } k_{E, M T} \text {, and } k_{\text {clear }} \text { for Patient } 4 \text { with } \sigma=0.01 \text {, and } 7 \\
\text { measurements during dialysis. }\end{array}$ & . & & \\
\hline 5.18 & $\begin{array}{l}\text { Estimation of } k_{E, O M} \text {, and } G \text { for Patient } 4 \text { with } \sigma=0.01 \text {, and } 7 \text { mea- } \\
\text { surements during dialysis. }\end{array}$ & & & \\
\hline .19 & $\begin{array}{l}\text { Estimation of } k_{E, A T} \text { and } G \text { for Patient } 4 \text { with } \sigma=0.01 \text {, and } 7 \text { mea- } \\
\text { surements during dialysis. }\end{array}$ & & & \\
\hline
\end{tabular}


5.20 Estimation of $k_{E, M T}$, and $k_{E, A T}$ for Patient 4 with $\sigma=0.01$, and 21 . . . 84 measurements during dialysis. 


\section{List of Tables}

$3.1 \quad$ Main body-composition components in the five-level model. . . . . . . . . 31

$3.2 \quad$ Body-composition models at different body-composition levels . . . . . . . 32

$3.3 \quad$ Examples of body composition models(Heymsfield et al.,1997). all units are in kilograms ..................... 34

$3.4 \quad$ Classification of BMI by $\mathrm{WHO}$. . . . . . . . . . . . . . . . . . . . . 45

$4.1 \quad$ Volumes (ltr), body weights $(\mathrm{kg})$ and $B M I s\left(\mathrm{~kg} / \mathrm{m}^{2}\right)$ for patients enrolled in the study. . . . . . . . . . . . . . . . . . 52

$4.2 \quad$ Duration $T_{d}$ of dialysis (min), urea distribution . . . . . . . . . . . . 53

volume $V_{\text {urea }}$ (ltr), $K=k_{\text {clear }} T_{d} / V_{\text {urea }}$ and the protein catabolic rate PCR for the patients enrolled in study.

$4.3 \quad$ Individual clearance rates and toxin production rates. . . . . . . . . . . . 53

$4.4 \quad$ Initial values and rate constants used for the simulations. . . . . . . . . . 53

$4.5 \quad$ Average toxin concentration during the interdia- . . . . . . . . . . . . . 54 lytic phase in the extracellular compartment.

\begin{tabular}{|c|c|}
\hline 5.1 & $\begin{array}{l}\text { Identification of } k_{\text {clear }} \text { and } G \text { for Patients } 1-6 \text { using } 7 \text { uniformly dis- } \\
\text { tributed measurements of } C_{\mathrm{E}} \text { during the dialytic phase. }\end{array}$ \\
\hline 5.2 & $\begin{array}{c}\text { Monte Carlo Identification of } k_{\text {clear }} \text { and } G \text { for Patients 1-6 using } 7 \\
\text { uniformly distributed measurements of } C_{\mathrm{E}} \text { during the dialytic phase. }\end{array}$ \\
\hline 5.3 & $\begin{array}{l}\text { Identification of } k_{E, O M}, k_{E, M T} \text { and } k_{E, A T} \text { for Patients 1-6 using } 7 \\
\text { uniformly distributed measurements of } C_{E} \text { during the dialytic phase. }\end{array}$ \\
\hline 5.4 & $\begin{array}{l}\text { Monte Carlo estimates of } k_{E, O M}, k_{E, M T} \text { and } k_{E, A T} \text { for Patients 1- } 6 \\
\text { using } 7 \text { uniformly distributed measurements of } C_{E} \text { during the dialytic } \\
\text { phase. }\end{array}$ \\
\hline
\end{tabular}




\begin{tabular}{|ll|ll}
\hline 5.5 & $\begin{array}{l}\text { Identification of } k_{\text {clear }}, G \text { and } k_{E, A T} \text { for Patient } 4 \text { using } 7 \text { uniformly } \\
\text { distributed measurements of } C_{\mathrm{F}} \text { during the dialytic phase. }\end{array}$ \\
\hline 5.6 & $\begin{array}{l}\text { Identification of } k_{\text {clear }} \text { and } G \text { for Patient } 4 \text { using } 6 \text { respectively } 21 \text { mea- } \\
\text { surements during the dialytic phase. }\end{array}$ & 80 \\
\hline 5.7 & $\begin{array}{l}\text { Identification of } k_{E, O m} \text { and } G \text { for Patient } 4 \text { using } 6 \text { respectively } 21 \\
\text { measurements during the dialytic phase. }\end{array}$ & 81 \\
\hline 5.8 & $\begin{array}{l}\text { Identification of } k_{E, M T} \text { and } k_{E, A T} \text { for Patient } 4 \text { using } 6 \text { respectively } 21 \\
\text { measurements during the dialytic phase. }\end{array}$ & 82 \\
\hline 5.9 & $\begin{array}{l}\text { Identification of } k_{E, M T} \text { and } k_{E, A T} \text { for Patient } 4 \text { using } 6 \text { respectively } 21 \\
\text { measurements during the dialytic phase. }\end{array}$ & 83 \\
\hline
\end{tabular}




\section{Dedicated}

To my Loving Parents

My sons

Muhammad Saveed Ali, Muhammad Sarmad Ali,

Muhammad Daud Asghar.

My Sister

Dr Shahnaz Akthar chaudhary

And My Brothers

Dr Muhammad Javeed, Dr Muhammad Rashid. 


\section{Abstract}

\section{MATHEMATICAL MODEL FOR SOLUTE KINETICS AND BODY COMPOSITION IN HEMODIALYSIS PATIENTS}

by

\section{Rashida Hussain}

\section{Chair by : Franz Kappel}

Dialysis patients with high BMI experience survival advantages as compared to dialysis patients with low BMI. Preliminary modeling results seem to confirm the dependence of survival probabilities on BMI, but also show that BMI is a too crude measure. The simulation results presented in this thesis strongly indicate that body composition instead of BMI is the important factor. The purpose of our work is to confirm these findings by simulations with a mathematical model using concrete data concerning body composition. In addition we want to demonstrate that the clearance rate during the dialysis process and the generation rate for uremic toxins are also to be considered. Moreover we present results of a sensitivity analysis for the parameters of the model which are confirmed by concrete results of parameter estimation procedures. 


\section{Acknowledgements}

Thanking Almighty Allah for giving me power and health to complete this work, and execute the dream of my mother into reality. I would like to thank the Higher Education Commission HEC Government of Pakistan, who financially supported me through out my degree to meet all the expenses.

I would like to introduce my deep gratefulness to my supervisor Em. Univ.Prof. Dr.Franz Kappel for his fairness and generosity, supervision, continuous encouragement and valuable advice in completing this work. He helped me resolving all other problems besides studies.

Dr. Peter Kontanko to whom I would like to express my deepest thankfulness. It has been an opportunity for me gaining his experience, learning the milestone of the scientific work principles, during these years.

I want to thank the staff of the Department of Mathematics, University of Graz, particularly the head of the Department, Prof. Dr. Karl Kunisch for his kind acceptance. I wish to express my sincere thanks to Dr. jerry Batzel for his guidance and help, I am also thankful to Miss Krois in managing the official work. I am very grateful to prof Dr. Wilhelm Schappacher to facilitate me during the course of my study.

I am deeply indebted to my family parents, brothers, sister, sister in-law, and parents in-law especially my son Muhammad Saveed Ali for his support during whole period. I feel so privileged to have parents like you, giving me your unconditional support and love through all this work. 
Last but not least, I am indeed grateful to my life companion, my husband Asghar Ali, whose decision of coming to Graz made this PhD possible. Your encouragement, confidence and forbearance during stressful period of my life help me to continue my studies.

Rashida Hussain,

Graz Austria. 


\section{Chapter 1}

\section{Introduction}

Kidneys are remarkable organs performing several essential regulatory roles in human beings as well as in most of animals. They have a unique anatomy, and serve the body as natural filter of blood. Kidneys excrete waste such as urea and ammonium. They are also responsible for re-absorption of water, glucose, and amino acids. Moreover kidneys produce the hormones calcitriol (which increases blood calcium levels), erythropoietin (which regulates red blood cell production), and renin (which helps to regulate the body's mean arterial blood pressure).

There are two types of kidney dysfunction: acute renal failure and chronic kidney disease. "Renal" refers to the kidneys. "Acute" means sudden. So acute renal failure means the kidneys have failed suddenly, often due to a toxin (a drug allergy or poison) or severe blood loss or trauma. The term "chronic" is usually applied when the course of the disease lasts for more than three months. Hence chronic kidney disease is a progressive loss in renal function over a period of months or years.

Diabetes is the number one cause of kidney disease, responsible for about $40 \%$ of all kidney failure. High blood pressure is the second cause, responsible for about $25 \%$. Another form of kidney disease is glomerulonephritis, a general 
term for many types of kidney inflammation. Genetic diseases, autoimmune diseases, birth defects, problems such as older age, antibiotic reaction, accident, smoking, hypertension are some other causes of kidney disease.

Emerging evidence indicates that obesity may also contribute directly to kidney damage through a cascade of additional hemodynamic, metabolic, and inflammatory mechanisms as well as by mechanical compression [20, 29, 56].

The National Kidney Foundation (NKF) divides kidney disease into five stages: Stage 1, a slightly diminished function, Stage 2, mild reduction, Stage 3 , moderate reduction, Stage 4, severe reduction, Stage 5, end stage renal disease (ESRD). Kidney function is normal in Stage 1, and minimally reduced in Stage 2. In end-stage renal disease, kidney functions can be replaced only by dialysis or by kidney transplantation. The planning for dialysis and transplantation is usually started in Stage 4 of chronic kidney disease. Only a small proportion of patients with chronic kidney disease reach stage 5, end stage renal disease, with estimates varying from 0.1 to 2.6 per 100 patients with stage 3 to 4 chronic kidney disease. The overall incidence rate of end stage renal disease is three times higher in the United States (339 per million population in 2004) compared with Northern Europe (110 per million population in 2004), possibly due to a higher prevalence of type 2 diabetes and to differences in pre-dialysis care in US population [20]. Renal replacement therapy becomes necessary when the chronic kidney disease patients progress to end-stage renal disease.

In Europe there are about 440,000 current patients, who are maintained on renal replacement therapy [20]. Kidney transplant is the optimal solution in renal replacement treatment for patients with end-stage renal disease. However not all patients undergo surgery, as waiting list for a matching kidney are long. Moreover, the probability of graft failure ranges from 6 to $10 \%$ in the first year after transplantation, so that dialysis treatment is again indicated 
[20].

Dialysis has been life-saving renal replacement therapy for patients with end-stage renal disease since the 1960 [53]. The word "dialysis" comes from a Greek word dialussis: dia mean through and lysis mean loosening or splinting. So dialysis is a process for removing waste and excess water from the blood. There are two types of dialysis: hemodialysis and peritoneal dialysis. Both types filter blood to rid the body of harmful wastes, extra salt and water.

Hemodialysis is done at hospitals or special dialysis centres. Typical treatment is about four hour per treatment and three times per week.

Peritoneal dialysis is done at home while sleeping, 5 to 7 times a week, for 6 to 8 hours. Home dialysis is a flexible modality and schedules can be changed day to day and week to week.

Those who undergo maintenance dialysis treatment have a high annual mortality rate of approximately $20 \%$ to $23 \%$ in the United States and $15 \%$ to $20 \%$ in Europe [27]. The number of patients treated for terminal kidney failure worldwide has continued to grow at a rate that is far in excess of the growth rate of the general population [3]. By 2001, more than 1 million patients were reported worldwide to receive dialysis treatment alone, with the numbers growing at an annual global average rate of $7 \%$ [2]. The above number of new dialysis patients rose 3.5 percent in 2009. The size of the current dialysis population increased $4 \%$ in 2009, reaching 398,861, and is now $40 \%$ larger than in 2000 [4].

Chronic kidney disease is a large public health problem with a prevalence of around $10 \%$ in most populations [25]. 


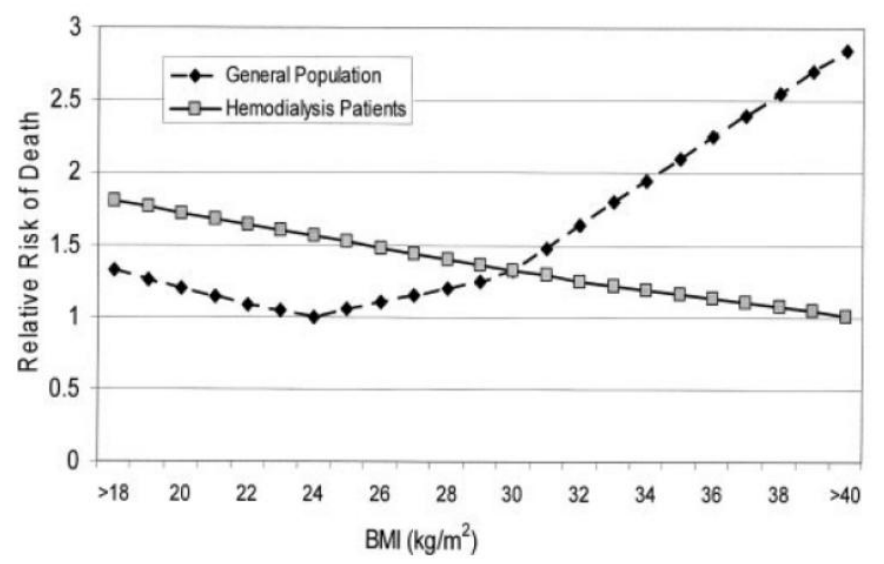

Figure 1.1. Reverse epidemiology of obesity in dialysis patients compared with general population. Comparison between the effect of BMI on allcause mortality in general population and in maintenance hemodialysis population.

Though dialysis treatment techniques have improved, the mortality rate of chronic dialysis patients remains alarmingly high worldwide with an annual mortality rate of about $20 \%$. The lifespan of dialysis patients remains abnormally short. Only about one third survives 5 years. Even patients who start dialysis in their 40s have no more than a $50 \%$ chance to live 5 more years. Over one million patients worldwide can survive due to different forms of kidney replacement therapy, and the increase in the population of patients with end-stage renal disease (ESRD) is $5-10 \%$ per year.

Dialysis patients with high BMI experience survival advantages as compared to dialysis patients with low BMI, a phenomenon known as "reverse epidemiology" (see Figure 1.1). Research related to this phenomenon can be found in [33, 15]. 

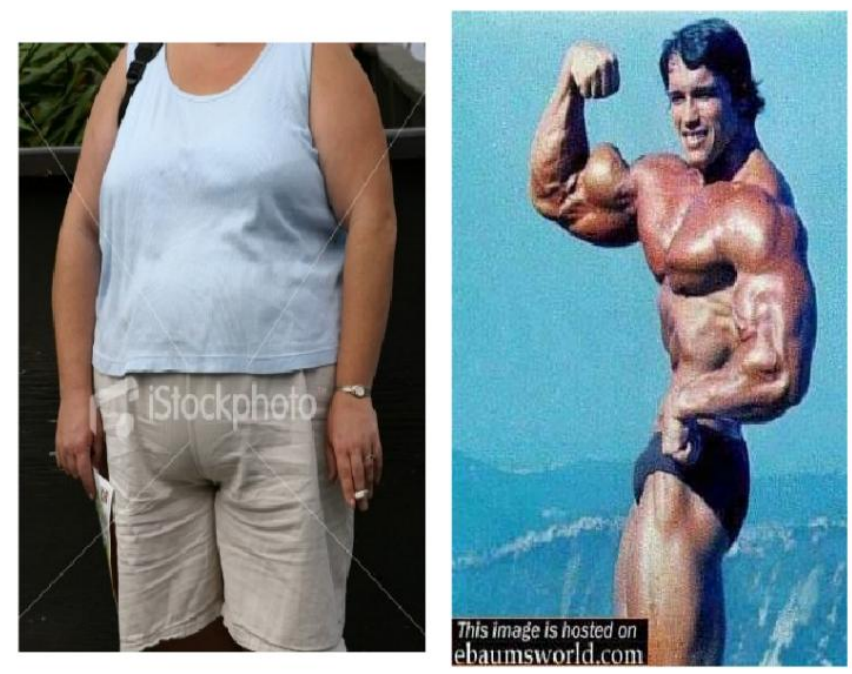

Figure 1.2. Same BMI, but different body composition, One has high BMI due to fat and other due to high muscles.

Body mass index is defined as the ratio of an individuals weight to the square of the individuals height (unit $\mathrm{kg} / \mathrm{m}^{2}$ ). The World Health Organization has given the following ranges: underweight is given to be in the range from 16 to 18.5, Normal from 18.5 to 25.0, overweight from 25.0 to 30.0, and obese class I from 30.0 to 35 . BMI ranges can vary with nationality and age. As BMI is just the ratio between body weight and height it does not differentiate between fat and muscle mass. To make that distinction body composition instead of BMI must be used. Two people at the same height and same body weight may look completely different from each other because they have a different body composition (see Figure 1.2.

Body composition is defined as the percentage of fat, muscle, and bone in the body. Usually it is expressed as a ratio of lean mass to fatty mass. Since body mass index is a poor surrogate of body composition, attempts were made to 
delineate muscle, fat and visceral organ mass in dialysis patients. Several lines of evidence indicate that (a) increased fat and muscle mass exerts protective effects, (b) some markers of inflammation may be increased with fat mass, and (c) a high visceral mass per body weight is associated with a reduced survival time. The reasons for the positive effects of fat and muscle mass on survival are not clear.

Preliminary modeling results seem to confirm the dependence of survival probabilities on BMI, but also show that BMI is too crude of a measure. The simulation results presented in this thesis strongly indicate that body composition instead of BMI is the important factor. The purpose of our work is to confirm these findings by simulations with a mathematical model using concrete data concerning body composition. In addition we want to demonstrate that the clearance rate during the dialysis process and the generation rate for uremic toxins are also to be considered. Moreover we present results of a sensitivity analysis for the parameters of the model which are confirmed by concrete results of parameter estimation procedures.

The thesis is organized in the following way. The thesis begins with a general introduction Chapter 1. Chapter 2 reviews the basic concepts of kidney function and hemodialysis. Chapter 3 is mainly devoted to the body composition analysis and methods of body composition assessments. In Chapter 4, a model of solute kinetics in hemodialysis patients with numerical computations and simulations is presented. Model validation is done through a sensitivity analysis and parameter estimation procedure presented in Chapter 5. Chapter 6 summarizes the results obtained in this study. Appendix A is devoted to define sensitivity while theoretical concepts of parameter estimation are presented in Appendix B. 


\section{Chapter 2}

\section{Human kidney And}

\section{Dialysis}

This chapter is divided into two sections. The first section is for the anatomy and function of kidneys. Section 2 is about hemodialysis. Most of the materials covered in this chapter can be found in the textbook of Medical Physiology by Guyton and Hall [23, Book 1, Clinical chemistry of the kidney and renal Associated physiology by David J. Anderson [16], thesis of Sunny Eloot [57, and a thesis of Hasan Erbil [26].

\subsection{Anatomy of Kidney}

The urinary system consists of two kidneys, two ureters, one bladder, and one urethra. Kidneys filter blood and the waste product where extra water become urine, which flows to the bladder through tubes called ureters. The bladder stores urine until it is released via the urethra as a urine. Ureters are tubes that are $25-30 \mathrm{~cm}$ in length and $4-5 \mathrm{~mm}$ in diameter. The bladder is "collapsible bag" that can contain up to $500 \mathrm{~mL}$ of urine. Bladder activity is controlled by the parasympathetic nervous system. The kidneys are a pair of bean-shaped organs located on the posterior wall of the abdominal cavity. they lie on either side of the spine in the lower middle of back, just below the rib cage. The asymmetry within abdominal cavity is caused by the liver. The right kidney is located below the liver, and left kidney lies a little 


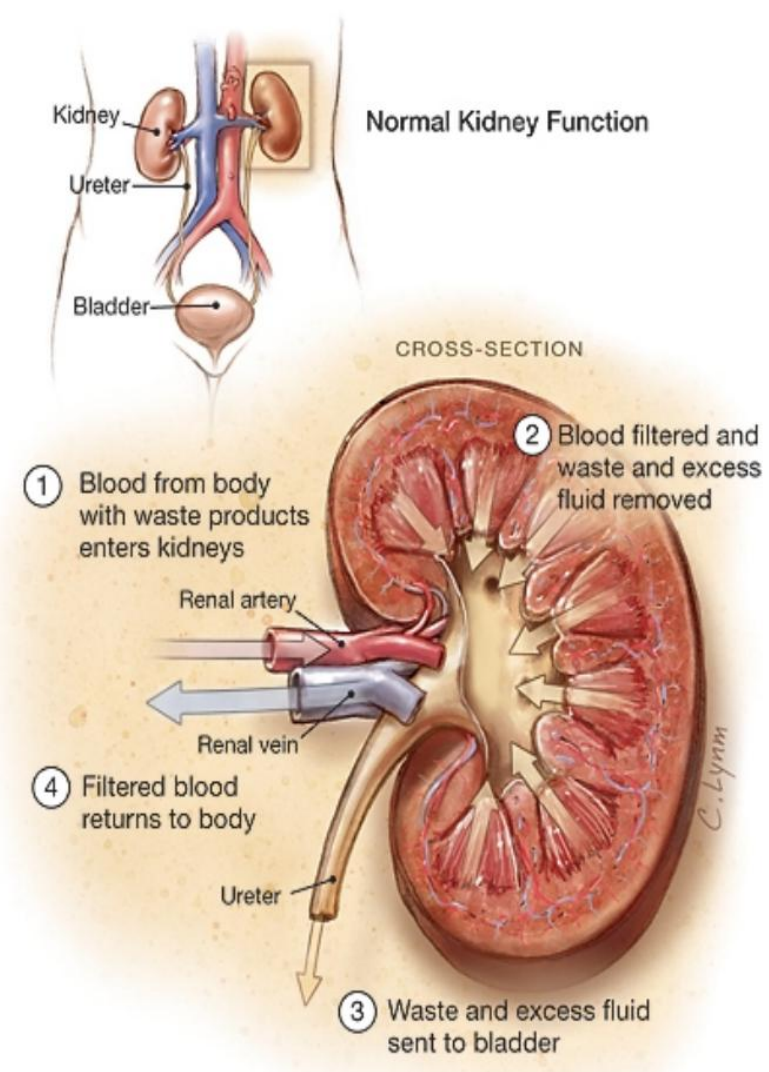

Figure 2.1. Human kidney.

higher than the right kidney. The right kidney is just below the diaphragm and posterior to the liver, the left below the diaphragm and posterior to the spleen. Adrenal glands lie on the top of each kidney. The upper parts of the kidneys are partially protected by the eleventh and twelfth ribs, and each whole kidney and adrenal gland are surrounded by two layers of fat (the perirenal and para-renal fat) and the renal fascia. Each kidney has convex and concave surfaces. The concave surface, the renal hilum, is the point at which the renal artery enters the kidney, and the renal vein and ureter leave. The kidney is surrounded by tough fibrous tissue, the renal capsule, which is itself 
surrounded by peri-nephritic fat, renal fascia (of Gerota) and para-nephritic fat. The anterior (front) border of these tissues is the peritoneum, while the posterior (rear) border is the transversalis fascia. One kidney is normally located just below the liver, on the right side of the abdomen and the other is just below the spleen on the left side.

Therefore, both move down on inhalation. Each adult kidney weighs between 125 and 170 grams in males and between 115 and 155 grams in females. The left kidney is typically slightly larger than the right. The kidney is approximately $11-14 \mathrm{~cm}$ in length, $6 \mathrm{~cm}$ wide and $4 \mathrm{~cm}$ thick. Kidneys weigh about 0.5 percent of total body weight. Each Kidney is enclosed in a transparent membrane called the renal capsule, which helps to protect them against infections and trauma.

The kidney is divided into two main areas, a light outer area called the renal cortex. Approximately $75 \%$ of the kidney tissue is cortex. The cortex contains glomeruli, proximal tubules, and distal convoluted tubules, and a darker inner area called the renal medulla. Within the medulla there are 8 or more cone-shaped sections known as renal pyramids, which contain the Henle loop. The areas between the pyramids are called renal columns.

The structure of human kidneys are shown in Fig 2.1 Blood enters the kidney via the renal artery. The kidney in the young adult receives about $20 \%$ of cardiac output at rest. There is only a single renal artery on each side. The main single artery divides into many smaller branches as it enter the kidney via the renal hilus. These smaller arteries divide into vessels such as the segmental artery, the interlobar artery, the arcuate artery and the interlobular artery. These eventually seperate into afferent arterioles, one of which serves each nephron in the kidney. The interstitum (or interstitium) is the functional space in the kidney beneath the individual filters (glomeruli) which are rich in blood vessels. The interstitum absorbs fluid recovered from urine. Various conditions can lead to scarring and congestion of this area, which can 
cause kidney dysfunction and failure. After filtration occurs the blood moves through a small network of venules that converge into interlobular veins. As with the arteriole distribution the veins follow the same pattern, the interlobular provide blood to the arcuate veins then back to the interlobar veins which come to form the renal vein exiting the kidney after transfusion of blood.

\subsection{Kidney Function}

The kidneys have several functions. One important function is to rid the body of waste materials that are either ingested or produced by metabolism. A second function that is especially critical is to control the volume and composition of the body fluids. For water and virtually all electrolytes in the body, the balance between intake (due to ingestion or metabolic production) and output (due to excretion or metabolic consumption) is maintained in large part by the kidneys. This regulatory function of the kidneys maintains the stable environment of the cells necessary for them to perform their various activities. The kidneys perform their most important functions by filtering the plasma and removing substances from the filtrate at variable rates, depending on the needs of the body. Ultimately, the kidneys "clear" unwanted substances from the filtrate (and therefore from the blood) by excreting them in the urine while returning substances that are needed by the body back to the blood. The kidneys serve multiple functions, including the following:

- Excretion of metabolic waste products and foreign chemicals

- Regulation of water and electrolyte balances

- Regulation of body fluid osmolality and electrolyte concentrations

- Maintenance of acid-base balance

- Regulation of arterial pressure

- Absorption of water, glucose and amino acids 


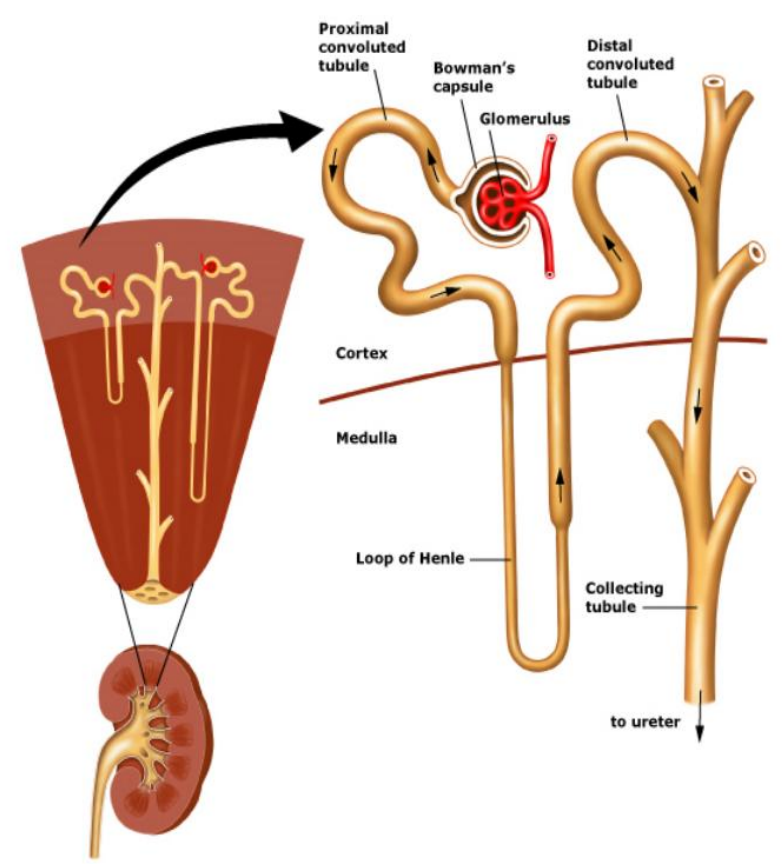

Figure 2.2. Functional Unit of Kidney.

- Secretion, metabolism, and excretion of hormones such as Calcitriol, Renin, and Erythropoietin

- Gluconeogenesis (Glucose synthesis process).

\subsubsection{Nephron as a Functional Unit}

Each human kidney contains about 1 million nephrons, each capable of forming urine. The kidney cannot regenerate new nephrons. Therefore with renal injury, disease, or normal ageing, there is a gradual decrease in nephrons number. After age 40, the number of functioning nephrons usually decreases about $10 \%$ every 10 years; thus, at age 80, many people have $40 \%$ fewer functioning nephrons than they did at age 40. This loss is not life threatening because adaptive changes in the remaining nephrons allow them to excrete the proper 
amounts of water, electrolytes, and waste products. Each nephron contains a tuft of glomerular capillaries called the glomerulus, through which large amounts of fluid are filtered from the blood, and a long tubule in which the filtered fluid is converted into urine on its way to the pelvis of the kidney. The glomerulus contains a network of branching and anastomosing glomerular capillaries that, compared with other capillaries, have high hydrostatic pressure (about $60 \mathrm{~mm} \mathrm{Hg}$ ). The total glomerulus is encased in Bowmans capsule (see Figure 2.2). Fluid filtered from the glomerular capillaries flows into Bowmans capsule and then into the proximal tubule. From the proximal tubule, fluid flows into the loop of Henle. Each loop consists of a descending and an ascending limb. The walls of the descending limb and the lower end of the ascending limb are very thin and therefore are called the thin segment of the loop of Henle. After the ascending limb of the loop has returned partway back to the cortex, its wall becomes much thicker, and it is referred to as the thick segment of the ascending limb. At the end of the thick ascending limb is a short segment, which is actually a plaque in its wall, known as the macula densa. The macula densa plays an important role in controlling nephrons function. Beyond the macula densa, fluid enters the distal tubule, which, like the proximal tubule, lies in the renal cortex. This is followed by the connecting tubule and the cortical collecting tubule, which lead to the cortical collecting duct. The initial parts of 8 to 10 cortical collecting ducts join to form a single larger collecting duct that runs downward into the medulla and becomes the medullary collecting duct. The collecting ducts merge to form progressively larger ducts that eventually empty into renal pelvis. In each kidney, there are about 250 of very large collecting ducts, each of which collect urine from 4000 nephrons. 


\subsubsection{Uraemic Syndrome}

Renal diseases can be divided into three categories according to the duration that the kidneys lose their ability to purify the blood: acute, sub-acute and chronic renal failure. Acute renal failure (ARF) is an abrupt or rapid decline in renal filtration function, it is often reversible in contrast to sub-acute and chronic renal failure. This may be due to infection, drugs (prescription, over-the-counter, recreational), traumatic injury, major surgery, nephrotoxic poisons, etc.

Chronic kidney disease or chronic renal failure (CRF), slowly and gradually destroys the filtering capacity of the kidneys. Once a kidney is damaged by it to a certain degree, it continues to deteriorate even if the underlying kidney disease can or could be cured. As chronic renal insufficiency continues and progresses, glomerular filtration rate as well as the amount of nephrons decreases and the person may eventually reach the point where it is considered to be end-stage renal disease (ESRD). The main causes of end stage renal disease are diabetes and hypertension, while the most important symptoms are found in the cardiovascular, neurological, haematological and immunological status.

\subsubsection{Renal Replacement Therapies}

Chronic renal failure is based on the indication of gradual diminution of renal function or a disorder in urine sedimentation. Creatinine clearance $(95 \pm 20$ $\mathrm{mL} / \mathrm{min}$ for women and $120 \pm 25 \mathrm{~mL} / \mathrm{min}$ for men) is used as a measure of the glomerular ultrafiltration rate and as a measure of the remaining renal function. In comparison with creatinine, the urea blood level is strongly dependent on the protein intake and the catabolic state of the patient, and furthermore, urea clearance is dependent on the urine flow rate. However, the increase of serum ureum is a useful additional marker of chronic renal failure. As renal replacement therapy, two types of treatments are available: a natural one 
(kidney transplantation from cadaver or living donors), and an artificial one (dialysis), which has two sub division: peritoneal dialysis and hemodialysis.

\subsubsection{Kidney Transplantation}

The first cadaveric kidney transplantation in the United States was performed in June 17, 1950, on Ruth Tucker, a 44-year-old woman.

The kidney is the most frequently transplanted organ. A healthy kidney is transplanted into a person with complete kidney failure. The donor and the recipient can function with one kidney and neither requires dialysis after successful transplantation. Surgery is done under general anesthesia and typically takes 2 to 3 hours. The failed kidneys are left in place and the healthy ones transplanted extra peritoneal.

\subsubsection{Peritoneal Dialysis}

In peritoneal dialysis, dialysis fluid (called dialysate) is injected into the abdominal cavity (called the peritoneal cavity) by a permanent peritoneal catheter. The fluid is held (dwells) within the abdomen for a prescribed period of time; this is called a dwell.

The lining of the abdomen (the peritoneum) acts as a semi-permeable membrane to allow excess fluids and waste products to pass from the bloodstream into the dialysate. When exchange is completed, the "used" dialysate can then be drained out of the abdomen. The amount and kind of dialysate and length of time for each exchange cycle vary with age, size, and condition of patient. There are three phases in each cycle. During inflow the dialysate is introduced into the peritoneal cavity. During equilibration (swell) the dialysate remains in the peritoneal cavity. By means of osmosis, diffusion and filtration, the needed electrolyte pass via the vascular peritoneum blood vessels of the abdominal cavity, and the waste products pass from the blood vessels through the vascular peritoneum into the dailyste. During the third phase (drain) 
the dialysate is allowed to drain from the peritoneal cavity by gravity. This used fluid contains the excess fluid and waste from the blood, which is usually eliminated in the urine. The peritoneal cavity is then filled again with fresh dialysate. This can occur automatically while the patient is sleeping (automated peritoneal dialysis, APD), or during the day by keeping two litres of fluid in the abdomen at all times, exchanging the fluids four to six times per day (continuous ambulatory peritoneal dialysis, CAPD). Peritoneal dialysis can be performed in five ways:

$\mathrm{CAPD}=$ Continuous Ambulatory Peritoneal Dialysis

$\mathrm{CCPD}=$ Continuous Cyclic Peritoneal Dialysis

DAPD = Daytime Ambulatory Peritoneal Dialysis

$\mathrm{IPD}=$ Intermittent Peritoneal Dialysis

NIPD $=$ Nighty Intermittent Peritoneal Dialysis.

\subsection{Hemodialysis}

Blood purification therapy is known as hemodialysis. During hemodialysis patient blood is circulated trough an artificial kidney, known as hemodialyzer. Patients with a vascular access (AV fistula or AV graft) will get two needle sticks in their access; one needle takes blood out of the body (shown blue in Fig 2.3), the other needle brings it back (shown red in Fig 2.3). Patients with a central venous catheter will have the two tubes from their access connected to the blood tubes that lead to the dialyzer and back to the body. Once the patient is put on the machine, the dialysis machine is programmed and then treatment begins. It is three to four hour treatment and three times in a week is typical.

Three primary methods are used to gain access to the blood: an intravenous catheter, an arteriovenous (AV) fistula and a synthetic graft. The type of access is influenced by factors such as the expected time course of a patient's renal failure and the condition of his or her vasculature. Patients may have 
multiple accesses, usually because an AV fistula or graft is maturing and a catheter is still being used.

Two types of hemodialyzer are in use: plate and hollow fiber dialyzer. In the case of plate dialyzer, membrane sheets are packed together and blood and dialysate flow in succeeding layers. The priming volume is around 30 percent larger than in a hollow fiber dialyzer. The hollow fiber dialyzer consists of thousands of small capillaries (inner diameter in the range of $200 \mu \mathrm{m}$ and wall thickness of 8-40 $\mu \mathrm{m}$ ). Blood flows inside the capllaries whereas dialysat flows counter currently around them. Typical blood flow rates are in the range of 200 up to $350 \mathrm{~mL} / \mathrm{min}$, where dialysate flow is twice that of blood flow. These dialyzers have an advantage of small blood volume, but suffer from problems like clotting in and clogging of capillaries. With respect to the membrane characteristics, distinction can be made between low, medium and high flux dialyzers.

\subsubsection{Properties of Fluids in Hemodialysis}

In hemodialysis therapy, the main purpose of the dialyzer is to clean human blood contaminated by the toxic products of human cells, through a semipermeable membrane and dialysate solution. Diffusion, ultrafiltration, and osmosis are the basic transport phenomena . The transport takes place between the blood and dialysate compartment over a semi-permeable membrane, and fluid characteristics and membrane properties should also be considered.

\subsubsection{Blood Characteristic}

An average adult has a total blood volume of about $5 \mathrm{~L}$, which is approximately $7 \%$ of total body weight. Blood is a dark red, viscous, slightly alkaline suspension ( $\mathrm{pH} 7.4$ ) of cells erythrocytes (red blood cells), leukocytes (white blood cells) and thrombocytes (platelets) suspended in a fluid (plasma). The 


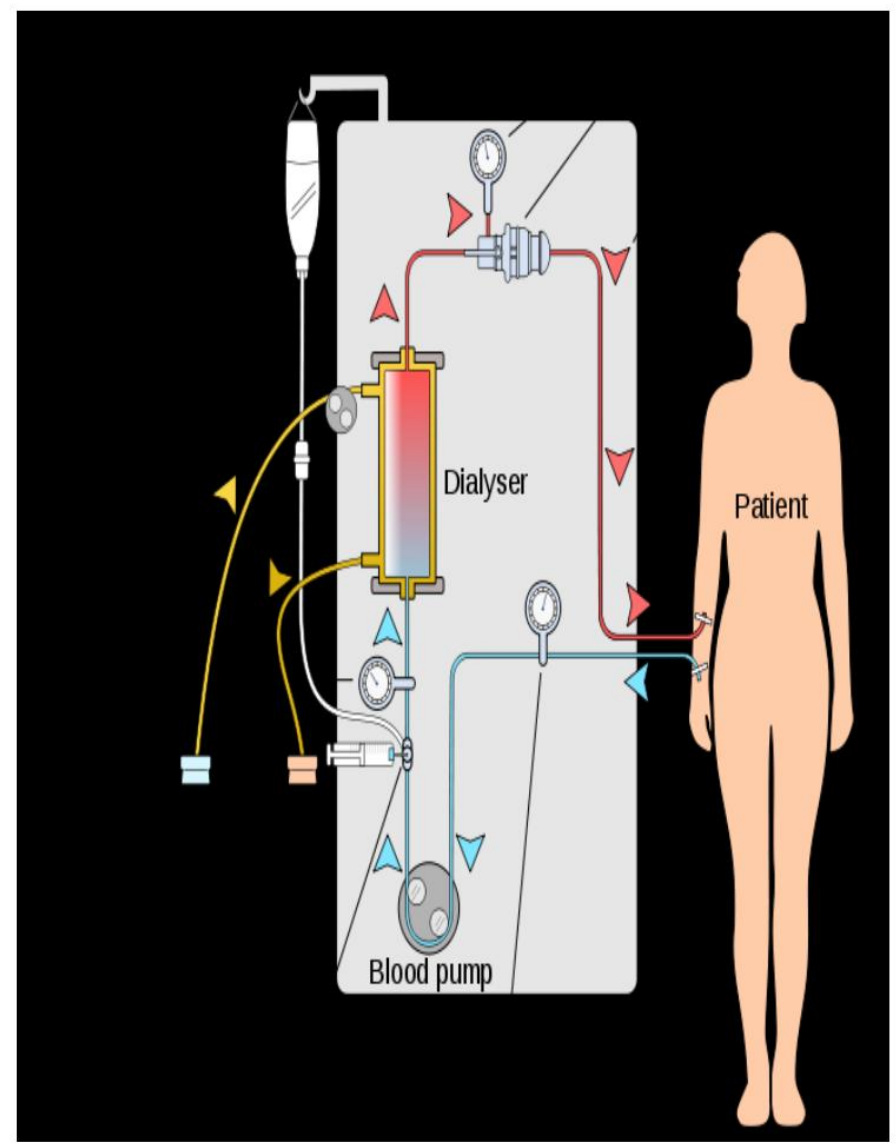

Figure 2.3. Dialysis.

amount of cells ( $45 \%$ for male, $43 \%$ for female) is better known as the hematocrit (Guyton 1986).

The main functions of blood include transportation of nutrients from the gastrointestinal system to all cells of the body and subsequently delivering waste products of these cells to organs for elimination. Oxygen $\left(\mathrm{O}_{2}\right)$ is carried from the lungs to all cells of the organism by the hemoglobin in the erythrocytes, whereas carbon dioxide $\left(\mathrm{CO}_{2}\right)$ is transported back to the lungs for elimination both by the haemoglobin and the plasma. Besides nutrients, numerous other metabolites, cellular products, and electrolytes are transported by the 
bloodstream. Additionally, blood has also a function of regulating the body temperature and maintaining the acid-base and osmotic balance of the body fluids. Plasma consists of water (90\%), proteins (9\%) and inorganic salts, ions, nitrogen's, nutrients and gases (1\%) (Guyton 1986). There are several plasma proteins with different origin and function, e.g. albumin (69000 Da), $\alpha$ - and $\beta$-globulins (80000- $1000000 \mathrm{Da}), \gamma$-globulins, clotting proteins, complement proteins ( $\mathrm{C} 1$ to $\mathrm{C} 9)$ and plasma lipoproteins.

\subsubsection{Dialysis Fluid Characteristics}

The hemodialysis fluid should be considered as a temporary extension of the patients extracellular fluid because of bi-directional transport process when blood and dialysate are flowing through the dialyzer. In achieving the desired blood purification and body fluid and electrolyte homoeostasis, the composition of dialysis fluid is critical. It contains reverse osmosis water, dextrose and different electrolytes like calcium, magnesium, potassium and sodium chloride and sodium acetate or bicarbonate. The latter two fulfil the function of dialyste buffer, responsible for the correction of metabolic acidosis in the uremic patient. Hydrogen ions $\left(H^{+}\right)$are, soon after their production, buffered by plasma bicarbonate, and can only be removed by the diffusive flux of alkaline from the dialysate into the blood replacing the blood buffers.

In addition with chemical composition, also the physical and microbiological characteristics are important. As the use of highly permeable membranes in hemodialysis is responsible for back filtration and / or back diffusion (filtration and / or diffusion from the dialysate compartment towards the blood compartment), toxic and pyrogenic substances can move from the dialysate towards the blood resulting in febrile reactions.

Currently, the composition of dialysis fluid is prescribed for each single patient to individualize the dialysis therapy according to the patients needs. The ac- 
tual dialysis machines guarantee accurate proportioning of treated water and concentrated salts, continuous monitoring of the final composition and constant maintenance of the required conductivity values.

The hemodialysis system is the end point of a hydraulic circuit where tap water is changed into reverse osmosis water through water supply, water pre-treatment, water purification, and dialysis fluid preparation. The pretreatment consists of flowing tap water through filters, softener, carbon filter and micro-filters. The subsequent treatment concerns flow through one or two reverse osmosis membranes and deionizer, closing the purification chain with ultra filtration and sub micro filtration [57].

\subsubsection{Membrane Properties}

Dialysis membranes are composed of semi-permeable compounds, allowing the separation of solutes between the blood and dialysate. Predominantly traffic is from blood to dialysate but may also be dialysate to blood, often in terms of unwanted compounds such as endotoxin fragments contaminating dialysate. Hemodialysis membrane vary in chemical composition structure, transport properties and biocompatibility. Polymers can be classified in three major groups: regenerated cellulose, modified cellulose membranes and synthetic membranes.

The first hollow fiber hemodialyzers were used clinically in the 1960s [41]. These units contained about $1.0 \mathrm{~m}^{2}$ of an unmodified cellulosic membrane. Cellulose membranes are still widely used for hemodialysis because their hydrogel structure and small thickness provide very effective removal of small solutes like urea. However, these membranes provide relatively little clearance for larger "middle" molecules like $\beta_{2}$-micro globulin that are known to be associated with many dialysis related disorders. In addition, the cellulosic structure contains a high density of hydroxyl groups, which are known to cause 
complement activation upon contact with blood [8]

The shortcomings in cellulose membranes have led to the development of hemodialyzers based on a variety of synthetic polymers (e.g. polysulfone, polyamide, and polyacrylonitrile) and modified cellulosic materials (e.g. cellulose tri acetate and Hemophan). By 1992 the registry form of the European Dialysis Transplant Renal Association listed more than 400 dialyzers having different base materials, pore size, and surface area [65]. Modified cellulose membranes are produced by replacing the hydroxyls with either acetate or large tertiary amine groups, leading to a significant reduction in complement activation. In addition, these membranes tend to have larger pore size, providing more effective removal of $\beta_{2}$-micro globulin.

Most synthetic membranes (polysulfone, polyacrylonitrile, and polymethylmethacrylate etc) were originally developed for convective treatments like hemofiltration. Subsequent reductions in membrane thickness have allowed these membranes to be used successfully for hemodialysis, with solute removal occurring by both diffusive and convective transport. Several studies suggest that patients treated with these newer dialyzers have superior clinical outcomes than patients treated with cellulosic dialyzers [12, 37]. One aspect of synthetic hemodialyzers which was often overlooked, is that these membranes have a very different morphological structure than the cellulose or modified cellulosic materials. Cellulosic membranes have a homogeneous or uniform pore structure throughout the hollow fiber. The AN 69 membrane also has a symmetric pore structure [14]. In contrast, most other synthetic membranes are asymmetric or anisotropic. These membranes have a thin skin layer approximately $1 \mu \mathrm{m}$ in thickness on the luminal surface, while the remainder of the membrane has much larger pores and provides the necessary structural support for the hollow fiber. This asymmetric structure can have a significant affect on the diffusive and convective transport characteristics of the membrane $[10]$. 
Examples of synthetically modified cellulose are cellulose (di) (tri) acetate and hemophan. The majority of cellulose and modified cellulose membranes have a thickness of 5-11 $\mu \mathrm{m}$ and a surface of $0.8-2.5 \mathrm{~m}^{2}$.

\subsubsection{Basic Transport Phenomena}

Renal replacement therapy involve any of 4 major transport mechanisms: diffusion, convection, adsorption and ultra-filtration.

Diffusion is the movement of a solute across a membrane via a concentration gradient. For diffusion to occur, another fluid must flow on the opposite side of the membrane. In blood purification this fluid is called dialysate. When solutes diffuse across a membrane they always shift from an area of higher concentration to an area of lower concentration until the solute concentration on both sides of the membrane is equal.

First law of diffusion of uncharged particles was derived by Adolf Fick given below as

$$
\mathrm{J}=-D_{s} \cdot \mathrm{A} \cdot \triangle \mathrm{C} / \triangle \mathrm{x}
$$

with $\mathrm{J}$ the net solute $(\mathrm{mol} / \mathrm{s}), D_{s}$ the solute diffusivity $\left(\mathrm{m}^{2} / \mathrm{s}\right)$ being a unique property of the solute-solvent at a specific temperature, A the area of diffusion $\left(m^{2}\right)$ and $\triangle \mathrm{C} / \triangle \mathrm{x}$ the concentration difference $\left(\mathrm{mol} / \mathrm{m}^{3}\right)$ over the membrane thickness $(\mathrm{m})$.

In hemodialysis, diffusion is the major transport phenomenon, while the term hemofilteration is used for the therapy in which solutes are mainly cleared by convection and then the excess water and vital solute removal are counter balanced by adding a dilution fluid at the dialyzers inlet (pre dilution) or outlet (post dilution technique). In case of hemodiafiltration therapy, toxic agents are removed by a combination of diffusion and convection resulting in a better clearance of high molecular weight (HMW) solutes (MW > 12000Da) while maintaining the performance for low molecular weight (LMW) solutes(MW < 
300Da) [57.

Convection is the movement of solutes through a membrane by the force of water. Convection is sometimes called solvent drag. Convection is able to move very large molecules if the flow of water through the membrane is fast enough. In continuous renal replacement therapy (CRRT) this property is maximized by using replacement fluids. Replacement fluids are crystallized fluids administered at a fast rate just before or just after the blood enters the filter. The increased fluid flow rate across the filter allows more molecules to be carried through to the other side. The faster the flow through the membrane, the larger the molecules that can be transported.

Adsorption is the removal of solutes from the blood because they cling to the membrane. High levels of adsorption can cause filters to clog and become ineffective.

Ultra-filtration refers to the passage of water through a membrane under a pressure gradient. The rate of ultra-filtration will depend upon the pressures applied to the filter and on the rate at which the blood passes through the filter. Higher pressures and faster flows increase the rate of ultra filtration. Lower pressures and slower flows decrease the rate of ultra-filtration.

\subsubsection{History}

Thomas Graham of Glasgow (1805-1869), was the first who presented the principles of solute transport across a semi permeable membrane in 1854 . He explained that solutes are removed by diffusion from fluids containing collides and crystalloid (1861). He did not proceed into this field further, although he predicted that his finding might be applied in medicine.

In 1913, John Abel (1857-1938) and colleagues invented a vividiffusion apparatus, which they called an artificial kidney. Their dialyzer, consist of eight parallel colloidal tubes of $8 \mathrm{~mm}$ diameter and $40 \mathrm{~cm}$ long. But very soon 
they extended this to 32 parallel tubes. The making of those delicate colloidal tubes and non-availability of heparin as an anticoagulant was the hardest problem they had to deal with. However they succeeded in preparing a non-toxic hirudin as anticoagulant and in extending the dialyzing capacity with 192 parallel tubes for use in human patients. Nevertheless it was more than 30 years before the use of an artificial kidney saved the first patient with acute renal failure.

The problems of anticoagulation and the development of a suitable membrane were well investigated by different researchers all over the world. Von Hess and McGuigan together (1914) prevented clotting and the formation of stagnant layers by creating a pulsatile blood flow and a turbulent dialsate flow, respectively.

Love (Chicago,1920) prepared dialysis membrane from chicken intestines, while Heinrich Necheles (Hamburg,1923) used semi permeable tubes made from gold beater's skin. To keep the blood volume small, these tubes were compressed between metal wire grids.

Georg Haas (1888-1971) carried out the first human dialysis in 1924. He constructed a colloidal tube $\left(1.2 \mathrm{~m}\right.$ long) dialyzer with surface area of $1.5-2.1 \mathrm{~m}^{2}$. During 1928-1937, two important advances were made:

Once purified heparin became available and a new type of membrane named cellophane became commercially available.

Leonard Rowntree, and B.B. Turner created the first artificial kidney. They used celloidin tubes held in a glass jacket. The jacket was filled with saline or artificial serum. They also used a primitive anticoagulant called hirudin, found in the blood of leeches. Although this device was revolutionary it was never used on humans.

The first hemodialysis treatment was carried out in 1924 by George Haas in Germany. The treatment lasted 15 minutes and went without complications. The first practical hemodialysis machine for use by people was developed by 


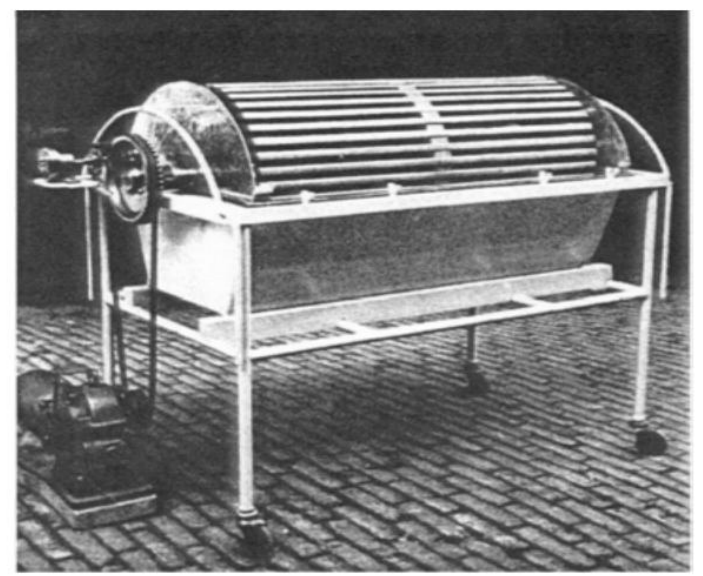

Figure 2.4. Kolff's original rotating drum(1943).

W.J. Kolff in the Netherlands as shown in fig 2.4. It resembled a steel rotating drum dialyzer. Cellophane sausage casing was wound around the drum. A 30 to $40 \mathrm{~m}$ cellophane tube (diameter $2.5 \mathrm{~cm}$ ) was wound around the cylinder and was perfused with the patient's blood by means of water pump copied from a ford containing 70-100L dialysis fluid. While the lower portion of the drum was suspended in a dialysis bath. This procedure needed a large amount of blood and the patient required many blood transfusions to make it work. After some life saving intermittent dialysis session using one needle for draining and reinfusing the blood, Kolff changed to continuous dialysis using two needles. He used surgical cut-downs into the vessels, which frequently caused bleeding during heparinization. The major reason "why chronic uraemic patients didn't survive for a long time" was the repeated access to bloodstream. Kolff was the first to construct a working dialyzer in 1943. The first successfully treated patient was a 67-year-old woman in uraemic coma who regained consciousness after 11 hours of hemodialysis with Kolff dialyzer in 1945. At the time of its creation, Kolff goal was to provide life support during recovery from acute renal failure.

In 1947 in Sweden, Nils Alwall developed a creative machine called the Alwall 
kidney. The machine was comprised of a barrel placed in a stainless steel canister. This enabled positive pressure to be applied so fluid could be removed. Nils Alwall was a pioneer in hemodialysis, and he modified a construction of the Kolff kidney by enclosing it inside a stainless steel canister. This allowed the removal of fluids, by applying a negative pressure to the outside canister, thus making it the first truly practical device for hemodialysis. Alwall treated his first patient in acute renal failure on the 3rd of September 1946. The patient responded well to the treatment but died of pneumonia a short while after. Alwall was also the inventor of the arteriovenous shunt for dialysis. He reported this first in 1948, where he used such an arteriovenous shunt in rabbits. Subsequently he used such shunts, made of glass, as well as his canister-enclosed dialyzer, to treat 1500 patients in renal failure between 1946 and 1960, as reported to the First International Congress of Neurology held in Evian in September 1960.

In the early 1960s hemodialysis was a procedure that would last 8-10 hours, every other day. Dialysis treatments were confined to patients with acute kidney disease (reversible kidney failure) because a patients veins could only be used for 7-10 treatments. As a result, dialysis was only available to a limited number of people and restricted to just a few centers. Early dialysis machines were also large and cumbersome and required a large amount of space. The dialysis membranes were reusable plates that had to be rebuilt for each treatment. In 1960, with the creation of a reusable vascular access called the Scribner shunt, dialysis treatments would change forever. Designed by Belding Scribner of Seattle Washington, the Scribner shunt used a U-shaped Teflon tube that routed blood from an artery back to a vein. The shunt protruded out from the skin and would then attach to the blood tubing. When the shunt was not in use, caps were placed over the tubing. With this new shunt, chronic kidney failure patients now had access to hemodialysis.

The single pass technique was introduced (1963) in order to avoid problems 
with dialysate contamination. This technique was the first step in the development of a central dialysate supply system. A second step was the substitution of acetate for bicarbonate in the dialysis fluid. Sodium acetate, in contrast to the precipitating bicarbonate, could be readily mixed with other salts and dextrose in the appropriate concentration. Babb developed a multi-patient dialysate proportioning system in 1964. As a consequence of all these available facilities, an enormous increase of regular dialysis treatments occurred. As an answer to the problems of the financing and the training of doctors and nurses, Shaldon (UK, 1963) introduced self dialysis, which was soon after extended to home dialysis. Although the predecessor of the current hollow fiber dialyzer was described by Stewart already in 1968, the Achilles heel of chronic patients remained the arterio-venous (A-V) shunt. Therefore, Brescia, Cimino, et al. (USA) created a surgically A-V fistula. Because some patients had recurrent problems, May introduced in 1969 the saphenous vein autograph as a loop or straight bridge between an artery and a vein.

In the 70's further developments were made in other domains: increasing the dialysis efficiency, shortening the dialysis time, increasing the quality of life and the comfort of the chronic patient, amelioration of the biocompatibility and miniaturization of the equipment.

Babb in 1971 reported that inadequate removal of the middle molecules causes complications such as peripheral neuropathy and pericarditis. To provide high diffusive and convective transport of middle and large molecules, high flux devices for use in hemodialysis were developed.

Synthetic membranes (e.g. polyacrylonitrile PAN, poly methyl methacrylate PMMA, polysulphone PSu) were introduction in 1972, which are far more biocompatible than cellulose membranes, prevented activation of the complement cascade.

To control the ultra filtration flow, a direct control or a control based on a differential flow measurement was used until Schultheis (Germany, 1975) de- 
scribed the volumetric control method relying on balancing chambers that equalize the flow of fresh and spent dialysate. 44

The modern machines for hemodialysis permit a complete manipulation of the dialysate composition, temperature, flows, and pressures to improve problems of metabolic acidosis and electrolyte imbalances 45. 


\section{Chapter 3}

\section{Body Composition}

To design a model for salute kinetics and body composition in hemodialysis patients, some relevant concepts such as body composition should be understood. In this chapter we present different levels of body composition models, and methods used for body composition assessment. Most material in this chapter is taken from the thesis of Jukka A Salmi [32, [55, 36], the thesis of Inga-Lill Engvall [30], and some references for body composition given at the end.

\subsection{Body Composition Definition}

Two people at the same height and same body weight may look completely different from each other because they have a different body composition. Body composition is defined as the percentage of fat, muscle, and bone in the body. Usually it is expressed as a ratio of lean mass to fatty mass. Lean mass includes muscles, bones, skin, internal organs and body water.

Fatty mass is mostly composed of body fat (subcutaneous fat) as well as internal essential fat surrounding organs. Body composition will typically be displayed as either a percentage of fat (body fat percentage or ) or as a percentage of lean body mass (LBM). It varies among individuals as a result of 


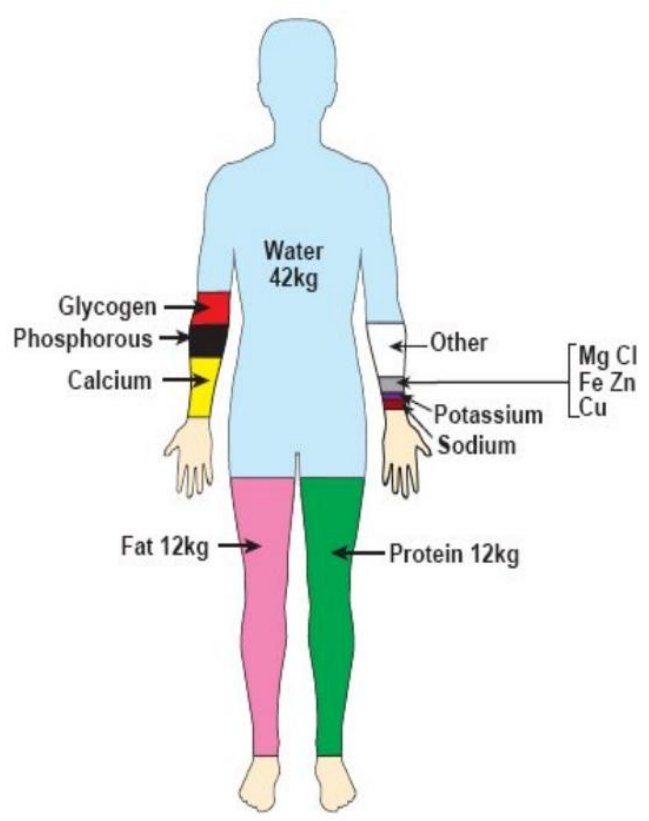

Figure 3.1. Body composition of a normal weight male.

differences in body density and degree of obesity.

The body composition of a normal weight adult is shown in Fig 3.1. Major components of the human body are water, protein and fat as well as bone and minerals.

\subsection{Body Composition Model}

The body composition can be classified into five distinct levels of model, depending on the purpose or analysis: atomic model, molecular model, cellular model, tissue system model, and whole body model [5, 55].

Several commonly applied principles are that $16 \%$ of protein is nitrogen, $77 \%$ of fat is carbon, and approximately two thirds of excess body weight in adults is fat [55]. An important concept when considering the five-level model is that 


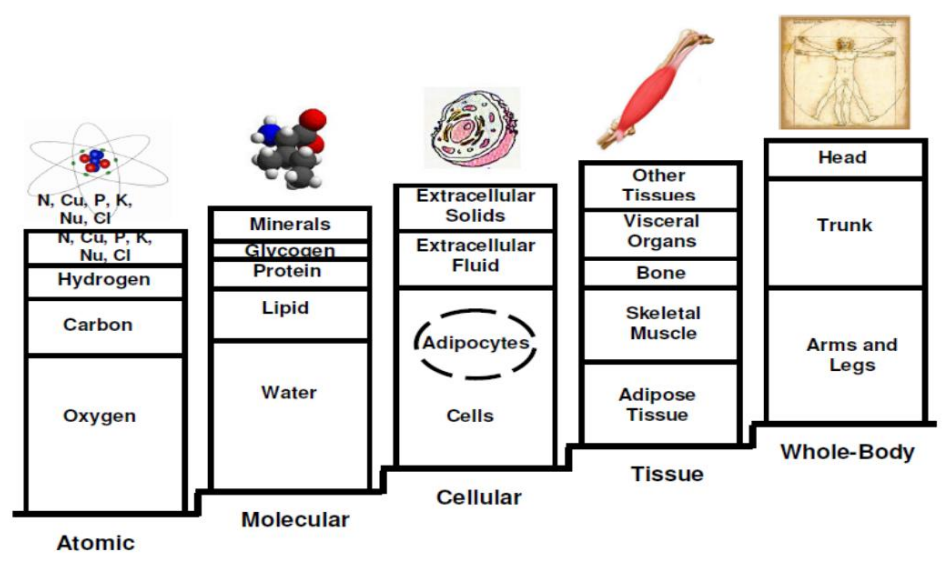

Figure 3.2. The five-levels of human body composition.

components at successively higher body composition levels are composed of lower level components. A classic example is that adipose tissue, a tissuesystem level component, includes components such as adipocytes at the cellular level, lipids at the molecular level, and carbon at the atomic level (Figure 3.2 ). Loss or gain of adipose tissue with a new intervention reflects changes in corresponding components at the cellular, molecular, and atomic levels.

\subsubsection{Atomic Model}

Approximately 50 out of the 106 elements found in nature are also found in the human body. As they are needed for both growth and health maintenance. Usually 11 main elements: oxygen $(\mathrm{O})$, carbon $(\mathrm{C})$, hydrogen $(\mathrm{H})$, nitrogen $(\mathrm{N})$, calcium $(\mathrm{Ca})$, phosphorus $(\mathrm{P})$, potassium $(\mathrm{K})$, sulphur $(\mathrm{S})$, sodium $(\mathrm{Na})$, chlorine $(\mathrm{Cl})$, and magnesium $(\mathrm{Mg})$ are included in an atomic level model (Table 3.1). Four elements O, C, H, and N account for over $95 \%$ of body mass and with an additional seven elements $\mathrm{Na}, \mathrm{K}, \mathrm{P}, \mathrm{Cl}, \mathrm{Ca}, \mathrm{Mg}$, and $\mathrm{S}$ comprise over $99.5 \%$ of body mass

All these main elements are measurable by neutron activation analysis (NAA), 
combined with whole body ${ }^{40} \mathrm{~K}$ counting.

Table 3.1. Main body-composition components in the five-level model.

\begin{tabular}{ll}
\hline \hline Level & component \\
\hline Atomic $(\mathrm{n}=11)$ & O, C, H, N, Ca, P. 5, K, Na, Cl, and Mg \\
Molecular $(\mathrm{n}=8)$ & Fat, water, protein, bone mineral, non bone tissue mineral, \\
& glycogen, fat-free body mass, and fat-free solids \\
Cellular $(\mathrm{n}=6)$ & Fat cells, cell mass, intracellular fluid, \\
& extracellular fluid, extracellular solids, and body cell mass \\
Tissue System $(\mathrm{n}=6)$ & Adipose tissue (AT), subcutaneous AT, visceral AT, \\
& bone, skeletal muscle, and skeleton \\
Whole body $(\mathrm{n}=5)$ & Head, neck, arms, trunk, and legs \\
\hline $\mathrm{n}:$ for each level is the number of components
\end{tabular}

\subsubsection{Molecular Model}

Different chemical compounds found in the human body can be classified into five main groups: lipids, water, proteins, carbohydrates (i.e. glycogen), and minerals. Sub-fractions of components can also be defined, as for example the triacylglycerol or fat portion of lipid, the extra and intracellular portions of total body water, and bone and soft-tissue minerals. Lipids are defined as chemical compounds that are soluble in lipid solvents. The most abundant lipid species in humans are the triacylglycerols, which generically are often referred to as fats. The non-fat lipids include phospholipids, sphingolipids, and steroids. In humans triacylglycerols or nonessential lipids are energy storage compounds, while the remaining lipid species are essential in various biochemical and physiological processes.

Minerals comprise about $5 \%$ of body weight in healthy adults and are distributed in two main compartments: bone minerals and non-bone or soft-tissue minerals. The main constituent of bone minerals is calcium hydroxyapatite $\left[\mathrm{Ca}_{3}\left(\mathrm{PO}_{4}\right)_{2}\right]_{3} \mathrm{Ca}(\mathrm{OH})_{2}$, with small contributions made by $\mathrm{Na}, \mathrm{K}, \mathrm{Mg}$, and $\mathrm{Cl}$. Soft-tissue minerals include well-known ions such as $\mathrm{Na}^{+}, \mathrm{K}^{+}, \mathrm{Cl}^{-}, \mathrm{HPO}_{4}^{2-}$, and $\mathrm{HCO}_{3}^{-}$. 
Although there are five main molecular level components, it is common

Table 3.2. Body-composition models at different body-composition levels

\begin{tabular}{ll}
\hline \hline Level & Equations \\
\hline Atomic(11-component level) & $\mathrm{BW}=\mathrm{O}+\mathrm{C}+\mathrm{H}+\mathrm{N}+\mathrm{Ca}+\mathrm{P}+\mathrm{S}+\mathrm{K}+\mathrm{Na}+\mathrm{Cl}+\mathrm{Mg}$ \\
Molecular & $\mathrm{BW}=\mathrm{F}+\mathrm{A}+\mathrm{Pro}+\mathrm{Ms}+\mathrm{Mo}+\mathrm{G}$ \\
6-component model & $\mathrm{BW}=\mathrm{F}+\mathrm{A}+\mathrm{Pro}+\mathrm{M}$ \\
4-component model & $\mathrm{BW}=\mathrm{F}+\mathrm{A}+$ solids \\
3-component model & $\mathrm{BW}=\mathrm{F}+\mathrm{Mo}+$ residual \\
3-component model & $\mathrm{BW}=\mathrm{F}+\mathrm{FFM}$ \\
2-component model & $\mathrm{BW}=\mathrm{CM}+\mathrm{ECF}+\mathrm{ECS}$ \\
Cellular & $\mathrm{BW}=\mathrm{CM}+\mathrm{ECF}+\mathrm{BW}=\mathrm{F}+\mathrm{BCM}+\mathrm{ECF}+$ ECS \\
Cellular & $\mathrm{BW}=\mathrm{AT}+\mathrm{SM}+$ bone + other tissues \\
Tissue System & Abbreviation: BW body weight, F fat, A water, Pro protein, Ms. soft tissue mineral, Mo bone \\
mineral, G glycogen, M mineral, FFM fat-free body mass, CM cell mass, ECF extracellular \\
fluid, ECS extracellular solids, BCM body cell mass, AT adipose tissue, SM skeletal muscle.
\end{tabular}

to combine components in order to develop body composition methods. For example, the molecular level can be described as any of the following combinations:

Two-compartment model in which body weight

$(\mathrm{BW})=$ fat + fat-free body mass, and

$\mathrm{BW}=$ lipid + lipid-free body mass;

Three-compartment model in which

$\mathrm{BW}=$ fat + water + residual (i.e. the sum of glycogen, minerals, and protein), and

$\mathrm{BW}=$ fat + bone mineral + lean soft tissue;

Four compartment model in which

$\mathrm{BW}=$ fat + water + minerals + residual (i.e.the sum of glycogen and protein).

\subsubsection{Cellular Model}

There are over $10^{18}$ cells in the human body that are bathed in extracellular fluid and supported by a framework of extracellular solids. The cell level's 
importance is centred primarily on the protoplasmic or intracellular compartment, which is the site of most metabolic processes.

The traditional cellular level model consists of three components: cell mass, extracellular fluid, and extracellular solids (Table 3.2). The extracellular solids are not of much clinical interest, as they consist mainly of bone minerals and collagen, reticular, and elastic fibers [5]. Extracellular fluid is slightly larger than extracellular water, also a molecular level component, as it includes dissolved electrolytes and proteins.

The most widely used cellular level model is $\mathrm{BW}=$ fat mass(FM) + extracellular fluid + extracellular solids + body cell mass(BCM). There are many relatively stable cellular-level relationships that are used in body composition research, and some of the more important of these are as follows:

$\mathrm{K} /$ intracellular water $=159 \mathrm{mmol}$ of $\mathrm{K} / \mathrm{kg}$ of $\mathrm{H}_{2} \mathrm{O}=6.22 \mathrm{~g}$ of $\mathrm{K} / \mathrm{kg}$ of $\mathrm{H}_{2} \mathrm{O}$; $\mathrm{K} /$ body cell mass $=4.69 \mathrm{~g} / \mathrm{kg} ; \mathrm{Ca} /$ extracellular solids $=0.177 \mathrm{~kg} / \mathrm{kg}$;

and extracellular water/extracellular fluid $=0.92$.

Extracellular fluids are measurable by dilution methods or by a combination of TBW and total body potassium. Extracellular solids can be estimated from a constant relationship between BMC and extracellular solids measured by DXA.

\subsubsection{Tissue system Model}

The main tissue-system level components are adipose tissue, skeletal muscle, bone, visceral organs, and brain. Adipose tissue is further divided into subcutaneous, visceral, yellow marrow, and interstitial subcomponents. Some reasonably stable relations at the tissue-system level include:

skeletal muscle/adipose tissue free body mass $=0.54$ (for men) or 0.49 (for women); $\mathrm{K} /$ skeletal muscle $=3 \mathrm{~g} / \mathrm{kg}$; fat $/$ adipose tissue $=0.8$; and bone mineral $/$ bone $=0.54$. 
Table 3.3. Examples of body composition models(Heymsfield et al.,1997). all units are in kilograms

\begin{tabular}{ll}
\hline \hline Level/Level & Model \\
\hline Atomic/Atomic & $\mathrm{TBS}=0.062 \times \mathrm{TBN}$ \\
Atomic/Atomic & $\mathrm{TBP}=0.456 \times \mathrm{TBCa}+0.555 \mathrm{x} \mathrm{TBK}$ \\
Atomic/Molecular & $\mathrm{TBCa}=0.364 \times \mathrm{MO}$ \\
Atomic/Molecular & $\mathrm{TBN}=0.16 \mathrm{x}$ protein \\
Atomic/Molecular & $\mathrm{TBK}=0.00266 \times$ fat-free body mass \\
Atomic/Molecular & $\mathrm{Carbon}=0.774 \times$ fat \\
Atomic/Molecular & $\mathrm{TBS}=0.010 \times$ protein \\
Atomic/Molecular & $\mathrm{TBK}=0.00469 \times$ body cell mass \\
Atomic/Whole body & $\mathrm{TBH}=0.10 \times \mathrm{BW}$ \\
Atomic/Molecular & $\mathrm{TBW}=0.732 \times$ fat-free body mass \\
Atomic/Molecular & $\mathrm{Glycogen}=0.044 \times$ protein \\
Whole body/Atomic & $\mathrm{BW}=\mathrm{O}+\mathrm{C}+\mathrm{H}+\mathrm{N}+$ Ca $+\mathrm{P}+\mathrm{S}+\mathrm{K}+\mathrm{Na}+\mathrm{Cl}+\mathrm{Mg}$ \\
Atomic/Molecular & $\mathrm{BW}=$ lipids + water + protein $+\mathrm{MO}+\mathrm{MS}+$ glycogen \\
Atomic/Molecular & $\mathrm{BW}=$ fat + fat-free body mass \\
Whole body/Cellular & $\mathrm{BW}=$ cell mass + extracellular fluids + extracellular solids \\
Whole body/Tissue System & $\mathrm{BW}=$ adipose tissue + skeletal muscle + bone + viscera + blood $+\mathrm{R}$ \\
Whole body/ Whole body & $\mathrm{BW}=$ head + neck + trunk + lower extremities + upper extremities \\
\hline Abbreviation: TB=Total body, $\mathrm{MO}=$ Bone mineral, BW=Body weight, MS $=\mathrm{soft}$ tissue minerals, \\
\end{tabular}

Anthropometrical methods are recently used for assessing body composition according to tissue-system model. Also computerized tomography (CT) and magnetic resonance imaging (MRI) have shown reassuring results.

\subsubsection{Multi-compartment Model}

Multi-compartment models are mixtures of different body composition models described above. The purpose of multi-compartment methods is to improve the accuracy of body composition assessment. The classical two-component (2-C) model is used for assessing of fat and fat-free mass (compartments), by measuring body density. To reduce the limitations in 2-C models expansion was made to three-component (3-C) configurations. A typical approach is to include total body water (TBW) to the 2-C model, usually with a dilution method. Unfortunately, this does not improve the method too much. For the subjects with unstable protein and/or mineral condition, the estimated values 
for the solids compartment will be incorrect. That leads to inaccurate body fat estimation as well [36]. In order to expand (3-C) to a four-component (4-C) model, protein or mineral measurements are added tothe $3-\mathrm{C}$ model. In the 4-C model the body is divided into fat, protein, fluid, and minerals. These factors are important in clinical use and are helpful in providing nutritional information (e.g. BCM, soft lean mass). The 4-C model can provide more thorough information and efficient classification in the health care field. The six-component (6-C) model is probably the latest and most challenging model of all. It consists from TBW, N, Ca, K, Na, and Cl, where TBW is measured by dilution method and remainder by NAA $([62,63])$.

\subsection{Method for Body Composition Assessment}

\subsubsection{Underwater Weighing(UWW)}

UWW is considered the gold standard for body composition assessment. It is the criterion method against which all other body composition measurements are compared. However, UWW is a laboratory technique involving equipment, which also needs 2 or 3 testers and takes about 25 minutes. It takes 1 hour of preparation prior to measuring and 45 minutes after the actual testing. UWW is the most commonly used method for assessing total body density, which requires the subject to be submerged in water. The residual lung volume is also measured, with a commonly used method of oxygen dilution with a closedcircuit spirometer system. The volume of water displaced or the weight of the subject underwater, compared to the subject's normal weight, are used to calculate the density of the whole body. The result is then corrected by the residual lung volume. The UWW methods were developed mainly as a means to measure body volume to assess body fatness (FM and/or F\%). Even if the body volume and weight could be measured without error, there would still 
be considerable uncertainty regarding the individual's body fat estimate due to normal variations in body hydration, protein, and mineral contents. It has been estimated that the total error for body fatness is approximately $3-4 \%$ of body weight for individuals [32]. Therefore, it has been recommended that without correction for variation in the water and mineral content of FFM, densitometry should not be used as a reference method for heterogenic population.

\subsubsection{Dilution Method}

The dilution method with labelled water is an accurate method for total body water (TBW) measurement. It is performed by introducing intravenously or orally a certain substance (a tracer) like deuterium oxide $\left(D_{2} \mathrm{O}\right)$, oxygen-18, or tritium (radioactive; not recommended) into the human body, and then collecting two body fluid samples (blood, urine, or saliva), one before introducing the tracer and second after an equilibration time of 2-4 hours. The substance (tracer) is then equilibrated with water in the subject's body, and the density of the substance is analyzed. Dilution takes many hours of measurement and cannot be measured repeatedly. However, because it is rather accurate, it is used to measure body water for research purposes.

For any tracer dilution technique there are four basic assumptions:

1)Tracers are distributed only in exchangeable pools,

2) The tracer is equally distributed within this pool,

3)It is not metabolised during the equilibration time,

4) The tracer equilibration is achieved relatively rapidly.

Mathematical terms that describes the dilution principles are shown in the equation below:

$$
\mathrm{V}=k_{1} \cdot k_{2} \cdot k_{3} \cdot k_{4} \cdot(D-E) /\left(\left[d_{t}\right]-\left[d_{0}\right]\right)
$$


where $\mathrm{k}$ values are constants, $\mathrm{D}$ is the trace period, $\left[d_{t}\right]$ is the tracer concentration in the fluid sampled after time $\mathrm{t}$ following the administration of dose, and $\left[d_{0}\right]$ is the baseline concentration before the tracer. For the measurements of total body water (TBW), extracellular water (ECW), and intracellular water (ICW), corrections for over-expansion, non equilibrium, and excretion of the tracers are needed.

Total body water Water and its dissolved constituents make up the bulk of our body, and determine the nature of nearly every physiological process. In most individuals, approximately $60 \%$ of the total weight is water. This percentage varies between $50 \%$ and $70 \%$, with the exact value primarily dependent on a person's fat content. Since fat has very low water, individuals with more fat will have a lower overall percentage of body weight as water. Water is found exclusively within the fat free mass FFM, which is approximately $73.2 \%$ water in adults. TBW includes both intracellular fluid and extracellular fluid. If there is an estimate of TBW, the amount of FFM can be estimated. Body FM is the difference between body weight and FFM.

The earliest, and still the most direct and easy measurement technique for the TBW is that based on dilution principle, using a tracer dose of labelled water (tritium, deuterium, or oxygen-18) and collection of two body fluid samples (blood, urine, or saliva) one pre-dose and second after an equilibration time approximation of $2-3 \mathrm{~h}$. Model analysis depends on the choice of tracer: radioactive $\beta$-counting for tritium, mass spectroscopy for ${ }^{18} \mathrm{O}$, and infra-red absorption, gas chromatography, or mass spectroscopy for deuterium.

Extracellular Water To measure the volume of ECW, the basic dilution techniques are the same as those used to measure total body water, except the tracer is added to the water and the body fluid most often sampled is plasma. Most commonly used non-radioactive tracer is bromide $\mathrm{Br}$. This is administered orally, with a second plasma sample usually collected about 3-4h later, 
although complete equilibration may not have been reached [36]. The analytical Br assay in most common use is high pressure liquid chromatography, although few investigators have used X-ray fluorescence, spectrophotometry, or mass spectrometry techniques [36].

Intracellular Water Dilution of radioactive potassium $\left({ }^{42} \mathrm{~K}\right)$ tracer can be used to take the measurements of ICW volume. However this isotope has a short half live $\left(t_{1 / 2}=12.4 \mathrm{~h}\right)$ and is no longer routinely commercially available. Measurement of the exchangeable potassium pool is rarely performed. The most commonly used method today to estimate ICW is to orally administer a combined $D_{2} \mathrm{O}$ plus Br dose, from which TBW and ECW are determined. Then ICW is calculated as the difference (ICW $=$ TBW - ECW) with modest precision.

\subsubsection{Dual Energy x-ray Absorptiometry(DEXA)}

DEXA stands for "dual energy X-ray absorptiometry". It is a test that measures the density of bones. Density means how much of something is present in a certain amount of space. The denser the tissue, the less X-rays pass through. Air and water are less dense than solid things such as bone. This is because the particles which make air and water are not held closely together. In general, the more dense the bone, the stronger it is, and the less likely for it to break.

There are two different types of DEXA scanning devices. Central DEXA devices are large machines that can measure bone density in the centre of the skeleton, such as hip and spine. Peripheral DEXA devices are smaller, portable machines that are used to measure bone density on the periphery of skeleton, such as wrist, heel or finger.

A DEXA scan uses low energy X-rays. A machine sends X-rays from two different sources through the bone being tested. Bone blocks a certain amount 


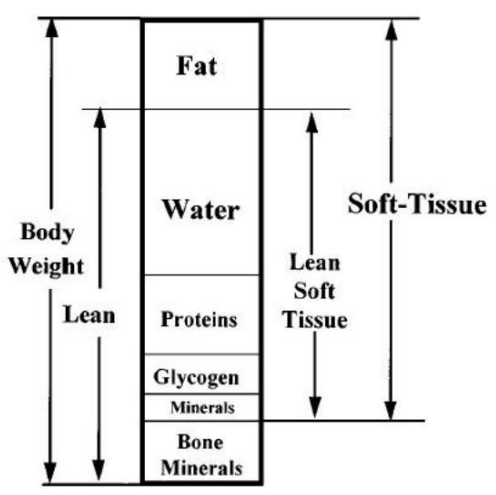

Figure 3.3. DXA molecular level model. (Adapted from Heymsfield et al., 1997).

of the X-rays. The more dense the bone is, the fewer X-rays get through to the detector. By using two different X-ray sources rather than one greatly improves the accuracy in measuring the bone density.

The amount of X-rays that comes through the bone from each of the two Xray sources is measured by a detector. This information is sent to a computer which calculates a score of the average density of the bone. A low score indicates that the bone is less dense than it should be, meaning some material of the bone has been lost, and is more prone to fracture.

Subject is allowed to lie on his back on a couch and is asked to keep still while an X-ray detector 'scanner' comes over the area to be tested. An X-ray machine fires X-rays towards the detector. The bones commonly scanned are the vertebrae (back bones), hip and wrist. The scan usually takes between 10 and 20 minutes, depending on which part of body is being examined, and whether a central or peripheral scanner is being used. Peripheral scanners are available in some surgeries and can be used to check the bone mass density of the heel, wrist or finger.

Dual energy X-ray absorptiometry (DXA) is the most used imaging method of body composition assessment. This is mostly used for bone density assessment 
for osteoporosis diagnostic purposes and clinical bone research, but it can also be used for whole body composition assessment. Hence, DXA is available in most of the bigger hospitals and research centers. When an X-ray or photon source is placed on one side of an object, the intensity of the beam on the opposite side of it is related to thickness, density, and chemical composition of the object. This attenuation phenomenon is also dependent on the energy of the incident photons and is dominated by two principles at low energies: the photoelectric effect and Compton scattering. The attenuation response is non linear, such that for a homogeneous material, it can be described by the exponential equation. If the absorber is composed of two or more materials, then the composite is the weight sum of the individual mass attenuation coefficients, each weighted for its fractional contribution to the total mass. The attenuation through bone, lean tissue, and fat is different, reflecting their differences in densities and chemical composition. With increasing photon energy, the differences in the attenuation properties for these tissues decrease. Thus, if the relative intensity of the transmitted beam can be measured, and the mass attenuation coefficients are accurately known, estimates of the bone mass and overlaying soft tissue mass can be calculated. The $2-\mathrm{C}$ model is also used when the beam passes through body regions without bone. In this case, the appropriate attenuation coefficients are those for fat and lean tissues, respectively. It should be evident that DXA is composed of two separate sets of equations, each used to describe a 2-C model. Dual-energy X-ray absorptiometry does not provide three independent measurements, even though three body composition values [bone mineral content (BMC), lean tissue mass (LTM), and fat mass (FM)] are reported (Figure 3.3). In the case of the whole body scan, about $40-45 \%$ of the pixels are classified as containing bone. The remaining pixels are used to estimate the body's fat-to-lean ratio, this value is applied to the soft tissue component in the adjacent bone pixels. Thus, the relative lean-to-fat composition of the total soft tissue mass is based on 
sampling only one-half of the whole body.

\subsubsection{Computed Tomography (CT)}

X-rays are used in the computed tomography (CT) technique. These rays are collimated to provide a fan-shaped beam that is passed through the body, while an array of detectors is on the opposite side of the subject to detect the transmitted radiation. The X-ray source and detector assembly are rotated as a single unit around the subject covering a full $360^{\circ}$. Alternatively, some devices have a full circle of detectors, and only the X-ray source is rotated. At each degree of rotation, for each detector the transmitted intensity is recorded, providing information about the internal structures along that beam circle [6]. This basic anatomical image contains information of the tissue density at each pixel. Both of these i.e information and anatomical location of the pixel in the image can be used to identify it as adipose, muscle, skin, visceral, or bone tissue. Reconstruction of total body mass and separate organ masses based on scans along the length of the body at $10 \mathrm{~cm}$ intervals has been shown to have excellent accuracy ( $<1 \%$ error) and precision $(<1 \%)$. Reconstructed CT images can be assigned to the level 4 or tissue system level of multi-compartment model. To separate the total adipose tissue mass into its subcutaneous and visceral components, or the lean tissues into skeletal muscle and visceral or organ mass, the CT images can also be used. Similarly, bone can be identified as cortical or trabecular in nature on the basis of density [6, 48]. The major disadvantage with $\mathrm{CT}$ is the radiation dose required per slice for scanning. However, if the pixel resolution required for routine CT scans can be reduced, then the dose can be significantly reduced. Recent studies have shown that a dose can be reduced to $1 / 25$ that of a routine clinical CT scan dose 6, 48, 


\subsubsection{Magnetic Resonance Imaging(MRI)}

The earth's magnetic fields is very weak. As a result atoms and molecules in the body are in random orientation. When the body is placed in a strong magnetic field, some nuclei tend to align with or against the magnetic field. In particular, hydrogen protons $\left({ }^{1} \mathrm{H}\right)$, have a high affinity for alignment with the magnetic field. Some more atoms in the human body $\left({ }^{13} \mathrm{C},{ }^{19} \mathrm{~F},{ }^{23} \mathrm{Na}\right.$, ${ }^{31} \mathrm{P}$, and ${ }^{39} \mathrm{~K}$ ) also show similar properties, but at a lower response than for hydrogen atoms. Although only a small percentage of nuclei will be aligned, the number is sufficient to detect a change in their orientation when the magnetic field is removed or changed. Larmor frequency is the frequency at which nuclei for each element will flip (relative to the direction of constant magnetic field). When radio frequency (RF) energy, at the Larmor frequency, is applied perpendicular to the direction of the magnetic field, the nuclei will absorb this energy and change its alignment. When the RF field is turned off, the nuclei will lose their alignment and release the stored energy. In order to measure the number of hydrogen nuclei of the tissue, the intensity of this signal can be used. This process can be repeated at each position along the length of body until the whole body is mapped and cross-sectional images at each slice can be generated. Magnetic resonance imaging (MRI) is successful because hydrogen, found mainly in water, is one of the most abundant non-bound elements in the body. For other elements, their concentrations in the body are lower and the Larmor frequency changes, thus requiring an increased magnetic field strength if imaging is to be considered [1]. When the hydrogen densities of adipose and lean tissues were markedly different, then it would be possible to develop images based solely on their number of nuclei. A second feature of the nuclei, called relaxation time (T1), is used in order to see the contrast between lean and fat tissues. This is the time it takes for the nuclei to release the RF-induced energy and return to a random configuration. The T1 for protons in fat is much shorter than that for protons in water. This contrast 
can be maximized by adjusting the time interval of the RF pulse and the time to detect the induced signal. The total process is often referred to as a pulse sequence or spin-echo sequence $([1,18,21,42,47])$.

For whole body measurements, a series of multiple scans along the length of the body is required, which may require the subject to be in the magnet's bore for $30 \mathrm{~min}$ or longer. To reduce artifacts introduced by movement, the subject is asked to hold his or her breath for each of the abdominal slices. MRI equipment is widely used but the technique is still regarded as a costly method for body composition purposes. MRI technique can separate visceral fat from subcutaneous fat, muscle from organ, and determine bone densities. It does not involve radiation, so it can perform a total body scan for maximal accuracy and fat distribution. But it is not possible to measure extreme obesity.

\subsubsection{Neutron Activation Analysis}

Neutron activation (NA) technique is used for the direct elemental analysis of the living human body. Other body composition techniques such as CT, MRI, DXA, BIA, and dilution methods provide estimates of tissue density or volume, but not chemical contents such as hydrogen, oxygen, sodium, chlorine, and potassium. The NA technique has been in use for more than 30 years.

\subsubsection{Bioelectric Impedance Analysis}

Bioelectric impedance analysis (BIA) measures body water based on the following principle: electricity flows through the tissues of body that contain water. When electric signals are sent to the body, electric current flows through the most conductive tissue. Based on the amount of water, the width of the passage of electricity flows is detemined. The aqueous tissue of body, due to 
their dissolved electrolytes, are major pathways of an electrical current, where body fat and bone have relatively poor conductivity.

To take the BIA measurements, a low alternating current is conducted through an outer pair of electrodes. An inner pair of electrodes (from which the impedance is measured) measure the drop of voltage. Two basic assumptions are used in order to convert this information to volume estimates: Firstly, body can be modelled as cylindrical conductor with its length proportional to the subject's height $(\mathrm{Ht})$. Secondly, the reactance component $(\mathrm{X})$ contributing to the body's impedance $(\mathrm{Z})$ is small, and the resistance component $(\mathrm{R})$ can be shown that the conducting volume is proportional to the term $\mathrm{Ht}^{2} / \mathrm{R}$, called the impedance index. A classical BIA method hypothesized that human body is like a cylinder, and BIA measures total body water (TBW). The amount of water is equal to the volume of the cylinder. The cell membrane and fat tissue show high impedance to electric current in BIA. Good conductivity is provided by the electrolyte dissolved in the water.

Body fat mass can be estimated from total body water. Lean body mass is in proportion to total body water. The estimate is based on the constant relationship of $72.3 \%$ water in LBM [61]. Body fat is equal to the difference of LBM and weight. Typically body fat mass is calculated with regression analysis equation directly from the impedance index. The bioelectrical impedance method is easy to use and can be readily repeated. Now a days BIA is probably the most frequently used method.

Single frequency bioimpedance analysis BIA measurements are traditionally performed using four electrodes; usually two are attached at the wrist and two a the ankle and measurements are performed in spine position. A single frequency current of $50 \mathrm{kHz}$ is used. The body's impedance has both resistive and reactive components at $50 \mathrm{kHz}$. 
Multi-frequency bioimpedance analysis Multi frequency bioelectric impedance analysis (MFBIA) is based on the hypothesis that lower frequencies $(\leqslant 50$ $\mathrm{kHz}$ ) flow within the extracellular compartment, whereas higher frequencies $(\geqslant 200 \mathrm{kHz})$ can pass trough cell membrane and hence measure the intracellular space.

In addition, the direction of the electricity can be changed by changing the frequency of electrical signal. By the use of this principle, intracellular fluid and extracellular fluid can be distinguished and measured separately. Frequencies used for MFBIA are normally from $1 \mathrm{kHz} \sim 1 \mathrm{MHz}$ ([13, 24, 59]).

Segmental bioimpedance analysis Segmental analysis of body composition can be defined in two different bases. Firstly, assessing the total body composition by measuring a certain body segment. Secondly, One can improve the accuracy of total body composition assessment, by measuring all different body segments separately.

\section{Segmental multi-frequency bioimpedance analysis(SMFBIA) SMFBIA is} a usefull method to evaluate whole body fat mass (FM) fate percentage (F\%) and fate free mass (FFM). Moreover this method is suitable for assessing segmental distribution of FFM from upper and lower extremities compared to whole body DXA.

Table 3.4. Classification of BMI by WHO

\begin{tabular}{lll}
\hline \hline Classification & $\mathbf{B M I}=\mathbf{k g} / \mathrm{m}^{2}$ & Population distribution \\
\hline Underweight & $<18.5$ & Thin \\
Normal & $18.5-24.9$ & Normal, healthy \\
Overweight & $\leqslant 25$ & \\
Pre-obese & $25-29.9$ & overweight \\
Obese class 1 & $30-34.9$ & Obesity \\
Obese class 11 & $35-39.9$ & Obesity \\
Obese class 111 & $\geqslant 40$ & Morbid obesity \\
\hline
\end{tabular}




\subsubsection{Other Measurement Methods}

In recent years, the UWW technique has begun to be replaced by air displacement plethysmorgraphy. Skinfold thickness is another method used for measuring subcutaneous fat, but the reliability of this method is low. Body mass index (BMI) is also an independent marker of body composition and therefore an available method for assessing obesity and overweight related diseases.

Body mass index (BMI) Body mass index is the most commonly used assessment index of obesity. BMI is calculated by dividing the weight $(\mathrm{kg})$ of an individual with the square of the height $(\mathrm{m})$.

$\mathrm{BMI}=$ weight/height ${ }^{2}$ with units kilogram and meter.

The World Health Organization has given the classification of body composition as BMI of a person, which is presented in Tab 3.4 The BMI does not differentiate between body fat and muscle tissue, because it is just the ratio between weight and height. Hence a large source of error comes from subjects with high muscle mass. In other words BMI fails to distinguish between lean body mass and fat $([39])$. 


\section{Chapter 4}

\section{Model}

\subsection{The Model}

The model employed here is the compartment model presented in [28, 33] with the following four compartments (see also Figure 4.1):

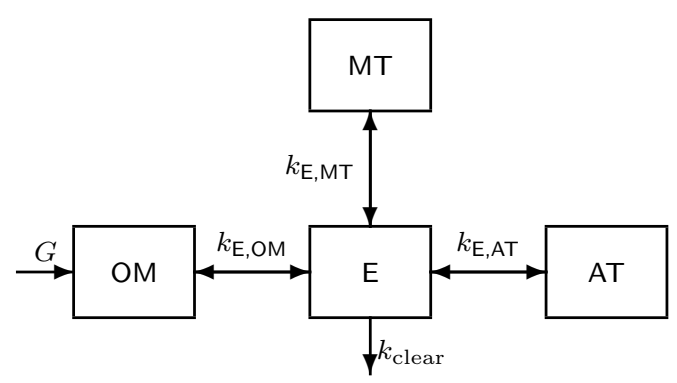

Figure 4.1. Structure of the model.

- the organ mass compartment OM,

- the muscle mass compartment MT,

- and the adipose tissue compartment AT,

- the extracellular compartment $\mathrm{E}$. 
The compartments are characterized by their volumes $V_{\mathrm{OM}}, V_{\mathrm{MT}}, V_{\mathrm{AT}}$ and $V_{\mathrm{E}}$ and the amounts $x_{\mathrm{E}}, x_{\mathrm{OM}}, x_{\mathrm{MT}}, x_{\mathrm{AT}}$ of toxins present in them. We assume that $V_{\mathrm{OM}}, V_{\mathrm{MT}}, V_{\mathrm{AT}}$ are constant. Because of ultra filtration the volume of the extracellular compartment definitely is time dependent, $V_{\mathrm{E}}=V_{\mathrm{E}}(t)$. Since we only have measurements for $V_{\mathrm{E}}$ before the treatment starts, $V_{\mathrm{E} \text {,pre, and after }}$ the treatment is finished, $V_{\mathrm{E} \text {,post }}$, we assume that $V_{\mathrm{E}}(t)$ increases linearly from $V_{\mathrm{E} \text {,post }}$ to $V_{\mathrm{E} \text {,pre }}$ during the interdialytic phase and decreases linearly from $V_{\mathrm{E} \text {,pre }}$ to $V_{\mathrm{E} \text {,post }}$ during dialysis. The concentrations of toxin in the compartments are given as

$$
C_{\mathrm{E}}=\frac{x_{\mathrm{E}}}{V_{\mathrm{E}}}, C_{\mathrm{OM}}=\frac{x_{\mathrm{OM}}}{V_{\mathrm{OM}}}, C_{\mathrm{MT}}=\frac{x_{\mathrm{MT}}}{V_{\mathrm{MT}}}, C_{\mathrm{AT}}=\frac{x_{\mathrm{AT}}}{V_{\mathrm{AT}}} .
$$

We make following basic assumptions:

(i) Exchange of toxin happens only between compartment $\mathrm{E}$ and compartments OM, MT, AT.

(ii) The exchange of toxin between compartments is only due to diffusive processes.

Let I be the extracellular compartment $\mathrm{E}$ and let II stand for one of the compartments OM, MT or AT. According to assumption (ii) the flux $q$ of toxin from compartment I into a compartment II is given by

$$
q=k_{\mathrm{I}, \mathrm{II}}\left(C_{\mathrm{l}}-C_{\mathrm{II}}\right)
$$


where $C_{\mathrm{l}}, C_{\mathrm{Il}}$ are the concentrations of toxin in the two compartments and $k_{\mathrm{I}, \mathrm{II}}>0$ is the diffusion constant. If $q$ is positive then toxin moves from compartment I into II. If $q$ is negative then the diffusion is from compartment II into I. The amounts $x_{1}, x_{\|}$of toxin in the two compartments change according to following equations:

$$
\begin{aligned}
& \dot{x}_{\mathrm{I}}=-k_{\mathrm{I}, \mathrm{II}}\left(C_{\mathrm{I}}-C_{\mathrm{II}}\right)=-\frac{k_{\mathrm{I}, \mathrm{II}}}{V_{\mathrm{I}}} x_{\mathrm{I}}+\frac{k_{\mathrm{I}, \mathrm{II}}}{V_{\mathrm{II}}} x_{\mathrm{II}}, \\
& \dot{x}_{\mathrm{II}}=k_{\mathrm{I}, \mathrm{II}}\left(C_{\mathrm{I}}-C_{\mathrm{II}}\right)=\frac{k_{\mathrm{I}, \mathrm{II}}}{V_{\mathrm{I}}} x_{\mathrm{I}}-\frac{k_{\mathrm{I}, \mathrm{II}}}{V_{\mathrm{II}}} x_{\mathrm{II}} .
\end{aligned}
$$

We used the diffusion constants $k_{\mathrm{E}, \mathrm{OM}}, k_{\mathrm{E}, \mathrm{MT}}, k_{\mathrm{E}, \mathrm{AT}}$. Furthermore we denote by $G$ the production rate of toxin in the organ mass compartment OM. During dialysis we have a clearance rate $k_{\text {clear }}$ of toxin from the extracellular compartment $\mathrm{E}$.

The above considerations show that the equations governing the dynamics of the model are the following:

$$
\begin{gathered}
\dot{x}_{\mathrm{OM}}=G-\frac{k_{\mathrm{E}, \mathrm{OM}}}{V_{\mathrm{OM}}} x_{\mathrm{OM}}+\frac{k_{\mathrm{E}, \mathrm{OM}}}{V_{\mathrm{E}}(t)} x_{\mathrm{E}}(\text { compartment } \mathrm{OM}), \\
\left.\dot{x}_{\mathrm{MT}}=\frac{k_{\mathrm{E}, \mathrm{MT}}}{V_{\mathrm{E}}(t)} x_{\mathrm{E}}-\frac{k_{\mathrm{E}, \mathrm{MT}}}{V_{\mathrm{MT}}} x_{\mathrm{MT}} \quad \text { (compartment } \mathrm{MT}\right), \\
\dot{x}_{\mathrm{AT}}=\frac{k_{\mathrm{E}, \mathrm{AT}}}{V_{\mathrm{E}}(t)} x_{\mathrm{E}}-\frac{k_{\mathrm{E}, \mathrm{AT}}}{V_{\mathrm{AT}}} x_{\mathrm{AT}} \quad(\text { compartment } \mathrm{AT}), \\
\dot{x}_{\mathrm{E}}=\frac{k_{\mathrm{E}, \mathrm{OM}}}{V_{\mathrm{OM}}} x_{\mathrm{OM}}+\frac{k_{\mathrm{E}, \mathrm{MT}}}{V_{\mathrm{MT}}} x_{\mathrm{MT}}+\frac{k_{\mathrm{E}, \mathrm{AT}}}{V_{\mathrm{AT}}} x_{\mathrm{AT}} \\
-\frac{1}{V_{\mathrm{E}}(t)}\left(k_{\mathrm{E}, \mathrm{OM}}+k_{\mathrm{E}, \mathrm{MT}}+k_{\mathrm{E}, \mathrm{AT}}+\delta k_{\mathrm{clear}}\right) x_{\mathrm{E}}
\end{gathered}
$$

(compartment E), 
where $\delta=1$ during dialysis and $\delta=0$ otherwise.

These equations can be written as a linear system of ordinary differential equations:

$$
\frac{d}{d t}\left(\begin{array}{c}
x_{\mathrm{OM}} \\
x_{\mathrm{MT}} \\
x_{\mathrm{AT}} \\
x_{\mathrm{E}}
\end{array}\right)=\boldsymbol{A} \boldsymbol{V}\left(\begin{array}{c}
x_{\mathrm{OM}} \\
x_{\mathrm{MT}} \\
x_{\mathrm{AT}} \\
x_{\mathrm{E}}
\end{array}\right)+\left(\begin{array}{l}
G \\
0 \\
0 \\
0
\end{array}\right) .
$$

The matrices $\boldsymbol{A}$ and $\boldsymbol{V}$ are given by

$$
\boldsymbol{A}=\left(\begin{array}{cccc}
-k_{\mathrm{E}, \mathrm{OM}} & 0 & 0 & k_{\mathrm{E}, \mathrm{OM}} \\
0 & -k_{\mathrm{E}, \mathrm{MT}} & 0 & k_{\mathrm{E}, \mathrm{MT}} \\
0 & 0 & -k_{\mathrm{E}, \mathrm{AT}} & k_{\mathrm{E}, \mathrm{AT}} \\
k_{\mathrm{E}, \mathrm{OM}} & k_{\mathrm{E}, \mathrm{MT}} & k_{\mathrm{E}, \mathrm{AT}} & \alpha
\end{array}\right)
$$

with

$$
\alpha=-\left(k_{\mathrm{E}, \mathrm{OM}}+k_{\mathrm{E}, \mathrm{MT}}+k_{\mathrm{E}, \mathrm{AT}}+\delta k_{\text {clear }}\right)
$$

and

$$
\boldsymbol{V}=\operatorname{diag}\left(\frac{1}{V_{\mathrm{OM}}}, \frac{1}{V_{\mathrm{MT}}}, \frac{1}{V_{\mathrm{AT}}}, \frac{1}{V_{\mathrm{E}}(t)}\right) .
$$

These equations can also be written in terms of the concentrations in the compartments (note that we have $\dot{x}_{\mathrm{E}}=\dot{C}_{\mathrm{E}} V_{\mathrm{E}}+C_{\mathrm{E}} \dot{V}_{\mathrm{E}}$ ):

$$
\frac{d}{d t}\left(\begin{array}{c}
C_{\mathrm{OM}} \\
C_{\mathrm{MT}} \\
C_{\mathrm{AT}} \\
C_{\mathrm{E}}
\end{array}\right)=\boldsymbol{V} \boldsymbol{A}\left(\begin{array}{c}
C_{\mathrm{OM}} \\
C_{\mathrm{MT}} \\
C_{\mathrm{AT}} \\
C_{\mathrm{E}}
\end{array}\right)+\left(\begin{array}{c}
G / V_{\mathrm{OM}} \\
0 \\
0 \\
-\frac{\dot{V}_{\mathrm{E}}(t)}{\left.V_{\mathrm{E}}(t)\right)} C_{\mathrm{E}}
\end{array}\right)
$$




\subsection{Data Acquisition}

In this section we first describe the study population, then discuss the methodologies used in order to obtain data on body composition of the patients. The data used for the simulations are listed in Tables 4.1 and 4.2 .

\subsubsection{Study Population}

Six ambulatory patients maintained on hemodialysis for more than 3 months were enrolled in the study. Patients were studied in the Body Composition Unit of St. Luke's Roosevelt Hospital after an overnight fast. All studies were done $1-2 \mathrm{~h}$ before dialysis. The Institutional Review Boards of Beth Israel Medical Center, New York, and St. Luke's Roosevelt Hospital, New York, approved the study protocol and written informed consent was obtained from each patient before entering the study. All patients were hemodynamically stable and were treated as outpatients three times a week with polysulphone dialyzers (F80s or OptiFlux 200s, Fresenius Medical Care, Lexington, MA, USA).

\subsubsection{Magnetic Resonance Imaging (MRI)}

MRI of the whole body was carried out as reported by Gallagher et al. [22]. Scans were prepared using a 1.5 Tesla scanner (General Electric, 6X Horizon, Milwaukee, WI). Patients were placed in a prone position with their arms extended overhead and two protocols involved the acquisition of 40 axial images of $10 \mathrm{~mm}$ thickness and $40 \mathrm{~mm}$ spacing from neck to foot and continuous spacing from the trunk. MRI provided estimates of fat, muscle, and bone volumes in the total body, and organs in the trunk. All MRI scans were segmented into the components mentioned above by highly trained analysts using image analysis software (Tomovision, Montreal, QC, Canada). In a multiple-step procedure, a threshold was selected for adipose tissue and lean tissue and 
lines were drawn around the selected regions by use of a Watershed algorithm. Thereafter, tissues of interest were color-labelled and the respective tissue areas $\left(\mathrm{cm}^{2}\right)$ for each MRI image were calculated by summing the specific tissue pixels and then multiplying by the individual pixel surface area. The volume per slice $\left(\mathrm{cm}^{3}\right)$ was derived by multiplying tissue area by slice thickness and the volume of each tissue for the space between two slices was calculated and converted to mass units $(\mathrm{kg})$ on the basis of specific tissue densities [22].

\begin{tabular}{|c|c|c|c|c|c|c|c|}
\hline Patient & $V_{\mathrm{E}, \text { pre }}$ & $V_{\mathrm{E}, \text { post }}$ & $V_{\mathrm{OM}}$ & $V_{\mathrm{MT}, \text { total }}$ & $V_{\mathrm{AT}, \text { total }}$ & $\mathrm{BW}$ & $\mathrm{BMI}$ \\
\hline 1 & 27.0 & 22.3 & 4.4 & 30.9 & 43.1 & 108 & 40.5 \\
\hline 2 & 18.6 & 17.3 & 4.9 & 27.7 & 43.6 & 100 & 36.9 \\
\hline 3 & 19.8 & 17.3 & 1.8 & 30.6 & 27.8 & 93 & 29.2 \\
\hline 4 & 25.3 & 14.2 & 4.5 & 24.5 & 22.4 & 78 & 25.3 \\
\hline 5 & 22.0 & 12.8 & 3.4 & 17.5 & 12.7 & 58 & 22.0 \\
\hline 6 & 20.6 & 10.9 & 3.0 & 16.0 & 14.8 & 54 & 20.6 \\
\hline
\end{tabular}

Table 4.1. Volumes (ltr), body weights $(\mathrm{kg})$ and $B M I \mathrm{~s}\left(\mathrm{~kg} / \mathrm{m}^{2}\right)$ for patients enrolled in the study.

\subsubsection{Dilution Methods}

Total body water (TBW) and extracellular volume (ECV) were measured before hemodialysis by $\mathrm{D}_{2} \mathrm{O}$ and $\mathrm{NaBr}$ dilution methods. Each patient was given an oral dose of $10 \mathrm{~g} \mathrm{D}_{2} \mathrm{O}$ (ICON: Summit, N.J.) and $5 \mathrm{~g}$ of a $4 \mathrm{~mol} / \mathrm{L}$ $\mathrm{NaBr}$ solution [50]. Blood samples were collected immediately before and 3 hours after intake of these substances, when equilibration had been reached.

\subsubsection{Multi-frequency Bio-impedance Spectroscopy}

A multi-frequency device (Xitron 4200) was used for automatic sequential measurements of BIS of the arm, trunk, leg and wrist-to-ankle, with frequencies ranging from $5 \mathrm{kHz}$ to $1 \mathrm{MHz}$ [66]. The current was injected through two electrodes placed on one wrist and the ipsilateral ankle. The voltage was 
recorded from four electrodes placed on the wrist and the ipsilateral shoulder, greater trochanter and ankle and the signal was transferred to the BIS device by a digital switch [66]. The arm not used for dialysis access was used for BIS measurements. With this method segmental BIS (SBIS) and whole body wrist-to-ankle BIS (WBIS) could be recorded together. To allow for equilibration of body fluids patients were positioned supine for at least 15 minutes before the start of measurements. Each measurement was repeated at least 10 times and the average value was used in subsequent computations. Extracellular (ECV) and intracellular (ICV) fluid volumes were calculated for segments [68] and for the whole body [17].

\begin{tabular}{|c|c|c|c|c|c|c|}
\hline Patient & 1 & 2 & 3 & 4 & 5 & 6 \\
\hline$T_{d}$ & 260 & 180 & 222 & 210 & 200 & 240 \\
\hline$V_{\text {urea }}$ & 41.7 & 39.9 & 43.9 & 35 & 32.2 & 27.2 \\
\hline$K$ & 1.39 & 1.57 & 1.53 & 1.6 & 1.7 & 2.49 \\
\hline PCR & 115.2 & 97.61 & 78.85 & 55.02 & 65.24 & 73.24 \\
\hline
\end{tabular}

Table 4.2. Duration $T_{d}$ of dialysis ( $\mathrm{min}$ ), urea distribution volume $V_{\text {urea }}$ (ltr), $K=k_{\text {clear }} T_{d} / V_{\text {urea }}$ and the protein catabolic rate PCR for the patients enrolled in study.

\begin{tabular}{|c|c|c|c|c|c|c|}
\hline Patient & 1 & 2 & 3 & 4 & 5 & 6 \\
\hline$k_{\text {clear }}$ & 0.223 & 0.348 & 0.303 & 0.267 & 0.274 & 0.282 \\
\hline $\mathrm{G}$ & 0.0128 & 0.0108 & 0.0088 & 0.0061 & 0.0073 & 0.0081 \\
\hline
\end{tabular}

Table 4.3. Individual clearance rates and toxin production rates.

\begin{tabular}{|c|c|c|c|c|c|c|}
\hline$C_{\mathrm{OM}}$ & $C_{\mathrm{MT}}$ & $C_{\mathrm{AT}}$ & $C_{\mathrm{E}}$ & $k_{\mathrm{E}, \mathrm{OM}}$ & $k_{\mathrm{E}, \mathrm{MT}}$ & $k_{\mathrm{E}, \mathrm{AT}}$ \\
\hline 35 & 35 & 35 & 35 & 0.046 & 0.032 & 0.019 \\
\hline
\end{tabular}

Table 4.4. Initial values and rate constants used for the simulations. 


\begin{tabular}{|c|c|c|c|c|c|c|}
\hline Pat & 1 & 2 & 3 & 4 & 5 & 6 \\
\hline \multicolumn{7}{|c|}{ average $G$ and individual $k_{\text {clear }}$} \\
\hline $\mathrm{TAC}$ & 0.575 & 0.588 & 0.529 & 0.665 & 0.685 & 0.64 \\
\hline \multicolumn{7}{|c|}{ individual $G$ and average $k_{\text {clear }}$} \\
\hline $\mathrm{TAC}$ & 0.855 & 0.746 & 0.576 & 0.433 & 0.531 & 0.616 \\
\hline \multicolumn{7}{|c|}{ individual $G$ and individual $k_{\text {clear }}$} \\
\hline TAC & 0.827 & 0.714 & 0.523 & 0.456 & 0.554 & 0.582 \\
\hline
\end{tabular}

Table 4.5. Average toxin concentration during the interdialytic phase in the extracellular compartment.

\subsection{Numerical Simulation of Model}

\subsubsection{Parameters}

The volumes of the compartments of the model were determined as described in the two previous subsections and are shown in Table 4.1. Following the discussion in 15] only the parts of muscle and adipose tissue, which are effective with respect to urea, were used:

$$
V_{\mathrm{MT}}=0.75 V_{\mathrm{MT}, \text { total }}, \quad V_{\mathrm{AT}}=0.1 V_{\mathrm{AT}, \text { total }} .
$$

The organ mass compartment OM comprises only liver and gut, since these organs are primarily responsible for the generation of urea.

The urea production rate $G$ was calculated according to the following formula:

$$
G=\mathrm{PCR} / 6.25 \text { gram urea } / \text { day }=\frac{\mathrm{PCR}}{6.25 \cdot 1440} \text { gram urea } / \mathrm{min}
$$

where PCR is the protein catabolic rate of the patients as given in Table 4.2 .

The clearance rate $k_{\text {clear }}$ was computed from values for $K=k_{\text {clear }} T_{d} / V_{\text {urea }}$ (see Table 4.2), i.e.,

$$
k_{\text {clear }}=\frac{K V_{\text {urea }}}{T_{d}} .
$$


The individual urea production rates and individual clearance rates are given in Table 4.3. In Table 4.4 we list the initial values for the concentrations and the rate constants $k_{\mathrm{E}, \mathrm{OM}}, k_{\mathrm{E}, \mathrm{MT}}, k_{\mathrm{E}, \mathrm{AT}}$ used in the simulations. However, in order to eliminate the influence of the initial values on the dynamics of the system we solved the model equations on time intervals which were long enough, so that the solutions already reached a periodic phase. The plots shown in Figures 2.2-2.4 and the values for the average toxin concentrations (TAC) given in Table 4.5 correspond to one dialysis cycle in the periodic phase.

\subsubsection{Simulations}

In Figure 4.2 we present the simulation results for the six patients. The graphs shows the toxin concentrations in the compartments OM, MT, AT, and E during one cycle (inter-dialytic phase plus dialysis phase) when the solution of the model has already reached a periodic state. The patients are numbered according to their BMI, i.e., Patient 1 has the highest BMI and Patient 6 the lowest (see Table 4.1). We should observe that the higher the BMI for a patient is, the closer are the toxin concentrations in the compartments E and AT during the whole cycle.

In Figure 4.3 we present the toxin concentration in the extracellular compartment for Patients 1-6 during one cycle using the individual toxin production rate and the individual clearance rate for each patient. We can see that the graphs of the toxin concentrations are ordered according to the BMI values of the patients only for the last three patients, the graph for Patient 4 being lowest. However, Patients 1 and 2 have the highest toxin concentrations (compare also the average toxin concentration for this case as given in Table 4.5. We can see that the ranking of the patients with respect to TACvalue is 216354 . This clearly shows that body composition is the important indicator and not BMI. 

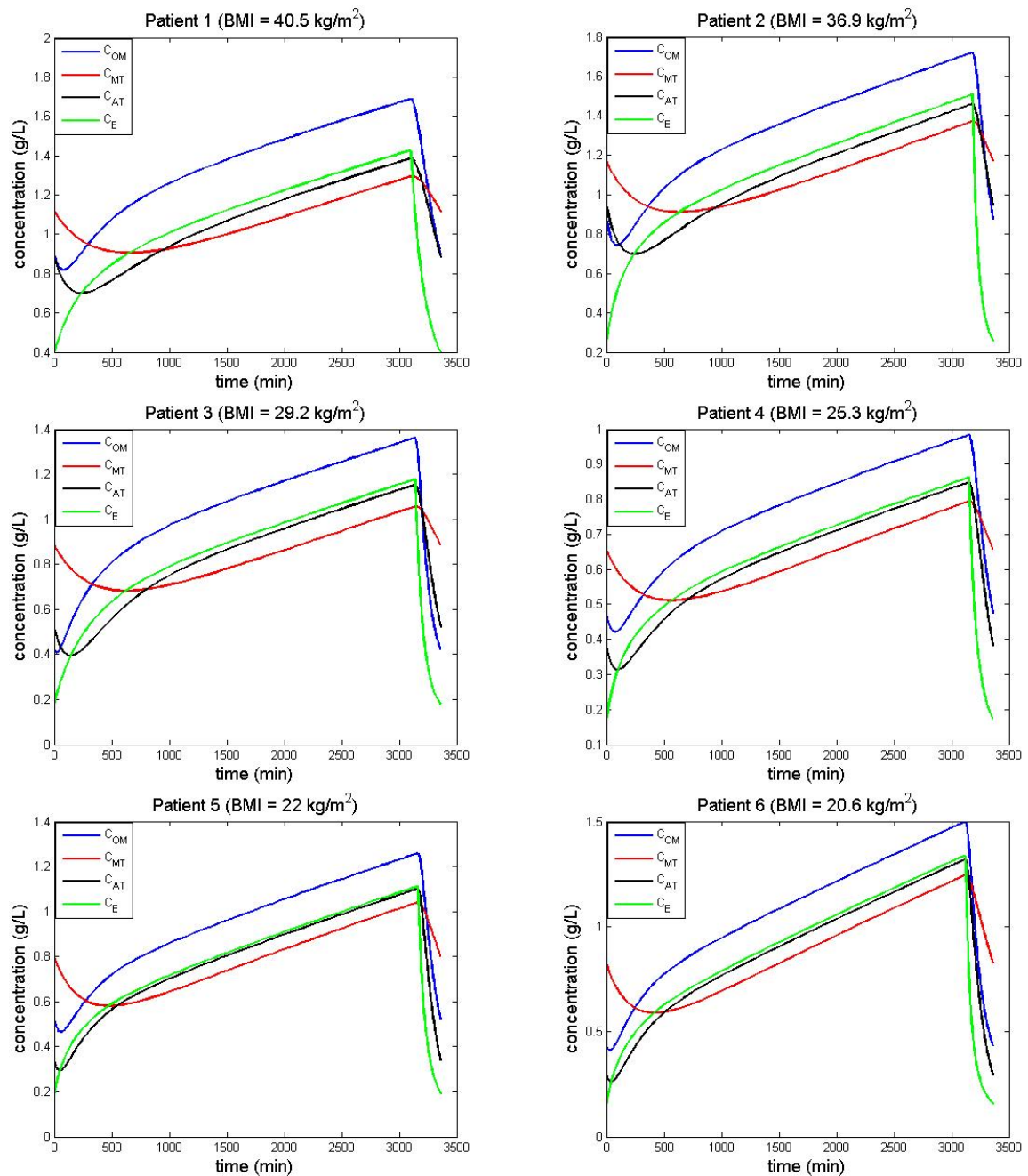

Figure 4.2. Uremic toxin concentration in all the four OM,MT,AT,E compartments for all 6 patients.

In Figure 4.4 we present the concentrations in the extracellular compartment for all six patients using the individual toxin production rates computed according to (1) (see Table 4.5) and the average clearance rate $k c l e a r=0.288$. We can see only a minor change compared to Figure 4.3 (the graphs for Patients 3 and 5 changed in their relative order).

In Figure 4.5, we show the concentrations in the extracellular compartment for all six patients using the average toxin production rate $G=0.0089$ and 


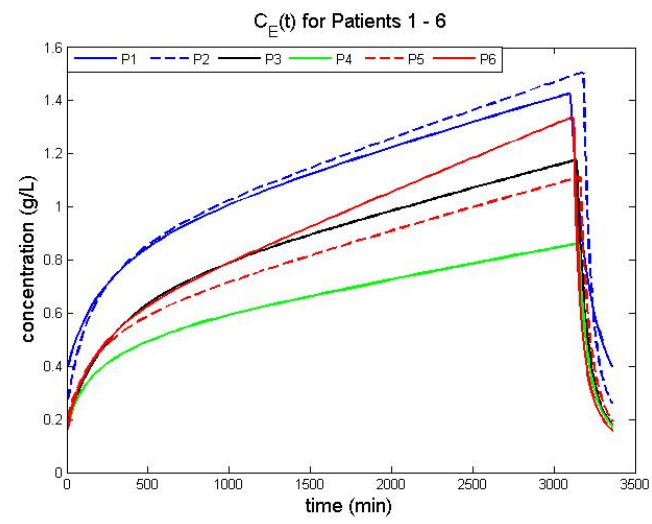

Figure 4.3. Uremic toxin concentration in the extracellular compartments for all 6 patients with individual toxin production rates and individual clearance rates.

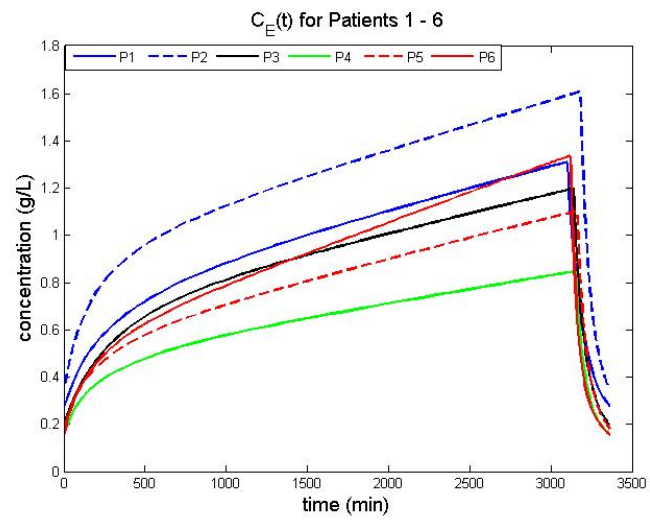

Figure 4.4. Uremic toxin concentration in the extracellular compartments for all 6 patients with individual toxin production rates $G$ and average clearance rates $k_{\text {clear }}$.

the individual clearance rates computed according to (2) (see Table 4.5). Now we can see that the results are drastically different from those represented in Figure 4.4 and Figure 4.3. We see that Patients 1-3 have the lowest three concentrations, whereas Patients 4-6 have the highest three concentrations. These results show that not only the body composition of a patient is important, but also the clearance rate for the toxin plays a major role. 


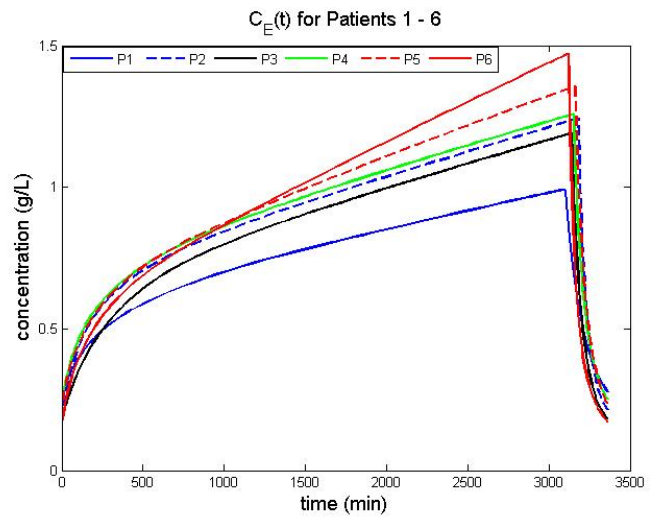

Figure 4.5. Uremic toxin concentration in the extracellular compartments for all 6 patients with average toxin production rates $G$ and individual clearance rates $k_{\text {clear }}$.

\subsection{Conclusion}

Using data for six patients the simulations with our compartment model provided the following results:

- $\mathrm{BMI}$ is not able to predict the toxin concentration in the extracellular compartment reliably. Instead of BMI we have to use data on body composition.

- Besides body composition it is necessary to include the individual clearance rate $k_{\text {clear }}$ for the toxin during dialysis and the production rate $G$ for the toxin into the considerations. However, it seems that the clearance rate is more influential than the production rate. 


\section{Chapter 5}

\section{Sensitivity Analysis and}

\section{Parameter Identification}

\subsection{Classical Sensitivities}

We computed the sensitivities of $C_{\mathrm{E}}(t)$ with respect to the rate constants $k_{\mathrm{E}, \mathrm{OM}}, k_{\mathrm{E}, \mathrm{MT}}, k_{\mathrm{E}, \mathrm{AT}}, k_{\text {clear }}$ and $G$, i.e., we computed

$$
\frac{k}{C_{\mathrm{E}}(t)} \frac{\partial C_{\mathrm{E}}(t)}{\partial k}
$$

where $k$ stand for one of the rate constants. The time interval considered is one cycle (i.e., $0 \leq t \leq 3360$ ) for the periodic solution.

In Figures 5.1 5.5), we present the sensitivities of all six patients with respect to all rate constants $k_{\mathrm{E}, \mathrm{MT}}, k_{\mathrm{E}, \mathrm{AT}}, k_{\mathrm{E}, \mathrm{OM}}, k_{\text {clear }}$ and $G$ for all four compartments $C_{\mathrm{OM}}, C_{\mathrm{MT}}, C_{\mathrm{AT}}, C_{\mathrm{E}}$.

In Figure 5.6, we present the sensitivities of $k_{\mathrm{E}, \mathrm{MT}}, k_{\mathrm{E}, \mathrm{AT}}, k_{\mathrm{E}, \mathrm{OM}}$ in the extracellular compartment, where in Figure 5.7 we present sensitivities of all the five rate constants $k_{\mathrm{E}, \mathrm{MT}}, k_{\mathrm{E}, \mathrm{AT}}, k_{\mathrm{E}, \mathrm{OM}}, k_{\text {clear }}$, and $G$ in the extracellular compartment. We see that in both cases the sensitivities with respect to $k_{\text {clear }}$ and $G$ are much larger than the sensitivities with respect to $k_{\mathrm{E}, \mathrm{OM}}, k_{\mathrm{E}, \mathrm{MT}}, k_{\mathrm{E}, \mathrm{AT}}$. Here we see that the sensitivities with respect to $k_{\mathrm{E}, \mathrm{OM}}$ and $k_{\mathrm{E}, \mathrm{MT}}$ are larger for patients 5 and 6 , whereas the sensitivity with respect to $k_{\mathrm{E}, \mathrm{AT}}$ is almost zero for both patients 5 and 6 , which reflects the fact that the volume of the 
adipose tissue compartment for patients 5 and 6 is very small.
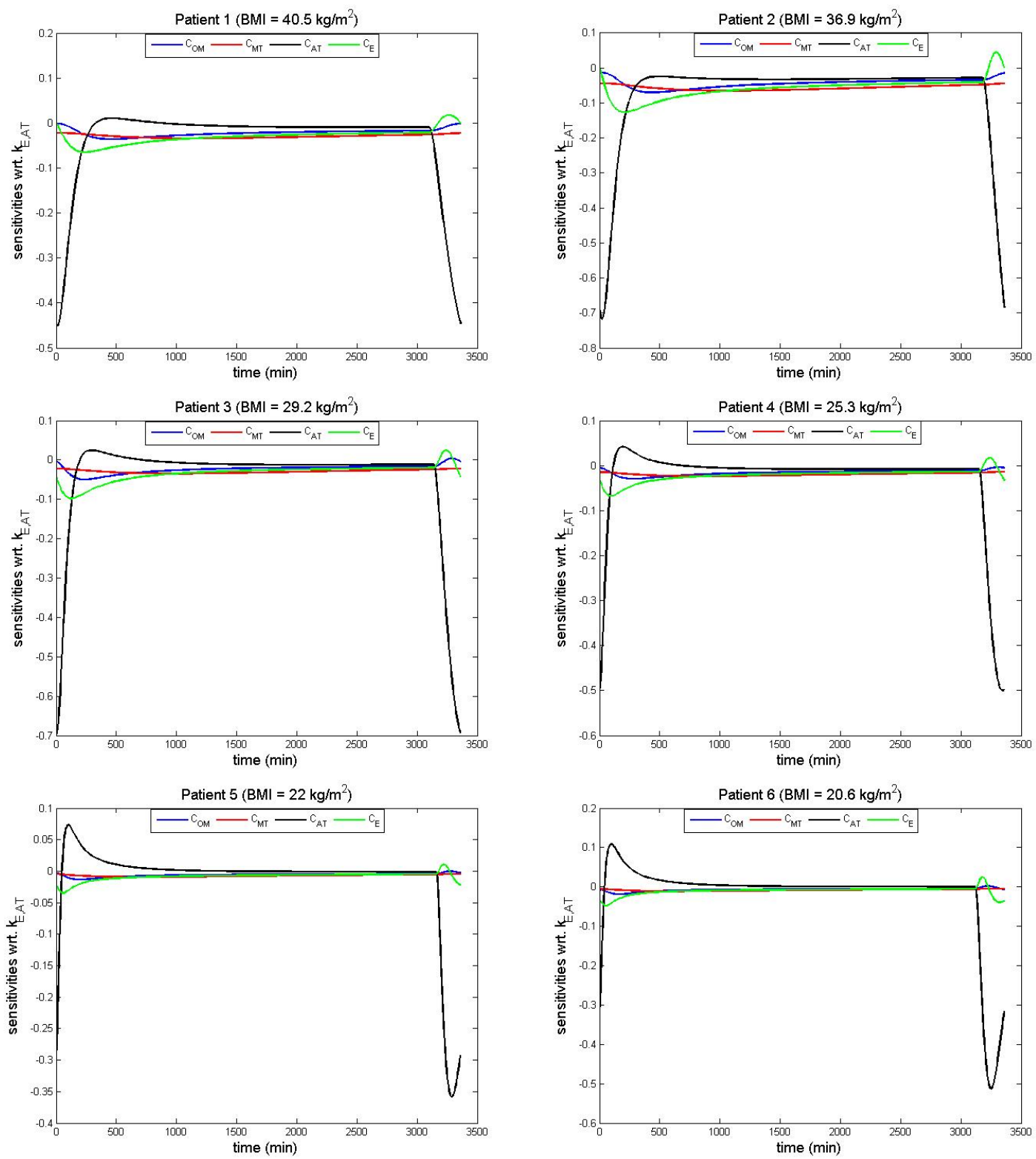

Figure 5.1. Sensitivity with respect to rate constant $k_{\mathrm{E}, \mathrm{AT}}$ for all 6 patients. 

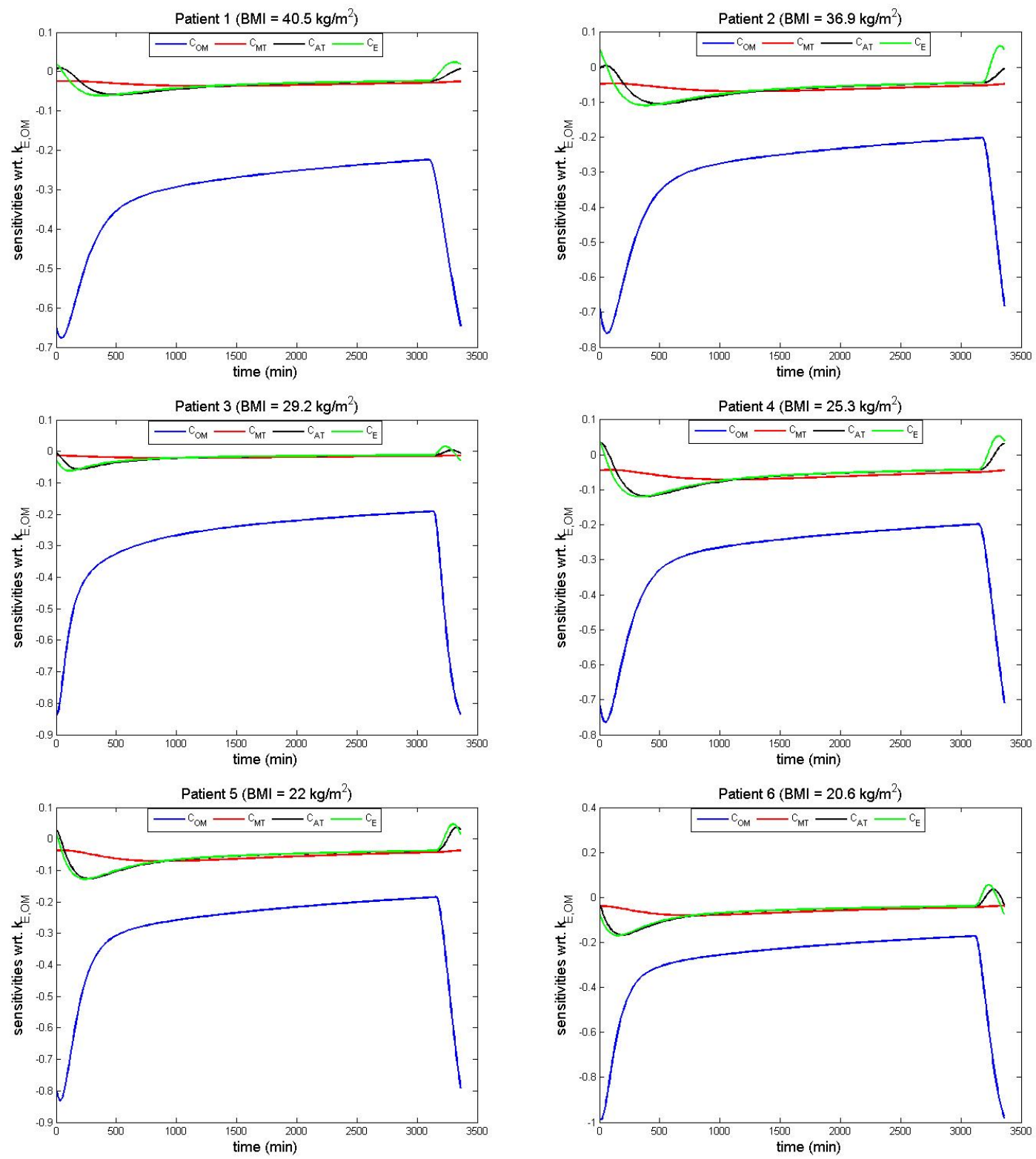

Figure 5.2. Sensitivity with respect to rate constant $k_{\mathrm{E}, \mathrm{OM}}$ for all 6 patients. 

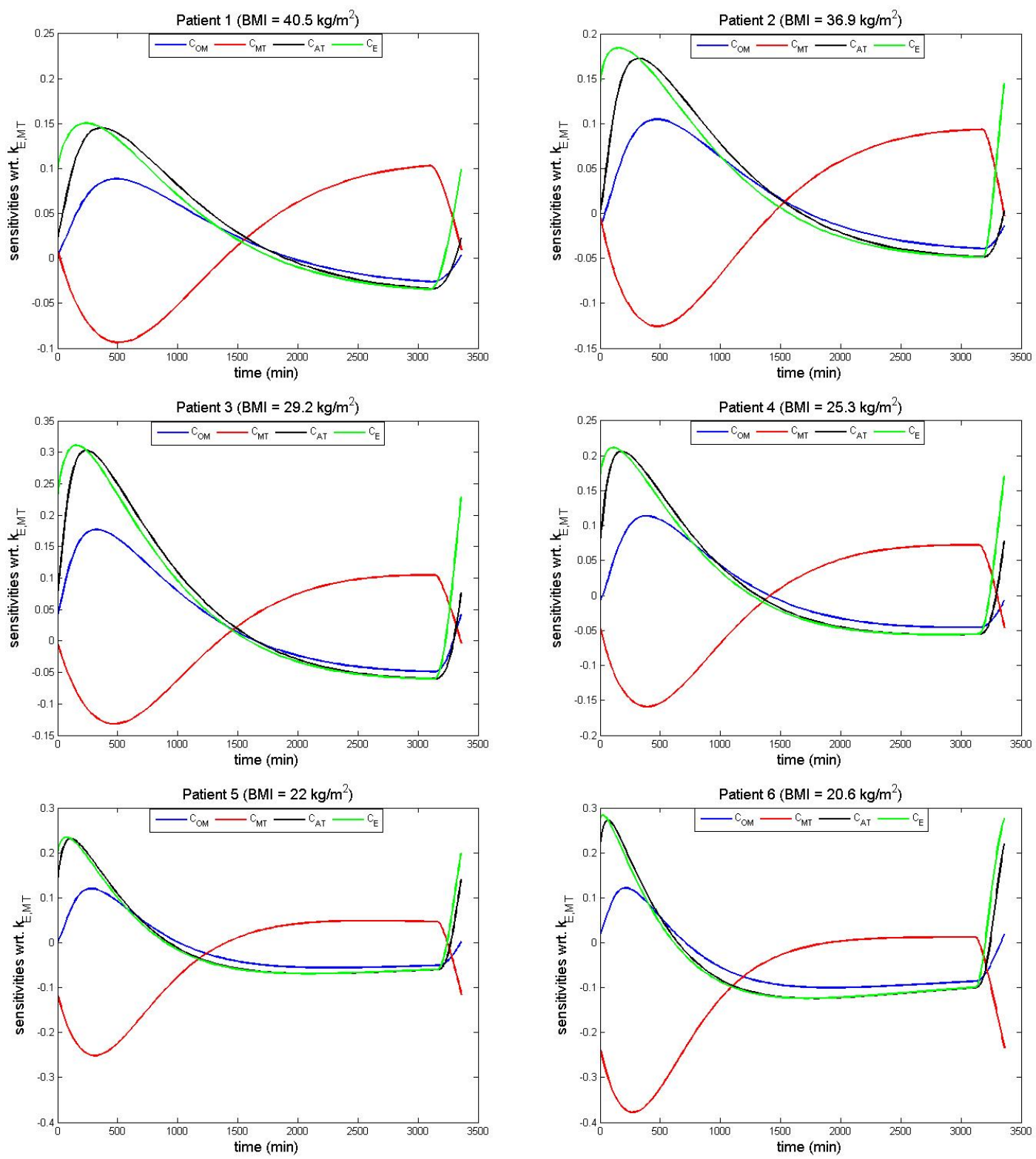

Figure 5.3. Sensitivity with respect to rate constant $k_{\mathrm{E}, \mathrm{MT}}$ for all 6 patients. 

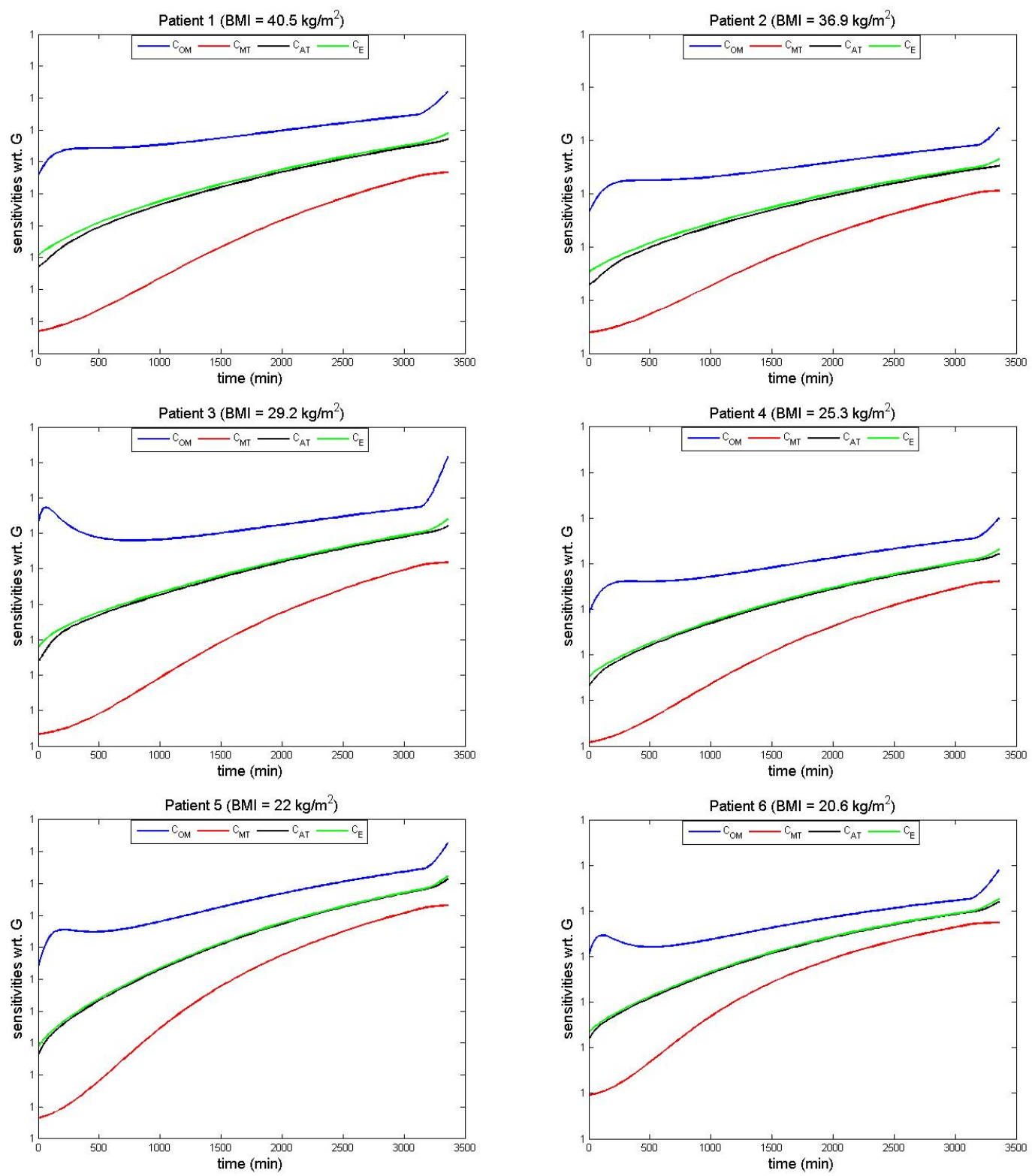

Figure 5.4. Sensitivity with respect to rate constant $G$ for all 6 patients. 

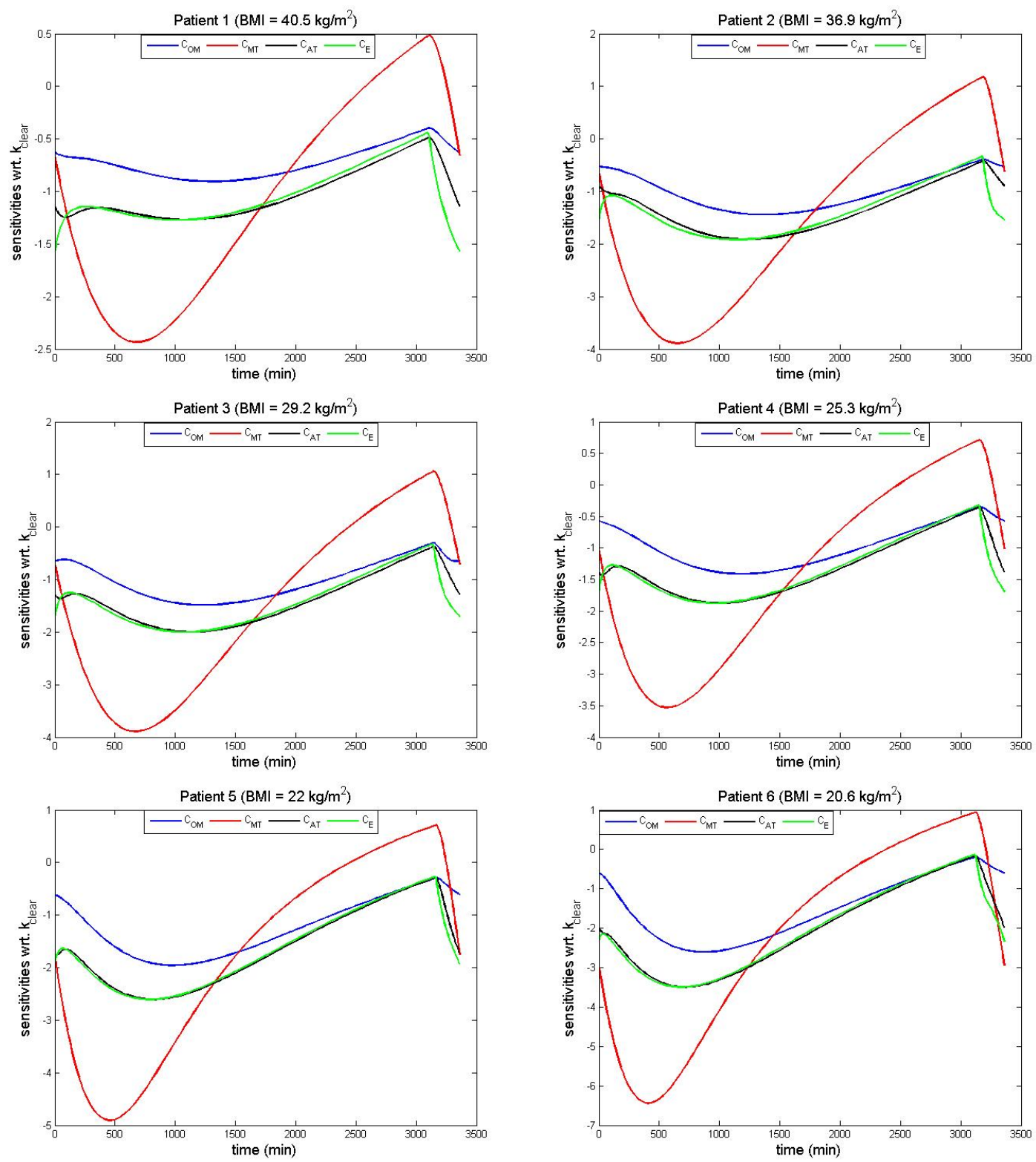

Figure 5.5. Sensitivity with respect to rate constant $k_{\text {clear }}$ for all 6 patients. 

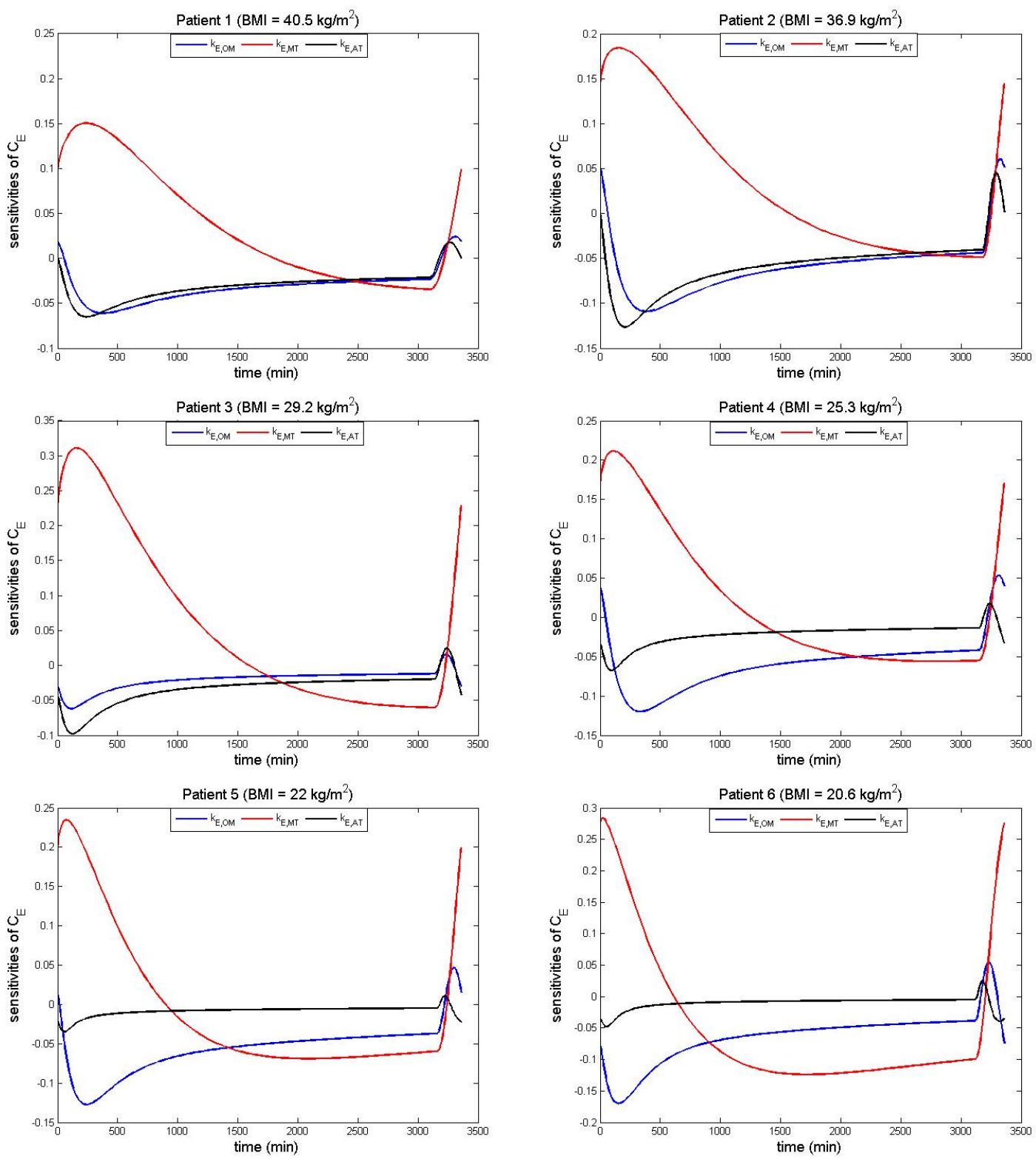

Figure 5.6. Sensitivity of $C_{\mathrm{E}}$ with respect to $k_{\mathrm{E}, \mathrm{MT}}, k_{\mathrm{E}, \mathrm{AT}}, k_{\mathrm{E}, \mathrm{OM}}$ for all 6 patients. 

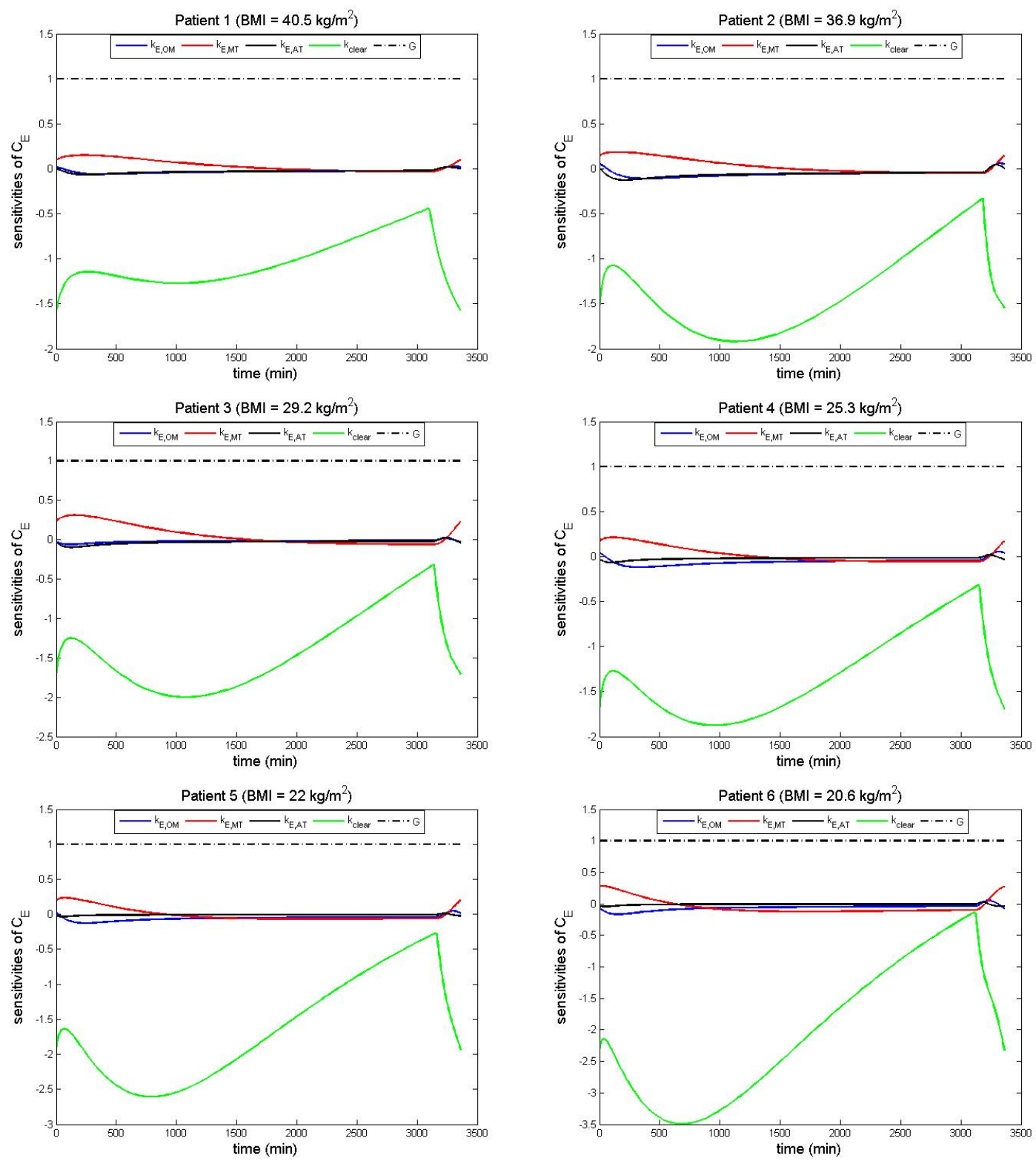

Figure 5.7. Sensitivity of $C_{\mathrm{E}}$ with respect to all parameters $k_{\mathrm{E}, \mathrm{MT}}, k_{\mathrm{E}, \mathrm{AT}}, k_{\mathrm{E}, \mathrm{OM}}$, $k_{\text {clear }}$ and $G$ for all 6 patients. 
From all above observations (sensitivity of all parameters ) we should expect, that identifying the rate constants $k_{\mathrm{E}, \mathrm{MT}}, k_{\mathrm{E}, \mathrm{AT}}, k_{\mathrm{E}, \mathrm{OM}}$ on the basis of measurements for toxin concentration $C_{\mathrm{E}}$ should be more difficult than identifying $k_{\text {clear }}$ and $G$. This is confirmed by our numerical calculations (see Section 5.2. However, we should be aware that identifying $k_{\text {clear }}$ and $G$ is not actually necessary, because these rates can be computed from data.

\subsection{Parameter Identification}

The vector of parameters of the system is

$$
\boldsymbol{\theta}=\operatorname{col}\left(k_{\mathrm{E}, \mathrm{OM}}, k_{\mathrm{E}, \mathrm{MT}}, k_{\mathrm{E}, \mathrm{AT}}, k_{\mathrm{clear}}, G\right) \in \mathbb{R}^{5} .
$$

The toxin concentration in the extra-cellular compartment is a natural candidate for the measurable output $y$ of the system,

$$
y(t, \boldsymbol{\theta})=c_{\mathrm{E}}(t, \boldsymbol{\theta}), \quad t \geq 0 .
$$

We assume that measurements are available at time instants $0 \leq t_{1}<\cdots<t_{N}$ and that these measurements are given by

$$
\xi_{j}=y\left(t_{j}, \boldsymbol{\theta}_{\mathbf{0}}\right)+\epsilon_{j}, \quad j=1, \ldots, N
$$

where $\boldsymbol{\theta}_{\mathbf{0}}$ is the 'true' or nominal parameter vector and $\epsilon_{j}$ is a representation of the measurement noise $\mathcal{E}_{j}$ at $t_{j}$ with $\mathrm{E}\left(\mathcal{E}_{j}\right)=0$ and $\operatorname{var} \mathcal{E}_{j}=\sigma_{j}^{2}$. As usual we assume that the random variables $\mathcal{E}_{j}$ are independent and identically distributed (i.i.d.). For our numerical experiments we took

$$
\boldsymbol{\theta}_{\mathbf{0}}=\operatorname{col}\left(0.046,0.032,0.019, k_{\text {clear }}^{\text {nominal }}, G^{\text {nominal }}\right)
$$


where $k_{\text {clear }}^{\text {nominal }}$ and $G^{\text {nominal }}$ are the values given in Table 4.3 for each patient. We assume that the variance $\sigma_{j}^{2}$ is constant, $\sigma_{j}=\sigma, j=1, \ldots, N$. The parameter estimate $\hat{\boldsymbol{\theta}}_{\mathbf{0}}$ is obtained as a minimization of an error functional $J$,

$$
\hat{\boldsymbol{\theta}}_{\mathbf{0}}=\underset{\boldsymbol{\theta}}{\operatorname{argmin}} J(\xi, \boldsymbol{\theta})
$$

where $\boldsymbol{\xi}=\operatorname{col}\left(\xi_{1}, \ldots \xi_{N}\right)$ and

$$
J(\boldsymbol{\xi}, \boldsymbol{\theta}):=\sum_{j=1}^{N}\left(\xi_{j}-y\left(t_{j}, \boldsymbol{\theta}\right)\right)^{2}
$$

As optimization algorithms we used the MatLab code solvopt, an implementation of Shor's r-algorithm (see [35] and [38]), which can handle non-smooth functions. For the error functional $J_{q u}$ solvopt was used with gradient information and for $J_{a b s}$ without gradient information.

\subsection{Different Combinations of Parameters}

The requirement to consider more global situations when modelling physiological systems leads to complex high dimensional models with a large number of parameters. In general it is impossible to estimate all these parameters reliably using data obtained from measurements of output of the real system. On the other hand, frequently only a considerably smaller number of parameters are really very influential for the dynamics of the system and we need rather precise estimates only for these influential parameters.

For the other parameters, rather rough estimates obtained by statistical or other methods are sufficient. Subset selection is a systematic procedure to determine those parameters which can be reliably estimated on the basis of available data. The model considered in this dissertation is not complex or of a high dimension and has only five parameters. Two of these are calculated from the data of body composition, so only three parameters are left for iden- 
tification. There is therefore no need of subset selection in this case, model simplicity is well suited to relate results obtained by sensitivity analysis with the results provided by parameters identification.

We first consider estimation of the rates $k_{\text {clear }}$ and $G$. In this case the other rates are fixed to their nominal values. Starting values for the optimization algorithm are $k_{\text {clear }}=0.5, G=0.08$. We generated 7 uniformly distributed measurements during the dialytic phase by computing the solution of our model corresponding to the nominal parameter vector $\theta_{0}$ at the measurement times and adding normally distributed noise with expected value zero and variance $\sigma^{2}=0.1$. Table 5.1 shows the results. In Figures 5.85 .11 we present the graphs for the solutions corresponding to the starting values for the optimization algorithm, the nominal values and the estimated values, in all of the compartments OM, MT, AT and extracellular compartment E. We can see that even with 7 measurements for $C_{\mathrm{E}}$ during the dialysis treatment we get very good estimates for the two parameters $k_{\text {clear }}$ and $G$.

In order to estimate transfer rates $k_{E, O M}, k_{E, M T}$, and $k_{E, A T}$, we use different combinations: In the first combination we estimate $k_{E, O M}, k_{E, M T}$, and $k_{E, A T}$ all together for all six patients and Simulations are shown in Figures 5.12 5.15). The estimates are given in Table 5.3 .

In the 2 nd combination we estimate $k_{E, A T}, k_{\text {clear }}$ and $G$ for Patients 4 . Results are shown in Figures 5.16 and estimated values are given in Table 5.5 .

In the 3rd combination we use $k_{E, A T}$ and $G$ for Patient 4. Graphs are shown in Figures 5.19 and estimated values are given in Table 5.8 .

In the fourth combination we use $k_{E, O M}$, and $G$ for Patient 4 . Graphs are shown in Fig 5.18, and estimated values are given in Table 5.7 .

In the fifth combination we use $k_{E, M T}$, and $k_{E, A T}$ for Patient 4 . With graphs shown in Fig 5.20, and estimated values given in Table 5.9.

In the last combination we use $k_{E, M T}$ and $k_{\text {clear }}$ for Patient 4 . The results are given in Table 5.8, Figure 5.19 shows the graphs corresponding to the 
estimates obtained with solvopt.
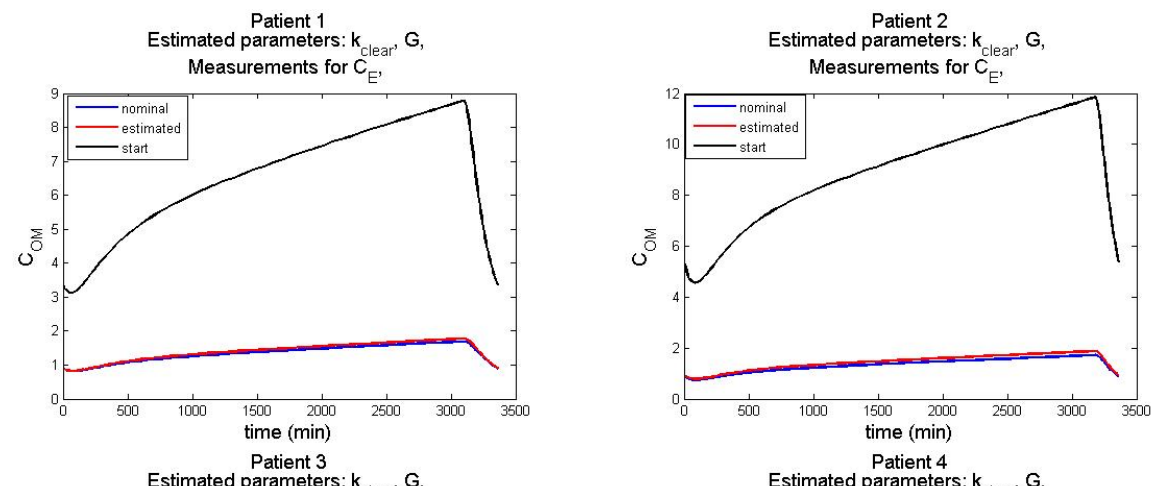

Estimated parameters: $k_{\text {clear }}, \mathbf{G}$

Measurements for $\mathrm{C}_{\mathrm{E}}$,

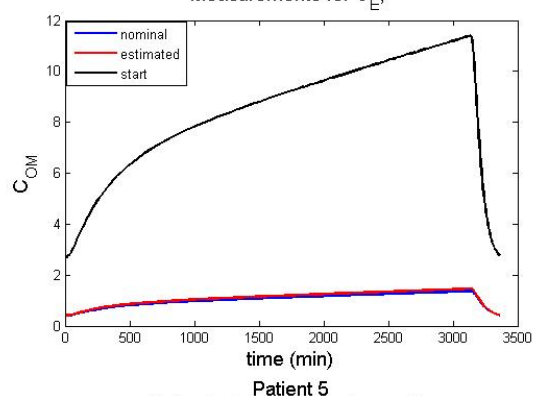

Measurements for $\mathrm{C}_{\mathrm{E}}$

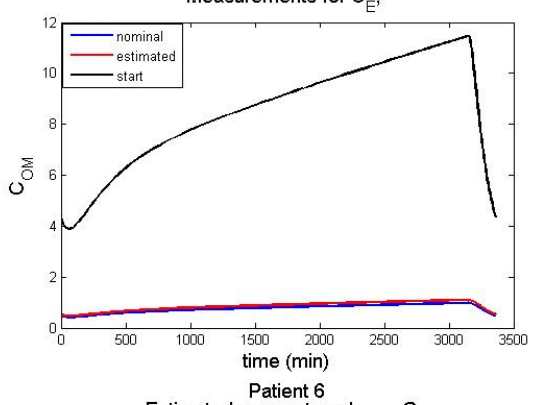

Estimated parameters: $\mathbf{k}_{\text {clear, }}, \mathbf{G}$,

Estimated parameters: $\mathrm{k}_{\text {clear' }} \mathbf{G}$,

Measurements for $\mathrm{C}_{\mathrm{E}}$,
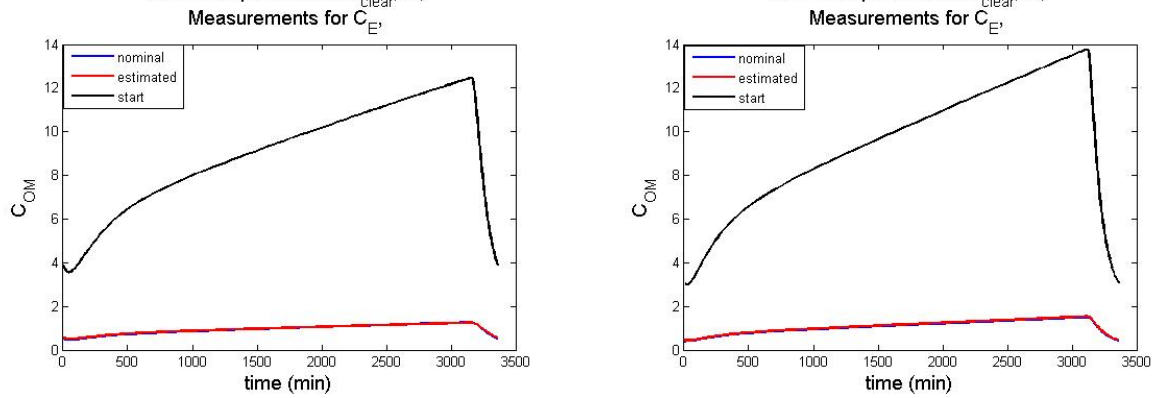

Figure 5.8. Estimation of $k_{\text {clear }}$ and $G$ for Patients $1-6$ with $\sigma=0.01$, and 7 measurements during dialysis, for $C_{O M}$.

In Fig 5.8 we present the estimation of parameter $k_{\text {clear }}$ and $G$ for all 6 patients using fminsearch for the error functional for $J_{q u}$ with starting values $k_{\text {clear }}=0.5, G=0.08$ in the organ mass compartment. 

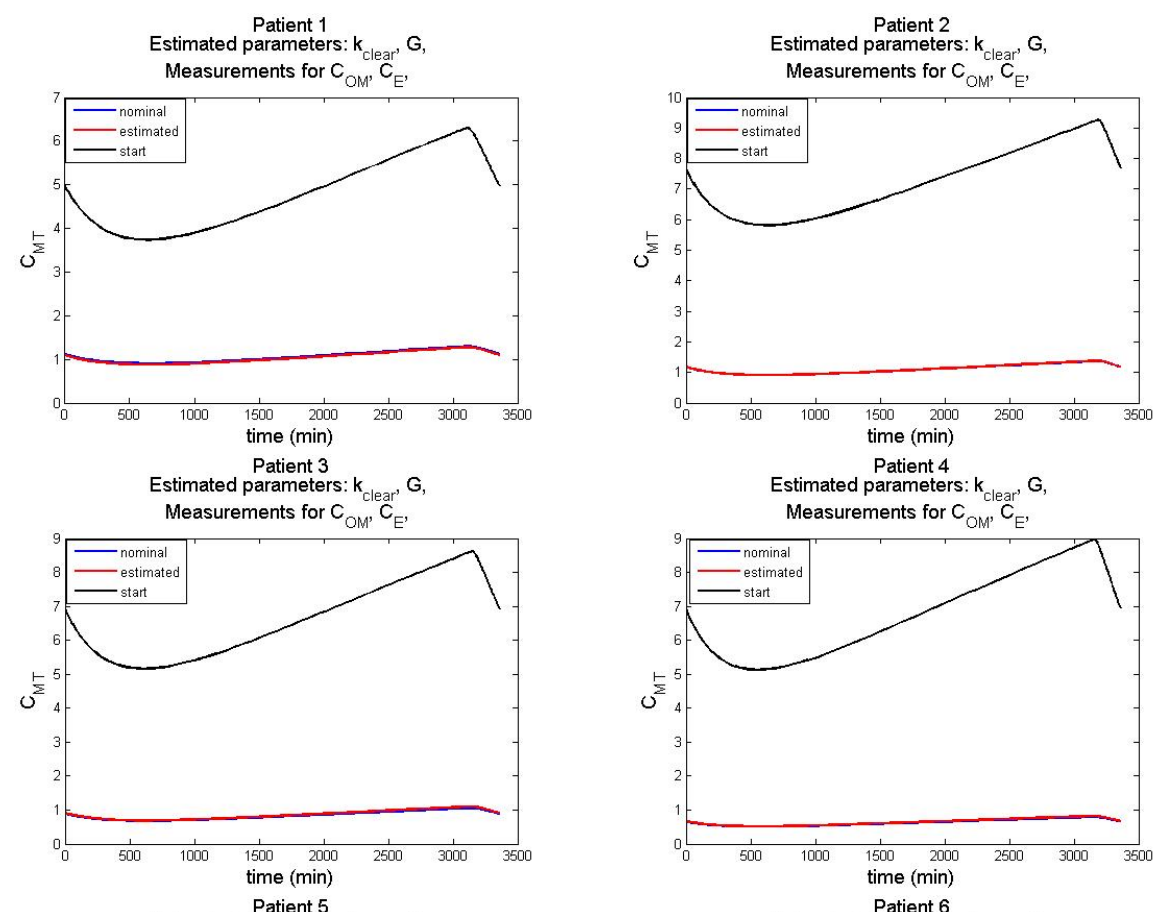

Estimated param

Measurements for $\mathrm{C}_{\mathrm{OM}}$, $\mathrm{C}_{\mathrm{E}}$,
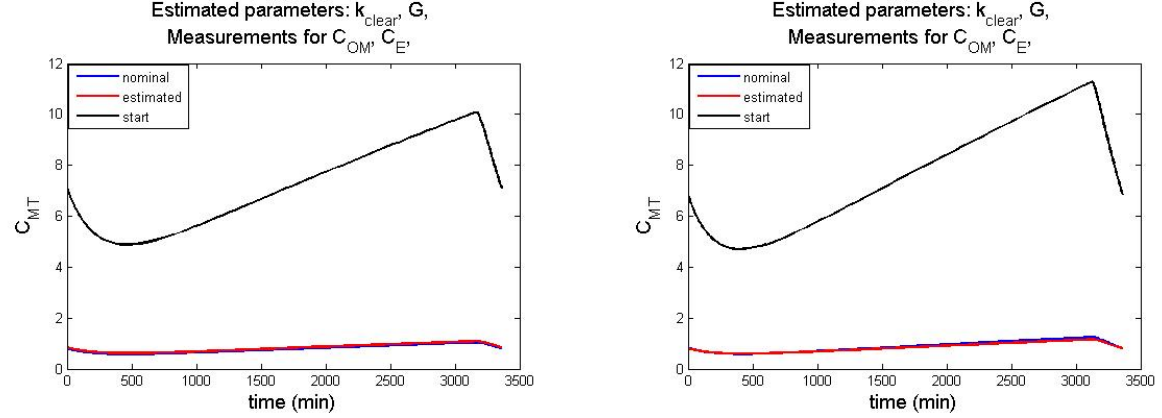

Figure 5.9. Estimation of $k_{\text {clear }}$ and $G$ for all 6 patients with $\sigma=0.01$, and 7 measurements during dialysis, for $C_{M T}$.

In Fig 5.9 we present the estimation of parameter $k_{\text {clear }}$ and $G$ for all 6 patients using fminsearch for the error functional for $J_{q u}$ with starting values $k_{\text {clear }}=0.5, G=0.08$ in the muscle tissue compartment. 

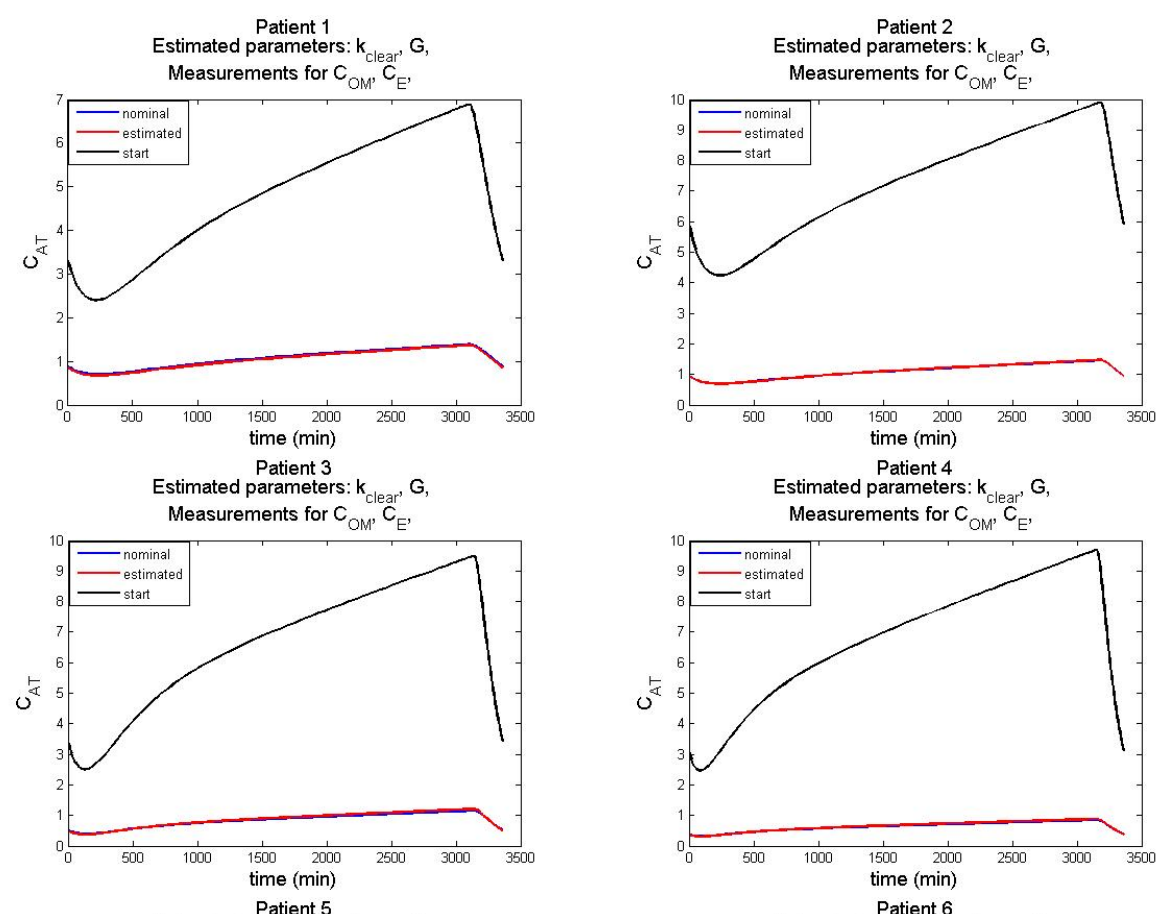

Estimated parameters: $\mathbf{k}_{\text {clear, }}, \mathbf{G}$,

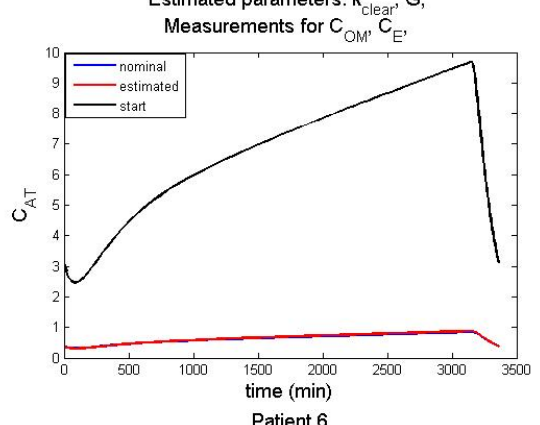

Patient 5

Measurements for $\mathrm{C}_{\mathrm{OM}}, \mathrm{C}_{\mathrm{E}}$,
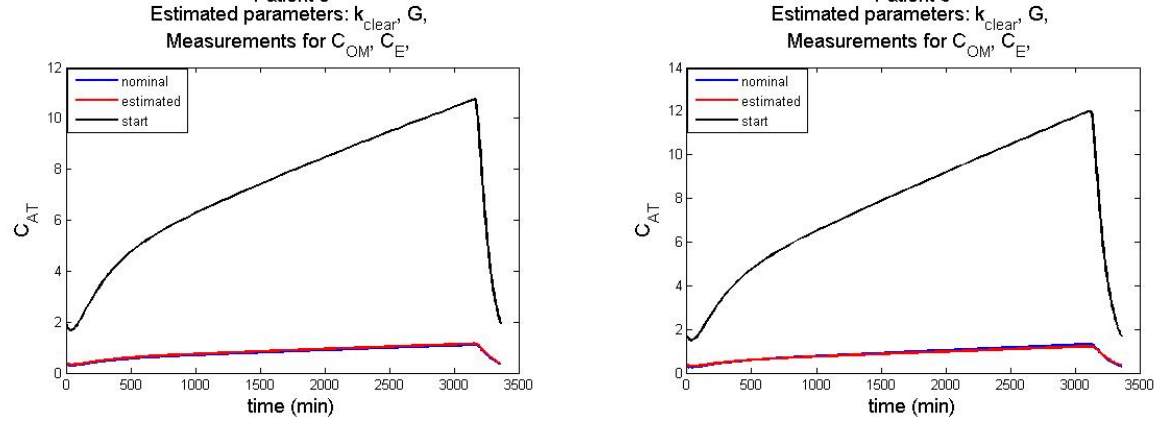

Figure 5.10. Estimation of $k_{\text {clear }}$ and $G$ for all 6 patients with $\sigma=0.01$, and 7 measurements during dialysis, for $C_{A T}$.

In Fig 5.10 we present the estimation of parameter $k_{\text {clear }}$ and $G$ for all 6 patients using fminsearch for the error functional for $J_{q u}$ with starting values $k_{\text {clear }}=0.5, G=0.08$ in the adipose tissue compartment. 

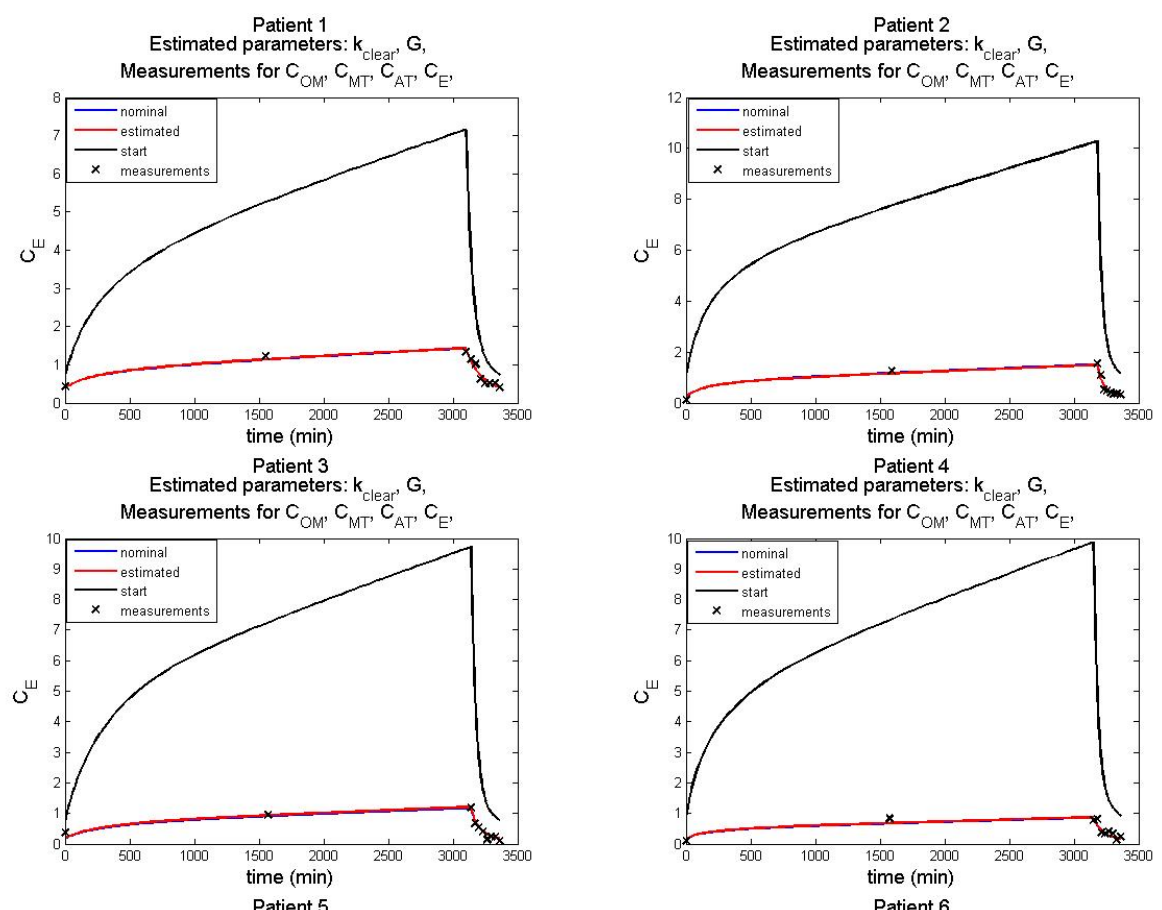

Estimated parameters:

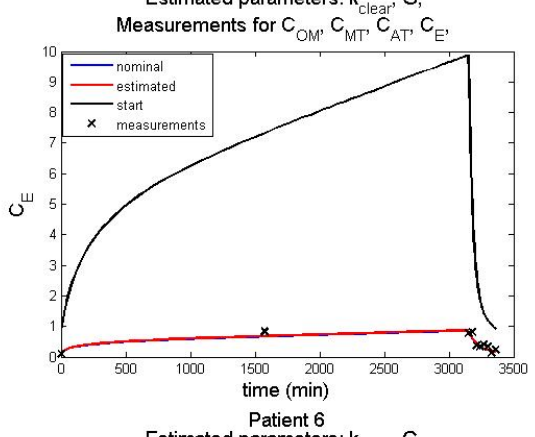

Estimated parameter
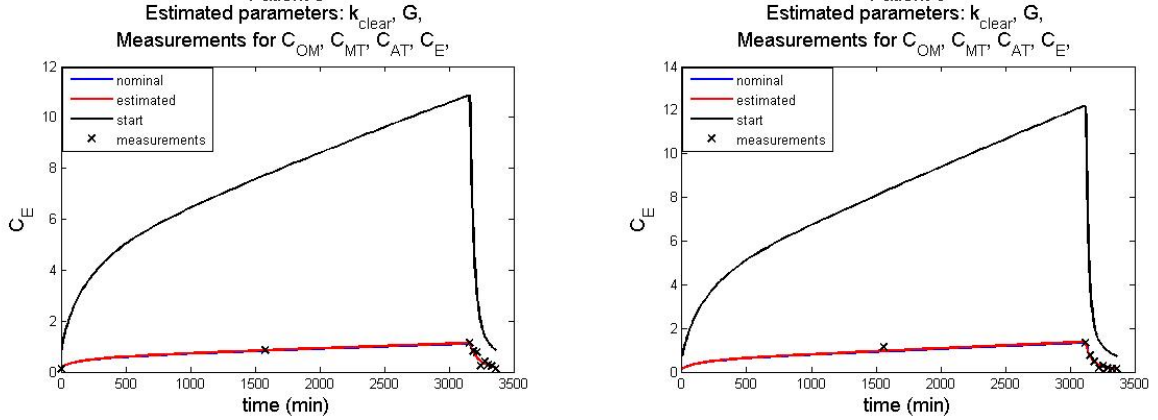

Figure 5.11. Estimation of $k_{\text {clear }}$ and $G$ for all 6 patients with $\sigma=0.01$, and 7 measurements during dialysis, when measurements are taken in extracellular compartment.

In Fig 5.11 we present the estimation of parameter $k_{\text {clear }}$ and $G$ for all 6 patients using fminsearch for the error functional for $J_{q u}$ with starting values $k_{\text {clear }}=0.5, G=0.08$ when measurements are taken in the extracellular compartment. Estimated values are given in Table 5.1, we can see that all the estimates are very good. 


\begin{tabular}{|c|c|c|c|c|c|c|}
\hline Patients & 1 & 2 & 3 & 4 & 5 & 6 \\
\hline \multicolumn{7}{|c|}{ Parameter $k_{\text {clear }}$} \\
\hline starting values & 0.5 & 0.5 & 0.5 & 0.5 & 0.5 & 0.5 \\
\hline nominal values & 0.223 & 0.348 & 0.303 & 0.267 & 0.274 & 0.282 \\
\hline estimated values & 0.2396 & 0.3472 & 0.3017 & 0.2625 & 0.2818 & 0.298 \\
\hline \multicolumn{7}{|c|}{ Parameter $G$} \\
\hline starting values & 0.08 & 0.08 & 0.08 & 0.08 & 0.08 & 0.08 \\
\hline nominal values & 0.012 & 0.0108 & 0.0088 & 0.0061 & 0.0073 & 0.0081 \\
\hline estimated values & 0.0135 & 0.0109 & 0.00906 & 0.00615 & 0.0075 & 0.0084 \\
\hline
\end{tabular}

Table 5.1. Identification of $k_{\text {clear }}$ and $G$ for Patients $1-6$ using 7 uniformly distributed measurements of $C_{\mathrm{E}}$ during the dialytic phase.

For a large number $(\mathrm{N}=1000)$ of the realization of $\epsilon_{j}$, we carried out the Monte Carlo estimates using the MatLab code solvopt with out gradient information, for both $k_{\text {clear }}$ and $G$. Estimates are are given below in Table 5.2

\begin{tabular}{|c|c|c|c|c|c|c|}
\hline Patients & 1 & 2 & 3 & 4 & 5 & 6 \\
\hline \multicolumn{7}{|c|}{ Parameter $k_{\text {clear }}$} \\
\hline starting values & 0.5 & 0.5 & 0.5 & 0.5 & 0.5 & 0.5 \\
\hline nominal values & 0.223 & 0.348 & 0.303 & 0.267 & 0.274 & 0.282 \\
\hline estimated values & 0.2247 & 0.3493 & 0.303 & 0.2699 & 0.2765 & 0.2843 \\
\hline \multicolumn{7}{|c|}{ Parameter $G$} \\
\hline starting values & 0.08 & 0.08 & 0.08 & 0.08 & 0.08 & 0.08 \\
\hline nominal values & 0.012 & 0.0108 & 0.0088 & 0.0061 & 0.0073 & 0.0081 \\
\hline estimated values & 0.0128 & 0.0108 & 0.0088 & 0.0061 & 0.0073 & 0.0081 \\
\hline
\end{tabular}

Table 5.2. Monte Carlo Identification of $k_{\text {clear }}$ and $G$ for Patients $1-6$ using 7 uniformly distributed measurements of $C_{\mathrm{E}}$ during the dialytic phase. 

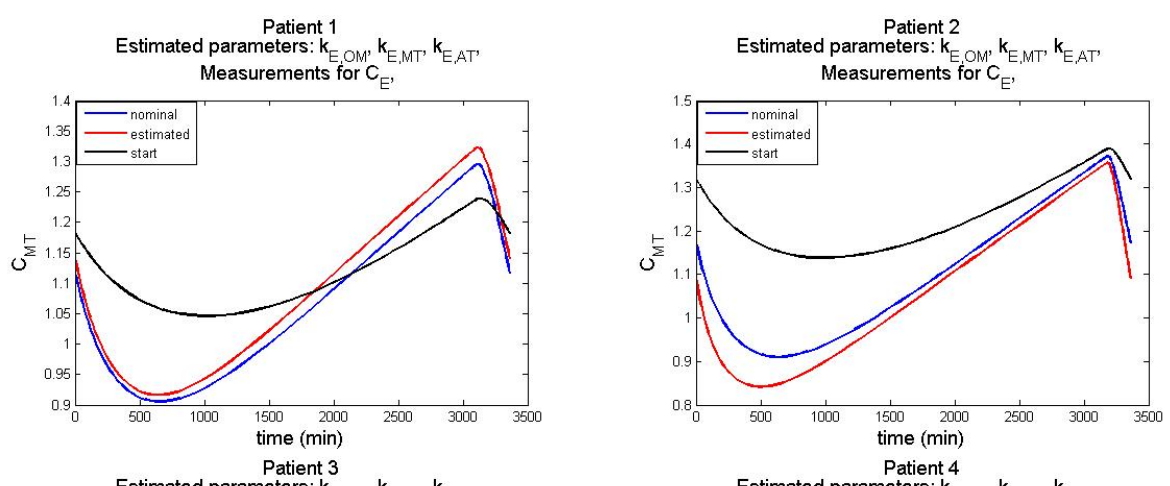

Estimated parameters: $\mathbf{k}_{E, O M}, \mathbf{k}_{E, M T}, \mathbf{k}_{E, A T}$,

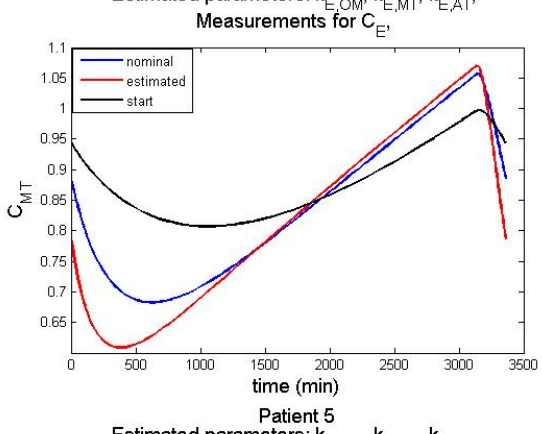

Estimated parameters. $k_{E},{ }, k_{E, M T}, k_{E, A T}$

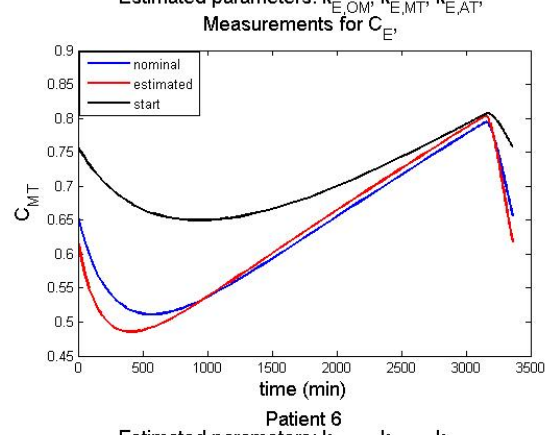

Estimated parameters: $k_{E, O M}, k_{E, M T}, k_{E, A T}$,

Estimated parameters: $\mathbf{k}_{E, O M}, \mathbf{k}_{E, M T}, \mathbf{k}_{E, A T}$
Measurements for $C_{E}$, Measurements for $C_{E}$,
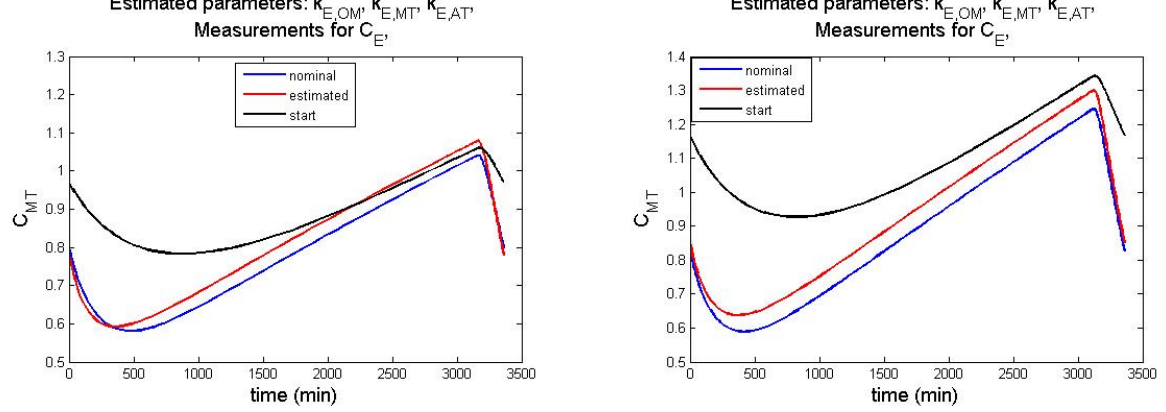

Figure 5.12. Estimation of $k_{E, O M}, k_{E, M T}$, and $k_{E, A T}$ for all six patients with $\sigma=0.01$, and 7 measurements during dialysis.

In Fig 5.12 we present the estimation of parameter $k_{E, O M}, k_{E, M T}$, and $k_{E, A T}$ for all six patients using fminsearch for the error functional for $J_{q u}$ with starting values $k_{E O M}=0.01, k_{E, M T}=0.01$, and $k_{E, A T}=0.01$ in the muscle tissue compartment $C_{M T}$. 

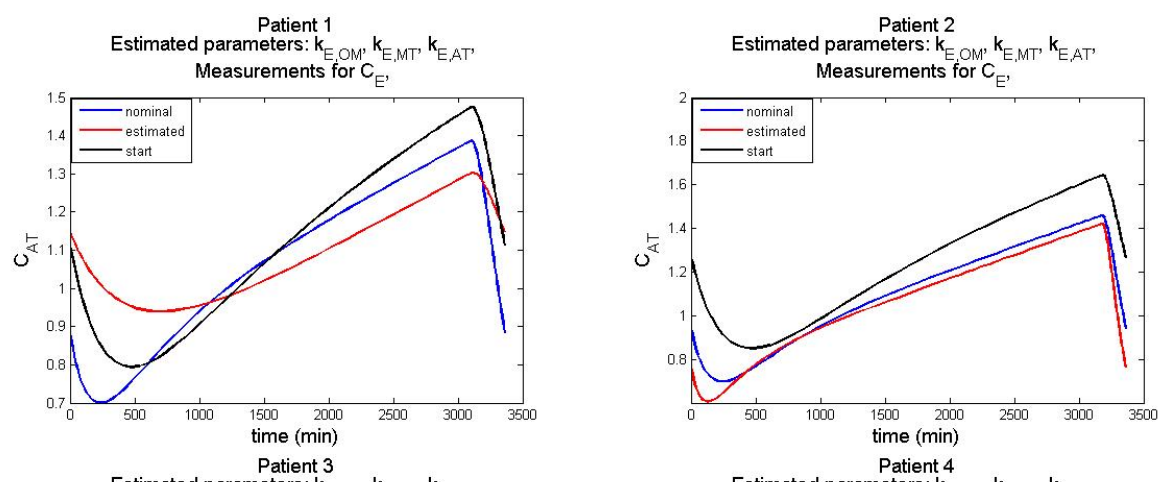

Estimated parameters: $\mathbf{k}_{E, O M}, \mathbf{k}_{E, M T}, \mathbf{k}_{E, A T}$,

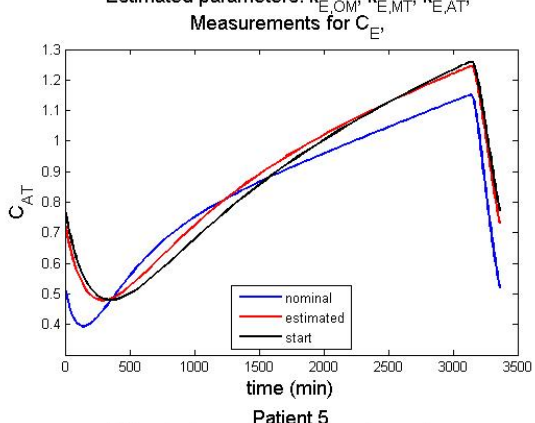

Estimated parameters: $\mathbf{k}_{E, O M}, \mathbf{k}_{E, M T}, \mathbf{k}_{E, A T}$, Measurements for $\mathrm{C}_{\mathrm{E}}$,

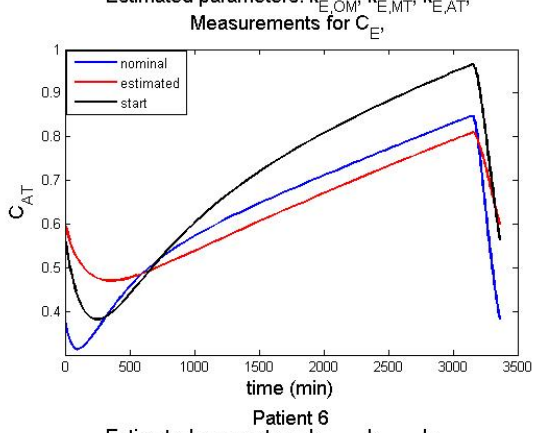

Estimated parameters: $\mathbf{k}_{E, O M}, \mathbf{k}_{E, M T}, \mathbf{k}_{E, A T}$ Measurements for $\mathrm{C}_{\mathrm{E}}$,
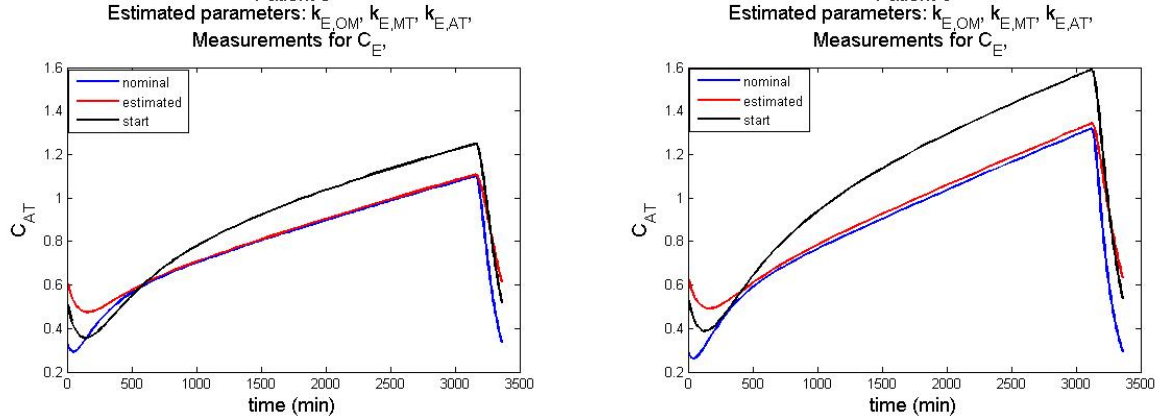

Figure 5.13. Estimation of $k_{E, O M}, k_{E, M T}$, and $k_{E, A T}$ for all six patients $\sigma=0.01$, and 7 measurements during dialysis.

In Fig 5.13 we present the estimation of parameter $k_{E, O M}, k_{E, M T}$, and $k_{E, A T}$ for all six patients using fminsearch for the error functional for $J_{q u}$, in the adipose tissue compartment $C_{A T}$ 

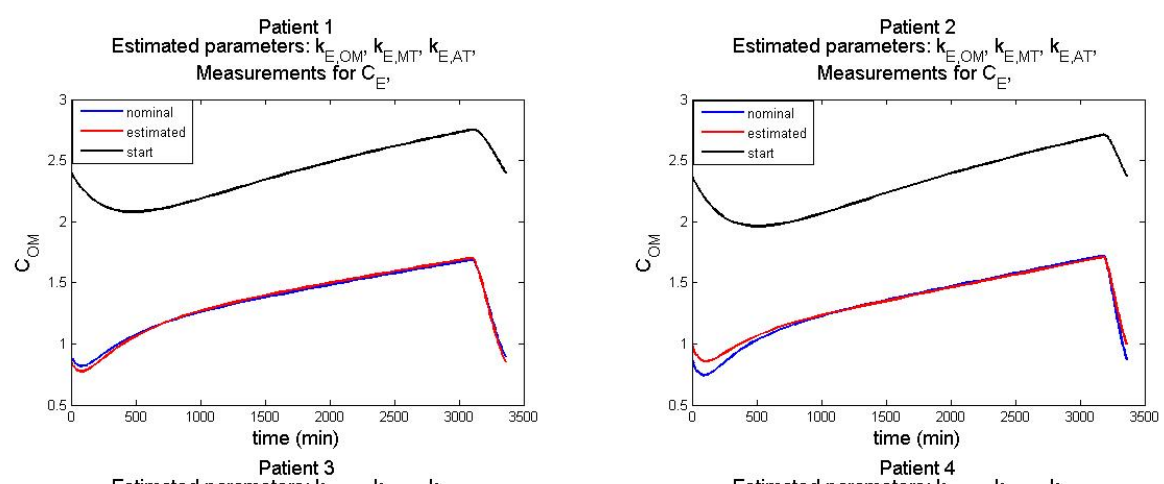

Estimated parameters: $\mathbf{k}_{E, O M}, \mathbf{k}_{E, M T}, \mathbf{k}_{E, A T}$, Measurements for $\mathrm{C}_{\mathrm{E}}$,

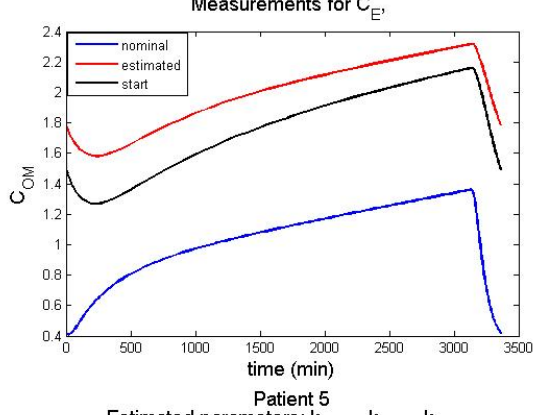

Estimated parameters: $\mathbf{k}_{E, O M}, k_{E M T}, k_{E A T}$, Measurements for $\mathrm{C}_{\mathrm{E}}$,

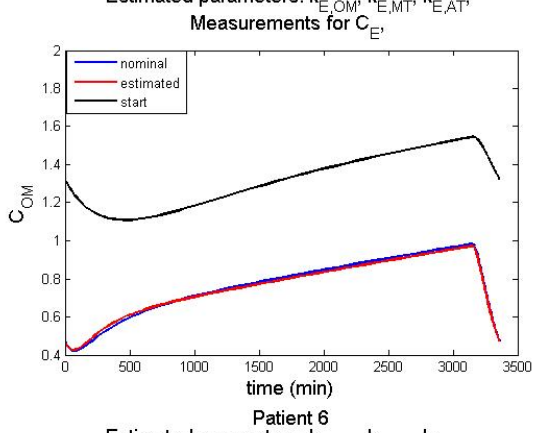

Estimated parameters: $k_{E, O M}, k_{E, M T}, k_{E, A T}$, Measurements for $C_{E}$,
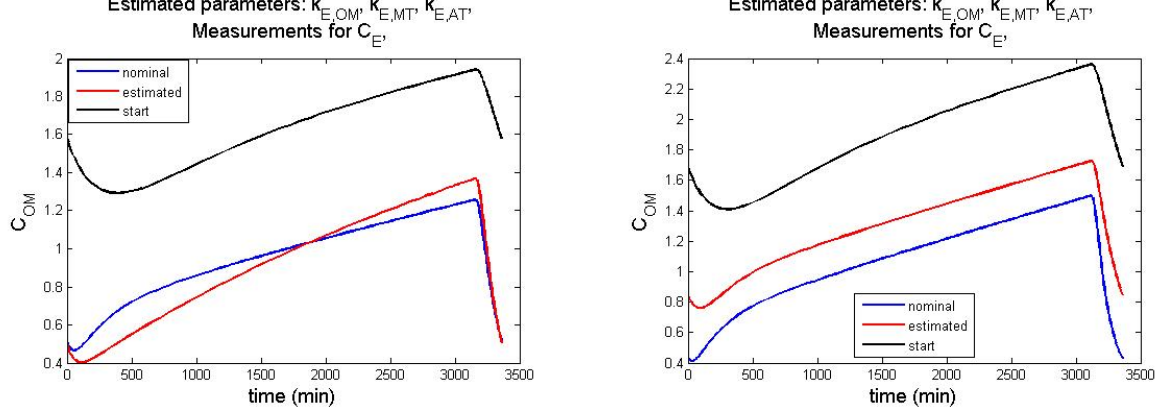

Figure 5.14. Estimation of $k_{E, O M}, k_{E, M T}$, and $k_{E A T}$ for all six patients with $\sigma=0.01$, and 7 measurements during dialysis in the organ mass compartment.

In Fig 5.14 we present the estimation of parameter $k_{E, O M}, k_{E, M T}$, and $k_{E, A T}$ for all six patients using fminsearch for the error functional for $J_{q u}$, in the organ mass compartment $C_{M T}$. 

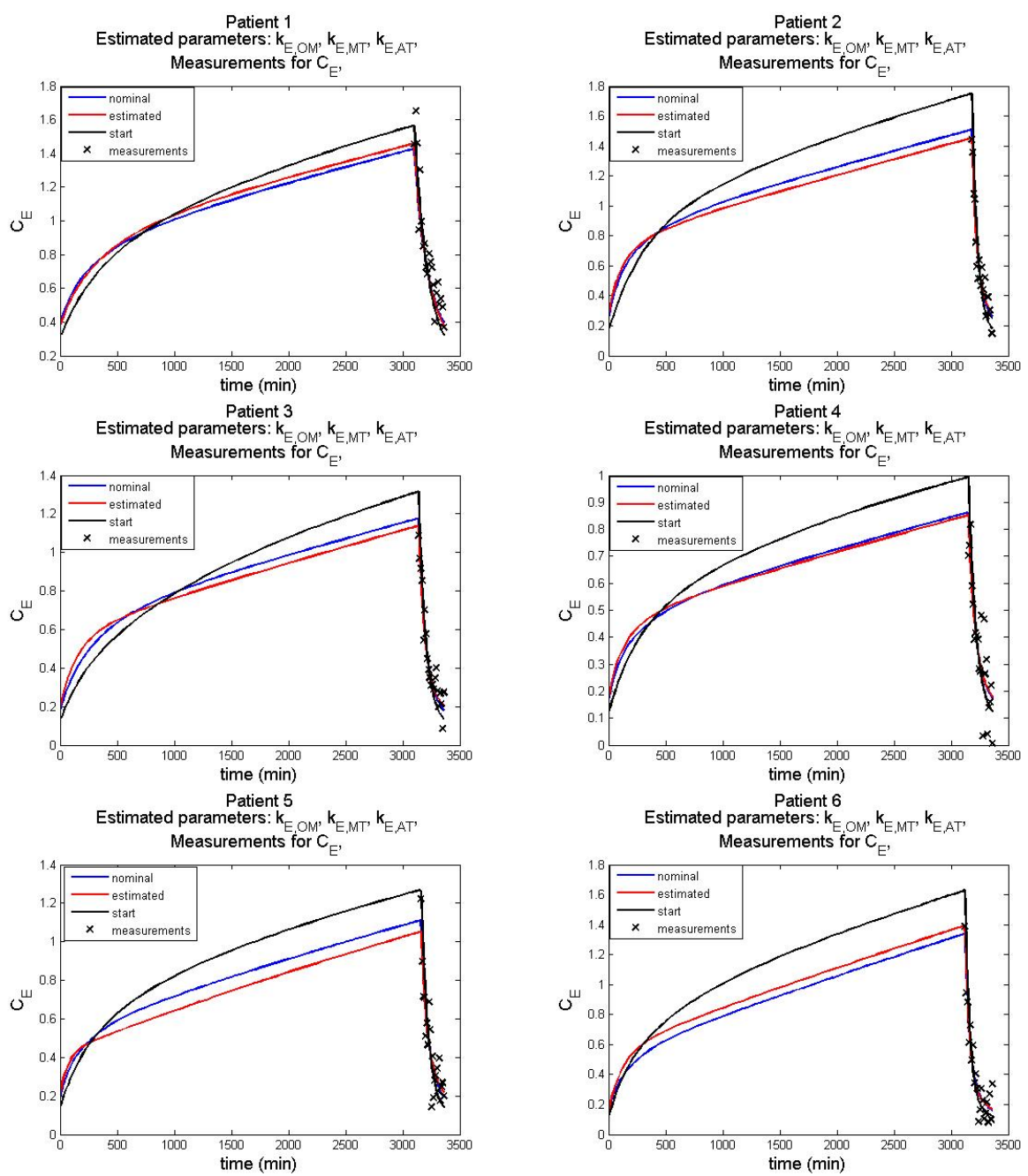

Figure 5.15. Estimation of $k_{E, O M}, k_{E, M T}$, and $k_{E, A T}$ for all six patients with $\sigma=0.01$, and 7 measurements during dialysis.

In Fig 5.15 we present the estimation of parameter $k_{E, O M}, k_{E, M T}$, and $k_{E, A T}$ for all six patients using fminsearch for the error functional for $J_{q u}$, when the measurements are taken in the extracellular compartment. The estimated values are given in Table 5.3 . 


\begin{tabular}{|c|c|c|c|c|c|c|c|}
\hline Patients & 1 & 2 & 3 & 4 & 5 & 6 \\
\hline \multicolumn{7}{|c|}{ Parameter $k_{E O M}$} \\
\hline starting values & 0.01 & 0.01 & 0.01 & 0.01 & 0.01 & 0.01 \\
\hline nominal values & 0.046 & 0.046 & 0.046 & 0.046 & 0.046 & 0.046 \\
\hline estimated values & 0.0488 & 0.0487 & 0.0402 & 0.0385 & 0.0416 & 0.04664 \\
\hline \multicolumn{7}{|c|}{ Parameter $k_{E M T}$} \\
\hline starting values & 0.01 & 0.01 & 0.01 & 0.01 & 0.01 & 0.01 \\
\hline nominal values & 0.032 & 0.032 & 0.032 & 0.032 & 0.032 & 0.032 \\
\hline estimated values & 0.0312 & 0.0111 & 0.0183 & 0.0022 & 0.0398 & 0.01123 \\
\hline \multicolumn{7}{|c|}{ Parameter $k_{E A T}$} \\
\hline starting values & 0.01 & 0.01 & 0.01 & 0.01 & 0.01 & 0.01 \\
\hline nominal values & 0.019 & 0.019 & 0.019 & 0.019 & 0.019 & 0.019 \\
\hline estimated values & 0.02578 & 0.0254 & 0.0154 & 0.0199 & 0.0179 & 0.00153 \\
\hline
\end{tabular}

Table 5.3. Identification of $k_{E, O M}, k_{E, M T}$ and $k_{E, A T}$ for Patients $1-6$ using 7 uniformly distributed measurements of $C_{\mathrm{E}}$ during the dialytic phase.

For a large number $(\mathrm{N}=1000)$ of the realization of $\epsilon_{j}$, we also carried out Monte Carlo estimates using the MatLab code fminsearch, for $k_{E, O M}, k_{E, M T}$ and $k_{E, A T}$. Estimates are given in Table 5.4

\begin{tabular}{|c|c|c|c|c|c|c|}
\hline Patients & 1 & 2 & 3 & 4 & 5 & 6 \\
\hline \multicolumn{7}{|c|}{ Parameter $k_{E, O M}$} \\
\hline starting values & 0.01 & 0.01 & 0.01 & 0.01 & 0.01 & 0.01 \\
\hline nominal values & 0.046 & 0.046 & 0.046 & 0.046 & 0.046 & 0.046 \\
\hline estimated values & 0.0235 & 0.0431 & 0.017 & 0.0686 & 0.0553 & 0.0346 \\
\hline \multicolumn{7}{|c|}{ Parameter $k_{E, M T}$} \\
\hline starting values & 0.01 & 0.01 & 0.01 & 0.01 & 0.01 & 0.01 \\
\hline nominal values & 0.032 & 0.032 & 0.032 & 0.032 & 0.032 & 0.032 \\
\hline estimated values & 0.0295 & 0.0312 & 0.0363 & 0.0408 & 0.0353 & 0.0454 \\
\hline \multicolumn{7}{|c|}{ Parameter $k_{E, A T}$} \\
\hline starting values & 0.01 & 0.01 & 0.01 & 0.01 & 0.01 & 0.01 \\
\hline nominal values & 0.019 & 0.019 & 0.019 & 0.019 & 0.019 & 0.019 \\
\hline estimated values & 0.0184 & 0.0357 & 0.0263 & 0.0166 & 0.0173 & 0.0071 \\
\hline
\end{tabular}

Table 5.4. Monte Carlo estimates of $k_{E, O M}, k_{E, M T}$ and $k_{E, A T}$ for Patients 1-6 using 7 uniformly distributed measurements of $C_{\mathrm{E}}$ during the dialytic phase. 

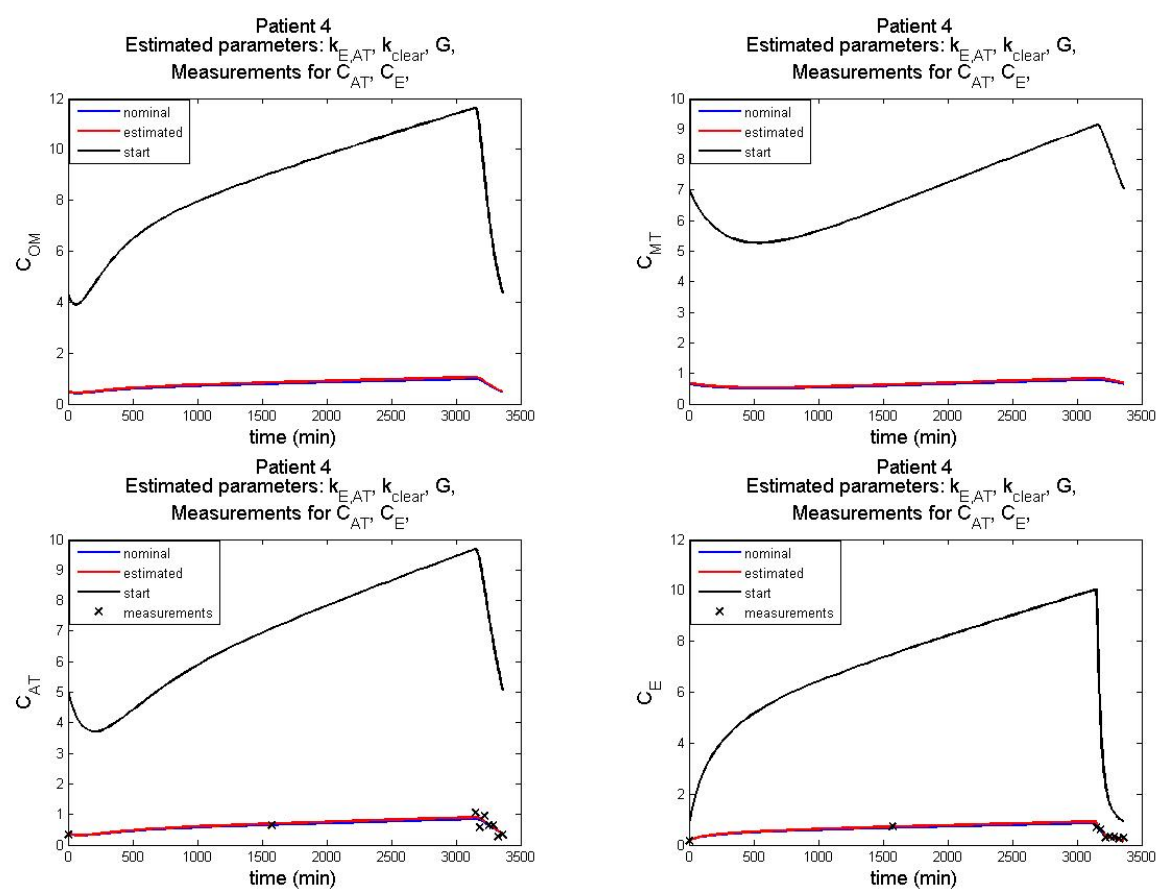

Figure 5.16. Estimation of $k_{E, A T}, k_{\text {clear }}, G$ for Patient 4 with $\sigma=0.01$, and 7 measurements during dialysis.

\begin{tabular}{|c|c|c|c|}
\hline & $k_{\text {clear }}$ & $G$ & $k_{E, A T}$ \\
\hline starting values & 0.05 & 0.03 & .01 \\
nominal values & 0.223 & 0.0061 & .019 \\
estimated values & 0.287 & 0.0067 & .0193 \\
\hline
\end{tabular}

Table 5.5. Identification of $k_{\text {clear }}, G$ and $k_{E, A T}$ for Patient 4 using 7 uniformly distributed measurements of $C_{\mathrm{E}}$ during the dialytic phase. 

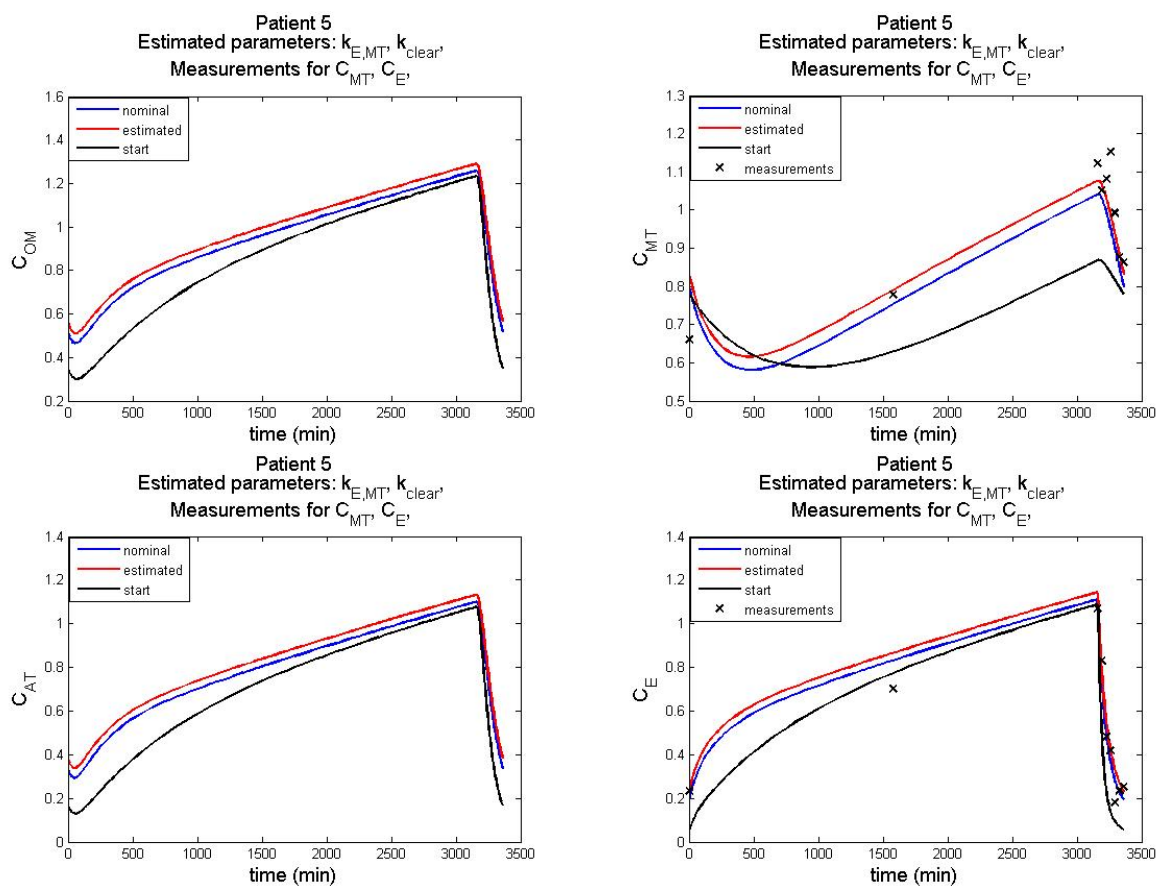

Figure 5.17. Estimation of $k_{E, M T}$, and $k_{\text {clear }}$ for Patient 4 with $\sigma=0.01$, and 7 measurements during dialysis.

\begin{tabular}{|c|c|c|}
\hline Algorithm & Error functional & $\left(k_{E, M T}, k_{\text {clear }}\right)$ \\
\hline \multicolumn{3}{|c|}{6 measurements during the dialytic phase } \\
\hline solvopt & $J_{q u}$ & $(0.0147,0.2492)$ \\
\hline fminsearch & $J_{q u}$ & $(0.0019,0.2931)$ \\
\hline \multicolumn{2}{|c|}{21 measurements during the dialytic phase } \\
\hline solvopt & $J_{q u}$ & $(0.0010,0.378)$ \\
\hline fminsearch & $J_{q u}$ & $(0.0030, .2808)$ \\
\hline
\end{tabular}

Table 5.6. Identification of $k_{\text {clear }}$ and $G$ for Patient 4 using 6 respectively 21 measurements during the dialytic phase. 

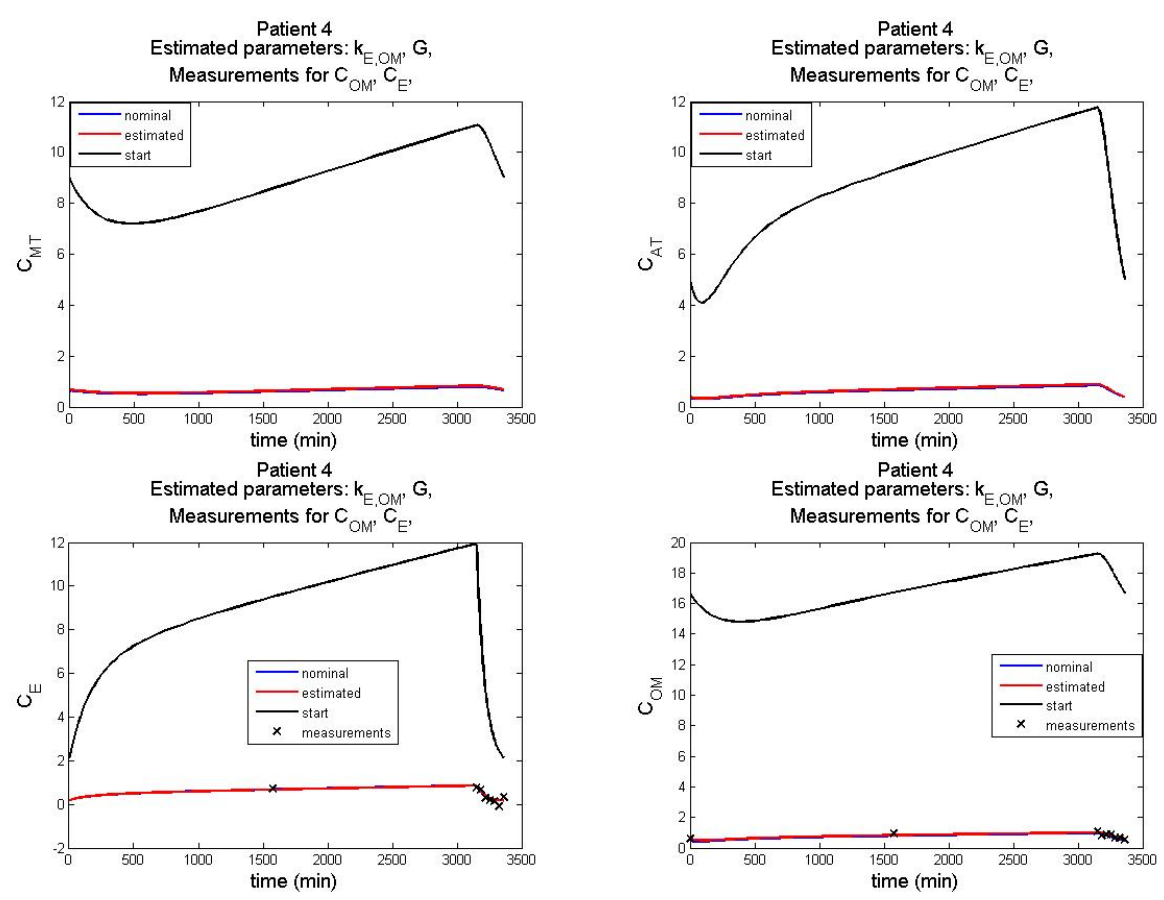

Figure 5.18. Estimation of $k_{E, O M}$, and $G$ for Patient 4 with $\sigma=0.01$, and 7 measurements during dialysis.

\begin{tabular}{|c|c|c|}
\hline Algorithm & Error functional & $\left(k_{E, O M}, G\right)$ \\
\hline \multicolumn{2}{|c|}{6 measurements during the dialytic phase } \\
\hline solvopt & $J_{q u}$ & $(0.043,0.0059)$ \\
\hline fminsearch & $J_{q u}$ & $(0.0375,0.1397)$ \\
\hline \multicolumn{2}{|c|}{21 measurements during the dialytic phase } \\
\hline solvopt & $J_{q u}$ & $(2.9038,0.0058)$ \\
\hline fminsearch & $J_{q u}$ & $(0.1148, .0060)$ \\
\hline
\end{tabular}

Table 5.7. Identification of $k_{E, O m}$ and $G$ for Patient 4 using 6 respectively 21 measurements during the dialytic phase. 

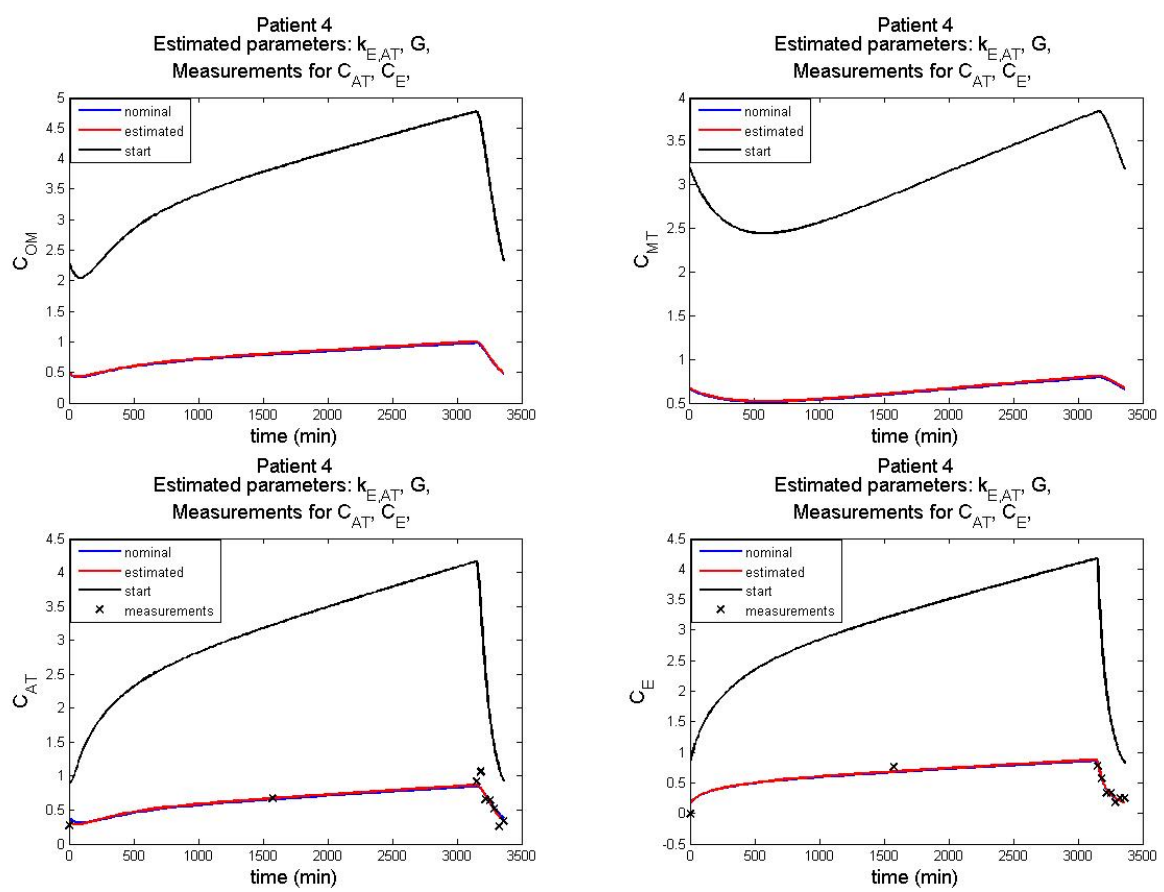

Figure 5.19. Estimation of $k_{E, A T}$ and $G$ for Patient 4 with $\sigma=0.01$, and 7 measurements during dialysis.

\begin{tabular}{|c|c|c|}
\hline Algorithm & Error functional & $\left(G, k_{E, A T}\right)$ \\
\hline \multicolumn{3}{|c|}{6 measurements during the dialytic phase } \\
\hline solvopt & $J_{q u}$ & $(0.0062,0.1332)$ \\
\hline fminsearch & $J_{q u}$ & $(0.0055,0.1715)$ \\
\hline 21 measurements during the dialytic phase \\
\hline solvopt & $J_{q u}$ & $(0.0059,0.0001)$ \\
\hline fminsearch & $J_{q u}$ & $(0.0069, .029)$ \\
\hline
\end{tabular}

Table 5.8. Identification of $k_{E, M T} a n d k_{E, A T}$ for Patient 4 using 6 respectively 21 measurements during the dialytic phase. 

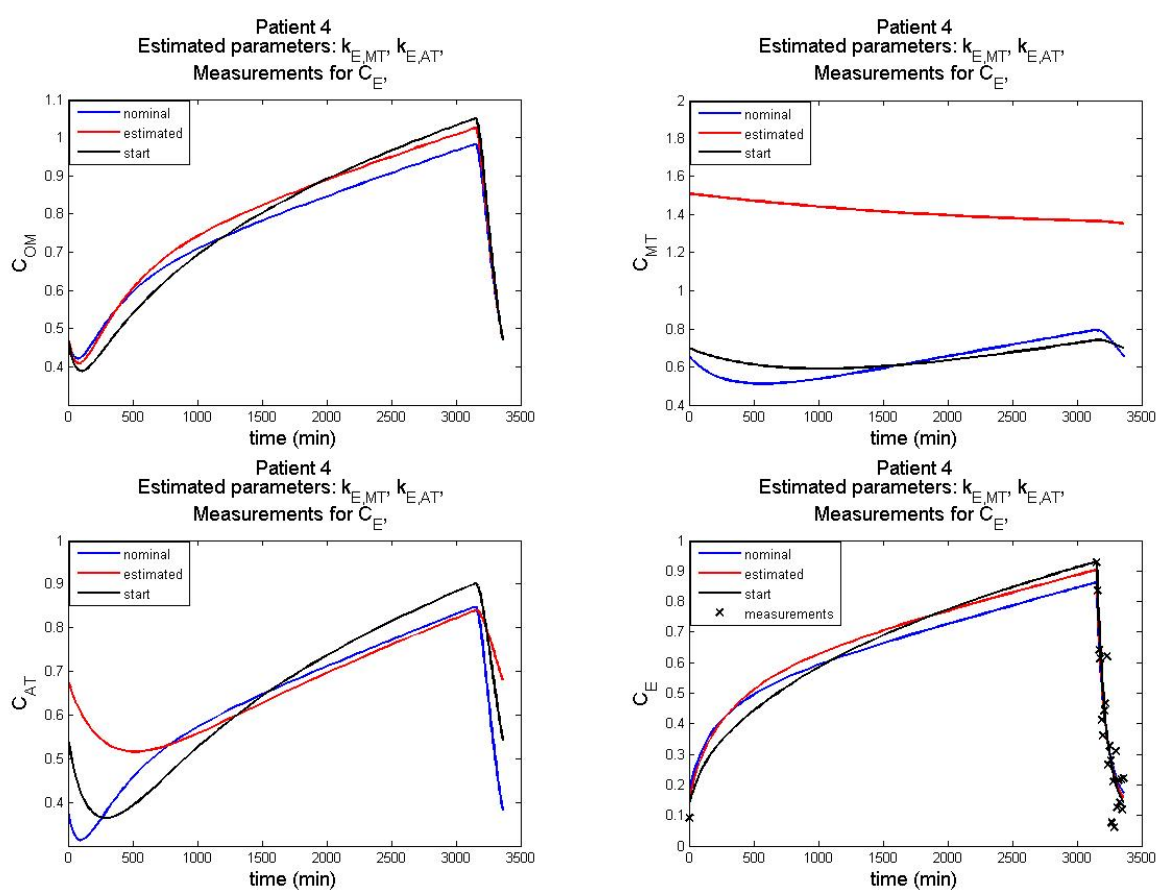

Figure 5.20. Estimation of $k_{E, M T}$, and $k_{E, A T}$ for Patient 4 with $\sigma=0.01$, and 21 measurements during dialysis.

\begin{tabular}{|c|c|c|}
\hline Algorithm & Error functional & $\left(k_{E, M T}, k_{E, A T}\right)$ \\
\hline \multicolumn{2}{|c|}{6 measurements during the dialytic phase } \\
\hline solvopt & $J_{q u}$ & $(0.046,0.0069)$ \\
\hline fminsearch & $J_{q u}$ & $(0.0375,0.1397)$ \\
\hline \multicolumn{2}{|c|}{21 measurements during the dialytic phase } \\
\hline solvopt & $J_{q u}$ & $(0.0587,0.0065)$ \\
\hline fminsearch & $J_{q u}$ & $(0.0126, .179)$ \\
\hline
\end{tabular}

Table 5.9. Identification of $k_{E, M T} a n d k_{E, A T}$ for Patient 4 using 6 respectively 21 measurements during the dialytic phase. 


\subsection{Conclusion}

- Both algorithms, fminsearch and solvopt behave well, because of high sensitivity of measured output with respect to $k_{\text {clear }}$ and $G$. Moreover the performance of both is comparable. However in cases where the measured out put is not very sensitive with respect to the parameters to be identified solvopt is somehow more accurate, whereas fminsearch is considerable faster.

- The parameters $k_{c l e a r}$ and $G$ are well estimated due to the high sensitivity of measured output with respect to $k_{\text {clear }}$ and $G$. However in general these parameters need not to be identified, as they are computed from data (see Subsection 4.3.1.

- For the parameters $k_{E, O M}, k_{E, M T}, k_{E, A T}$ we faced difficulties in view of the low sensitivity of the measured output with respect to these parameters.

- If we want to identify one of the parameters $k_{E, O M}, k_{E, M T}, k_{E, A T}$ together with $G$ or $k_{\text {clear }}$ then the results are good concerning $G$ or $k_{\text {clear }}$, but also sometime better for the other parameter in comparison to the previous item. 


\section{Chapter 6}

\section{Remarks and Perspectives}

An important feature of the modelling study could incorporate results based on body composition data obtained by magnetic resonance imaging and bioimpedance spectroscopy for individual patients.

We use the same model as presented in [33]. Preliminary modeling results seem to confirm the dependence of survival probabilities on BMI, but also show that BMI is too crude a measure.

The simulation results presented in Chapter 4 strongly indicate that body composition instead of BMI should be considered. Moreover we demonstrated that the clearance rate during the dialysis process and the generation rate for uremic toxins are also key factors. Simulation results show that clearance rate of toxin is more influential than the production rate of toxins (see Figure 4.5). Model validation was done (in Chapter 5 by performing sensitivity analysis and extensive parameter estimation test. Sensitivity analysis also tells us that both $k_{\text {clear }}$ and $G$ are very sensitive for model output.

Summarize all our results as:

- BMI is not able to predict the toxin concentration in the extracellular compartment reliably. Instead of BMI we have to use data on body composition.

- Besides body composition it is necessary to include the individual clear- 
ance rate $k_{\text {clear }}$ for the toxin during dialysis and the production rate $G$ for the toxin into the considerations. However, it seems that the clearance rate is more influential than the production rate.

- Data on the concentration of urea in the extracellular fluid taken during the dialysis treatment are sufficient in order to get reliable estimates for the urea clearance rate $k_{\text {clear }}$ and the the urea production rate $G$. However, these rate constants can also be determined from other data and parameter estimation is not needed here (compare Subsection 4.3.1).

- The transfer rates for urea between the extracellular compartment and the other compartments, i.e., $k_{E, O M}, k_{E, M T}$ and $k_{E, A T}$, cannot be estimated reliably from measurements for the urea concentration in the extracellular fluid. One would need additional data for quantities which have some relation to these rates.

- Looking more detail for different toxins. And investigate cheaper method to determine body composition. 


\section{Appendix A}

\section{A.1 Classical Sensitivity}

Classical sensitivity analysis explores the influence of changes in parameters on model output. It is the normalized derivative of a given model output with respect to a given parameter.

In particular, let the single model out put variable be $y=y(p)$ and $p$ be single parameter. Let $p_{0}$ and $y_{0}$ are the values around which changes are computed. we assume that $p_{0} \neq 0$ and $y_{0}=y\left(p_{0}\right) \neq 0$.

Corresponding to $\triangle p$ with $p_{0}+\triangle p$ we define $\triangle y=y\left(p_{0}+\triangle p\right)-y\left(p_{0}\right)$ and consider the relative errors $\triangle p / p_{0}$ and $\triangle y / y_{0}$. The sensitivity $\sigma_{y, p}\left(p_{0}\right)$ of $y$ with respect to $p$ at $p_{0}$ is defined as:

$$
\sigma_{y, p}\left(p_{0}\right)=\lim _{\triangle p \rightarrow 0} \frac{\triangle y / y_{0}}{\triangle p / p_{0}}=\frac{p_{0}}{y_{0}} y^{\prime}\left(p_{0}\right)
$$

This formulation implies that $\sigma_{y, p}$ is invariant under change of units in $p$ or $y$. Since various outputs may have different units it is best to consider normalized derivatives as expressed above. Note that in this formulation time is fixed so that classical sensitivities are functions of time over the time interval of interest. Also note that these quantities provide local estimates of sensitivity. 


\section{A.2 Sensitivity matrix}

We describe the sensitivity matrix for a model defined by a system of ordinary differential equations with one output $y$ and parameters $\left(p_{1}, \ldots, p_{m}\right)$.

$$
\dot{y}(\mathrm{t})=f(t, y(t), p), \quad y(0, p)=y^{0}(p),
$$

For each time point in the interval of measurement, collecting the derivatives of model output $y$ with respect to the parameter $p_{j}$ in order to generate the sensitivity matrix: Following augmented system of equations are solved to find the sensitivity matrix:

$$
\begin{aligned}
\frac{d y(t, p)}{d t} & =f(t, y(t, p), p), \quad y(0, p)=y^{0}(p) \\
\frac{d S(t, p)}{d t} & =\frac{\partial f}{\partial y}(t, y(t, p), p) S(p)+\frac{\partial f}{\partial p}(t, y(t, p), p) \\
S^{0}(p) & =\frac{\partial y^{0}(p)}{\partial p}
\end{aligned}
$$

Calculating the derivatives in the sensitivity equations, which is based on repeated application of the chain rule. 


\section{Appendix B}

\section{B.1 Parameter Estimation}

Let $y(t)$ be the output of a the model defined below, and let $\theta$ be an admissible parameter:

$$
\left\{\begin{array}{l}
y(t)=f(\mathrm{t}, \theta) \quad \mathrm{t} \in[0, \mathrm{~T}], \quad \theta \in \mathcal{A} \subset \mathbb{R}^{p} \\
f:[0, \mathrm{~T}] \times \mathcal{A} \longrightarrow \mathbb{R} .
\end{array}\right.
$$

Measurements $\xi_{i}$ are taken at the sampling time $0 \leqslant t_{1}<\cdots<t_{N} \leqslant T$. We assume that the measurement $\xi_{i}$ at $t_{i}$ for $y\left(t_{i}\right)$ are given by:

$$
\xi_{i}=\xi_{i}\left(\theta_{0}\right)=f\left(t_{i} ; \theta_{0}\right)+\epsilon_{i} \quad i=1, \ldots N
$$

where $\theta_{0}$ is the true or nominal parameter vector, and $\epsilon_{i}, i=1, \ldots, N$ represent the measurement noise $\mathcal{E}_{i}$ at $t_{i}$, which is a random variable. In order to develop the theory, some assumptions are made:

Assumptions on $\epsilon_{i}$ :

The $\epsilon_{i}$ are realizations of random variables $\mathcal{E}_{i}$.

1) $\mathcal{E}_{i}, i=1, \ldots, N$ are i.i.d i.e., are independent and identically distributed.

2) $\mathrm{E}\left(\mathcal{E}_{i}\right)=0$, i.e., the measuring device must be unbiased. 
3) The variance $\left(\mathcal{E}_{i}\right)=\sigma_{0}^{2}$, is constant i.e., independent of $t$ and $\theta_{0}$.

\section{Assumption on Measurements:}

The $\xi_{i}$ are representations of independent and identically distributed random variables $\Xi_{i}$.

where

$$
\Xi_{i}=f\left(t_{i} ; \theta_{0}\right)+\mathcal{E}_{i}
$$

with

$$
\begin{gathered}
\mathrm{E}\left(\Xi_{i}\right)=f\left(t_{i} ; \theta_{0}\right) \text { and } \\
\operatorname{variance}\left(\Xi_{i}\right)=\sigma_{i}^{2}, i=1, \ldots, N,
\end{gathered}
$$

In order to estimate parameters, it is necessary to consider the design of estimation scheme which we will take to be an output least squares approach, where quadratic cost functional should be minimized to arrive at the parameter estimate $\hat{\theta}=\hat{\theta}\left(\theta_{0}\right)$. This cost functional takes the form

$$
\hat{\theta}=\hat{\theta}\left(\theta_{0}\right)=\underset{\tau \in \mathcal{A}}{\operatorname{argmin}} J(\tau, \xi)
$$

in a neighbourhood $\mathcal{A}$ of $\theta_{0}$, where $J(\tau)$ is given as

$$
J(\tau, \xi)=\sum_{i=1}^{N} \frac{1}{\sigma_{i}^{2}}\left(\xi_{i}-f\left(t_{i} ; \tau\right)\right)^{2}
$$

with $\xi=\left(\xi_{1}, \ldots, \xi_{N}\right)^{T}$, where $\xi_{i}$ is defined in 6.0.1. For each concrete data set $\xi$, the estimate $\hat{\theta}\left(\theta_{0}\right)$ is a representation of a random variable $\hat{\Theta}\left(\theta_{0}\right)$.

\section{Assumption for $\hat{\Theta}\left(\theta_{0}\right)$}

We assume we have unique identifiability, i.e., for all nominal parameters in a neighbourhood of $\theta_{0}$ the parameter estimation problem has a unique local solution, and that the estimation procedure is unbiased, i.e., we have $\mathrm{E}\left(\hat{\Theta}\left(\theta_{0}\right)\right)$ $=\theta_{0}$.

By the assumption on unique identifiability in a neighbourhood $\mathcal{A}$ of $\theta_{0}$ we 
have

$$
\left.\nabla_{\tau} J(\xi(\theta), \tau)\right|_{\tau=\hat{\theta}(\theta)}=0, \quad \theta \in \mathcal{A}
$$

For a given data set $\xi(\theta)$, we want to see how the sensitivity of the parameter estimate $\hat{\theta}(\theta)$ changes as function of $\xi^{(k)}=\left(\xi_{1}(\theta), \ldots, \xi_{k}(\theta)\right)^{T}$ for $k=1, \ldots, N$. This means that, for each $k=1, \ldots, N$, we are interested in $(\partial \hat{\theta}(\theta) / \partial \theta)\left(\theta_{0}\right)$ assuming that only the measurements in $\xi^{k}$ vary with $\theta$, but the measurements $\xi_{k+1}, \ldots, \xi_{N}$ are fixed to their values for $\theta=\theta_{0}$. Differentiating 6.0.5 with respect to $\theta$ we obtain

$$
\left.\nabla_{\tau, \tau} J\left(\xi\left(\theta_{0}\right), \tau\right)\right|_{\tau=\hat{\theta}\left(\theta_{0}\right)} \frac{\partial \hat{\theta}}{\partial \theta}\left(\theta_{0}\right)+\left.\nabla_{\xi^{(k)}, \tau} J\left(\xi\left(\theta_{0}\right), \tau\right)\right|_{\tau=\hat{\theta}\left(\theta_{0}\right)} \frac{\partial \xi^{(k)}}{\partial \theta}\left(\theta_{0}\right)=0
$$

From above equation we can compute $\partial \hat{\theta} / \partial \theta$ for all $k=1, \ldots, N$, assuming that the Hessian $\nabla_{\tau, \tau J}$ is non singular. For this we take $\varepsilon_{i}, i=1, \ldots, N$ and $\hat{\theta}\left(\theta_{0}\right)$ the expected values 0 and $\theta_{0}$, respectively. We arrive at

$$
G_{k}\left(\theta_{0}\right):=\frac{\partial \hat{\theta}}{\partial \theta}\left(\theta_{0}\right)=\mathcal{F}\left(t_{N}, \theta_{0}\right)^{-1} \mathcal{F}\left(t_{k}, \theta_{0}\right), k=1, \ldots, N
$$

where

$$
\mathcal{F}\left(t_{k}, \theta_{0}\right):=\sum_{i=1}^{k}\left(1 / \sigma_{i}^{2}\right) \nabla_{\theta} f\left(t_{i} ; \theta_{0}\right)^{T} \nabla_{\theta} f\left(t_{i} ; \theta_{0}\right), k=1, \ldots, N
$$

The matrix $\mathcal{F}\left(t_{k}, \theta_{0}\right)$ is the Fisher information matrix for our parameter estimation problem. With additional assumptions, the quantity $G_{k}\left(\theta_{0}\right)$ can be considered as an approximation of expected value of Jacobian $(\partial \hat{\theta} / \partial \theta)\left(\theta_{0}\right)$ for the case when only the first $\mathrm{k}$ measurements are assumed to vary with $\theta$. 


\section{References}

[1] Abate, N., D. Burns, R. M. Peshock, A. Garge, and S. M. Grundy. Estimation of adipose tissue mass by magnetic resonance imaging: validation against dissection in human cadavers. J. Lipid Res. 35: 1490-1496, 1994.

[2] Aileen Grassmann, Simona Gioberge, Stefan Moeller and Gail Brown, ESRD patients in 2004: global overview of patient numbers, treatment modalities and associated trends Nephrol Dial Transplant (2005) 20: 25872593 doi:10. 1093/ndt/gfi 159 Advance Access publication 4 October 2005.

[3] Andrew Kusiak, Bradley Dixon, Shital ShahPredicting survival time for kidney dialysis patients: a data mining approach Computers in Biology and Medicine 35 (2005) 311-327.

[4] Annual Data Report US Renal Data System, USRDS 2011 : Atlas of End-Stage Renal Disease in the United States, National Institutes of Health, National Institute of Diabetes and Digestive and Kidney Diseases, Bethesda, MD, Accessed on 2012, Feb 03, Website: http://www.usrds.org/atlas.htm.

[5] Am. J. Clin, The five level model: a new approach to organizing body composition research.Wang ZM, Pierson RN Jr, Heymsfield SB. 1992. Nutr. 61:457-65 
[6] Baumgartner, R. N., W. C. Chumlea, and A. F. Roche. Bioelectric impedance phase angle and body composition. Am. J. Clin. Nutr. 48: 16-23, 1988.

[7] Baumgartner, R. N., S. B. Heymsfield, S. Lichtman, J. Wang, and R. N. Pierson, JR. Body composition in elderly people: effect of criterion estimates on predictive equations. Am. J. Clin. Nutr. 53: 1345-1353, 1991.

[8] Baeyer H. V, Lajous-Petter A, Debrandt W, et al. Surface reactions on blood contact during hemodialysis and haemofiltration with various membrane types. J. Membr. Sci. 36 : 215. 1988

[9] Body composition, http://www. rowett. ac. uk/ed $u_{w e b} / s e c_{p u p} /$ body comp. pdf 1-8, retrieved on Nov 2011.

[10] Boyd R. F, Zydney A. L. Sieving characteristics of multilayer ultrafiltration membranes. J. Membr. Sci. 131 : 155. 1997.

[11] Beddhu Srinivasan, Lisa M. Pappas, Nirupama Ramkumar, and Matthew Samore, Effects of body size and body composition on survival in hemodialysis patients, J. Amer. Soc. Nephrology 14 (2003), 2366 - 2372.

[12] Bloembergen W, Hakim R, Stannard D, et al. Relationship of dialysis membrane to cause-specific mortality. Am. J. Kidney Dis. 33. 1999.

[13] Cha, K., Chertow, G.M., Gonzalez, J., Lazarus, J.M. and Wilmore, D.W. Multifrequency bioelectrical impedance estimates the distribution of body water. Journal of Applied Physiology 79, 1316-1319, 1995.

[14] Clark W. R, Gao D. Properties of membranes used for hemodialysis therapy. Seminars Dialysis 15 : 191. 2002.

[15] D. Cronin-Fine, F. Gotch, N. Levin, P. Kotanko, and M. Lysaght, A mathematical model comparing solute kinetics in low and high BMI hemodialysis patients, Internatl. J. Artificial Organs 30(11) (2007), 1000 - 1007. 
[16] David J.Anerson, Clinical Chemistry of the kidney and Renal Associated Physilogy written Material for CHM 651/751, Clinical Chemistry 2009.

[17] De Lorenzo Andreoli A., J. R. Matthie, and P. O. Withers, Predicting body cell mass with bioimpedance by using theoretical methods: a technological review, J. Appl. Physiol. 82 (1997), 1542 - 1558.

[18] Despres, J.-P., R. Ross, and S. Lemieux. Imaging techniques applied to the measurement of human body composition. In: Human Body Composition, edited by A. F. Roche, S. B. Heymsfield, and T. G. Lohman. Champaign, IL: Human Kinetics, 1996, p. 149-166.

[19] DEXA Scan, http://www. patient. co. uk/health/DEXA-Scan. htm, retrieved on Nov 2011.

[20] de Mutsert, R., Nutritional status in chronic dialysis patients : associations with development of disease and survival Doctoral thesis, Leiden University, 2009-01-29.

[21] Foster, M. A., J. M. Hutchison, J. R. Mallrd, and M. Fuller. Nuclear magnetic resonance pulse sequence and discrimination of high and low fat tissues. Magn. Reson. Imaging 2: 187-192, 1984.

[22] D. Gallagher, D. Belmonte, P. Deurenberg, Z. Wang, N. Krasnow, F. X. Pi-Sunyer, and S. B. Heymsfield, Organ-tissue mass measurement allows modelling of REE and metabolically active tissue mass, Am. J. Physiol. 275 (1998), E249 - E258.

[23] Guyton, Arthur C. Textbook of medical physiology / Arthur C. Guyton, John E. Hall. 11th ed. 2006.

[24] Gudivaka, R., Schoeller, D.A., Kushner, R.F., and Bolt, M.J. Single- and multifrequency models for bioelectrical impedance analysis of body water compartments. Journal of Applied Physiology 87, 1087-1096, 1999. 
[25] Hallan SI, Coresh J, Astor BC, et al. International comparison of the relationship of chronic kidney disease prevalence and ERSD risk. J Am Soc Nephrol 17:2275-2284, 2006.

[26] Hasan Erbil , Modeling of hemodialysis operation A thesis of Hasan Erbil at Izmir Institute of Technology, year 2008.

[27] Harold Simmons, Body composition and outcomes in dialysis patients and renal transplant recipients. Nephro-Urol Mon. 2011;3(3):155-163.

[28] Hussain, R. Kappel, F. Kotanko, P. Levin, N.W. Mathematical model for solute kinetics and body composition in hemodialysis patients, Emerging Technologies (ICET), 2010 6th International Conference (IEEE explore) 978-1-4244-8057-9 , p 118 - 123 .

[29] Iseki K, Ikemiya Y, Kinjo K, Inoue T, Iseki C, Takishita S: Body mass index and the risk of development of end-stage renal disease in a screened cohort.Kidney Int 65:1870-1876, 2004.

[30] Inga-Lill Engvall thesis , Body Composition and bone mineral density in Rheumatoid arthitis influence of inflammation and treatment with clocorticordsand TNF blocking agents. Thesis ISBN: 978-91-7409-666-8, 2009.

[31] Jacek Waniewski, Mathematical modelling of fluid and solute transport in hemodialysis and peritoneal dialysis, Journal of Membrane Science 274 (2006) 24-37.

[32] Jukka A. Salmi,Body composition assessment with segmental multi frequency bioimpedance method Kuopio, September 2003.

[33] Kappel F. , J. J. Batzel, M. Bachar, and P. Kotanko, A mathematical model comparing solute kinetics in low and high BMI hemodialysis patients, Institute for Mathematics and Scientific Computing, University of Graz, Tech. Report No. 1 (2009). 
[34] Kamyar Kalantar-Zadeh, Kevin C. Abbott, Abdulla K. Salahudeen, Ryan D. Kilpatrick, and Tamara B. Horwich, Survival advantages of obesity in dialysis patients, Amer. J. Clin. Nutrition 81 (2005), 543 - 554.

[35] F.Kappel and A.V.Kuntsevich,An implementation of shor's ralgorithm,Computational Optimization and Applications15(2000),193 205.

[36] Kenneth J. Ellis. Human Body Composition:In Vivo Methods, Vol. 80, No. 2, April 2000.

[37] Koda Y, Nishi S, Miyazaki S, Haginoshita S. Switch from conventional to high flux membrane reduces the risk of carpal tunnel syndrome and mortality of hemodialysis patients. Kidney Int. 52 : 1096. 1977.

[38] A.V.Kuntsevich and F.Kappel, http://www. kfunigraz. ac. at/imawww/kuntsevich/solvopt/.

[39] Lahti-Koski, M. Body Mass Index and Obesity Among Adults in Finland. Department of Epidemiology and Health Promotion, National Public Health Institute and Department of Public Health, Academic Dissertation, University of Helsinki, Helsinki. , p. 102, 2001.

[40] Leavey Sean F., Keith McCullough, Erwin Hecking, David Goodkin, Friedrich K. Port, and Eric W. Young, Body mass index and mortality in healthier as compared with sicker haemodialysis patients: results from the Dialysis Outcomes and Practice Patterns Study (DOPPS), Nephrol. Dial. Transplant 16 (2001), 2386 - 2394.

[41] Lipps B, Stewart R, Perkins H, Holmes G, et al. The hollow fiber artificial kidney. Trans. Am. Soc. Artif. Intern. Org. 13 : 200. 1969.

[42] Mitsiopoulos, N., R. N. Baumgartner, S. B. Heymsfield, W. Lyons, D. Galagher, AND R. Ross. Cadaver validation of skeletal muscle measure- 
ment by magnetic resonance imaging and computerized tomography. J. Appl. Physiol. 85: 115-122, 1998.

[43] Peter Kontanko, Stephan Thijssen, Thomas Kitzler, Grzegorz Wystrychowski, Size Matters: Body Composition and out comes in Maintenance Hemodialysis Patients Blood purif 2007; 25: 27-30.

[44] Polaschegg HD, Levin NW, Hemodialysis machines and monitors, in Replacement of renal function by dialysis, edited by Jacobs C, Kjellstrand CM, Koch KM, Winchester JF, 4th ed, Dordrecht, Kluwer Academic Publisher, 1996, pp 333-379.

[45] Ronco C, Fabris A, Feriani M, Hemodialysis fluid composition, in Replacement of renal function by dialysis, edited by Jacobs C, Kjellstrand CM, Koch KM, Winchester JF, 4th ed, Dordrecht, Kluwer Academic Publisher, 1996, pp 256-276.

[46] Ross, R. Magnetic resonance imaging provides new insights into the characterization of adipose and lean tissue distribution. Can. J. Physiol. Pharmacol. 74: 778-785, 1996.

[47] Ross, R. goodpaster, B., Kelly, D., and Boada, F. Magnetic resonance imaging in human body composition research.From quantitative to qualitative tissue measurement. Annals of new York Academy of science 904,12$17,2000$.

[48] Rossner, S., W. J. BO, E. Hiltbrandt, W. Hinson, N. Karstaedt, P. Santago, W. T. Sobol, and J. R. Crouse. Adipose tissue determinations in cadavers: a comparison between cross-sectional planimetry and computed tomography. Int. J. Obesity 14: 893-902, 1990.

[49] S. R. Sarkar, M. K. Kuhlmann, P. Kotanko, F. Zhu, S. B. Heymsfield, J. Wang, I. S. Meisels, F. A. Gotch, G. A. Kaysen, and N. W. Levin, 
Metabolic consequences of body size and body composition in hemodialysis patients, Kidney International 70 (2006), 1832 - 1839.

[50] D. A. Schoeller, Hydrometry, in "Human Body Composition. Human Kinetics" (A. F. Roche, S. B. Heymsfield, and T. G. Lohman, eds.), pp. 25 - 44, Champaign, IL, 1996.

[51] Schoeller,D.A.Isotope dilution methods.In:Obesity, edited by P. Bjorntorp and B. N. Brodoff. New York: Lippincott, 1991, p.80-88.

[52] Schoeller,D. A. Hydrometry. In: Human Body Composition, edited by A. F. Roche, S. B. Heymsfield, and T. G. Lohman. Champaign, IL: Human Kinetics, 1996, p. 25-43.

[53] Scribner BH, Buri R, Caner JE, Hegstrom R, Burnell JM: The treatment of chronic uremia by means of intermittent hemodialysis: a preliminary report.Trans Am Soc Artif InternOrgans 6: 114-122. 1960.

[54] Sheng,H.P., AND R. A. Huggins. A review of body composition studies with emphasis on total body water and fat. Am. J. Clin. Nutr. 32: 630-647, 1979 .

[55] Steven B., Heymsfield and ZiMian Wang, Richard N. Baumgartner, Rober Ross, Human Body Composition:Advances in Models and Methods, Annu. Rev. Nutr. 1997. 17:527-58.

[56] Stengel B, Tarver-Carr ME, Powe NR, Eberhardt MS, Brancati FL: Lifestyle factors, obesity and the risk of chronic kidney disease.Epidemiology 14:479-487, 2003.

[57] Sunny Eloot,Experimental And Numerical Modelling of Dialysis, PhD thesis Ghent University, Year 2004-2005.

[58] Sutcliffe, J. F. A review of in vivo experimental methods to determine the composition of the human body. Physics Med. Biol. 41: 791-833, 1996. 
[59] Tagliabue, A., Andreoli, A., Comelli, M., Bertoli, S., Testolin, G., Oriani, G. and De Lorenzo, A. Prediction of lean body mass from multifrequency segmental impedance: influence of adiposity. Acta Diabetologica 38, 93-97

[60] Thomas, L. D., D. Van Der Velde, and P. R. Schloeb. Optimum doses of deuterium oxide and sodium bromide for the determination of total body water and extracellular fluid. J. Pharm. Biomed. Analysis 9: 581-584, 1991.

[61] Wang, Z., Deurenberg, P.,Wang W., Pietrobelli, A., Baumgartner, R.N. and Heymsfield, S.B. Hydration of fat free body mass: review and critique of classic body composition constant. American journal of clinical Nutrition 76, 833-841, 1999.

[62] Wang, Z., Pi-Sunyer, F.X., Kotler, D.P., Wielopolski, L., Withers, R.T., Pierson, R.N., Jr. and Heymsfield, S.B. Multicomponent methods: evaluation of new and traditional soft tissue mineral models by in vivo neutron activation analysis. American journal of clinical Nutrition 76, 968-974, 2002 .

[63] Wang, Z., Z.M., Deurenberg, P., Guo, S.S., Pietrobelli, A., Wang, J., Pierson, R.N., Jr. and Heymsfield, S.B. Six-compartment body composition model: inter-method comparisons of total body fat measurement. International journal of Obesity and Related Metabolic Disorder 22, 329-337, 1998.

[64] Wong,W. W., W. J. Cochran, W. J. Klish, E. O. Smith, L. S.Lee, And P. D. Klein. In vivo isotope-fractionation factors and the measurement of deuterium- and oxygen-18-dilution spaces from plasma, urine, saliva, respiratory water vapor, and carbon dioxide. Am. J. Clin. Nutr. 47: 1-6, 1988.

[65] Woffindin C, Hoenich N. A. Hemodialyzer performance: a review of the trends over the past two decades. Artif. Org. 19 : 1113. 1995. 
[66] F. Zhu, D. Schneditz, E. Wang, and N. W.Levin, Dynamics of segmental extracellular volumes during changes in body position by bioimpedance analysis, Journal of Applied Physiology 85 (1998), 497 - 504.

[67] Self-Learning, Principles of Continuous Renal Replacement Therapy SelfLearning Packet 2005.

[68] F. Zhu, M. K. Kuhlmann, G.A. Kaysen, S. Sarkar, C. Kaitwatcharachai, R. Khilnani, L. Stevens, E. F. Leonard, J. Wang, S. Heymsfield, N. W. Levin, Segment-specific resistivity improves body fluid volume estimates from bioimpedance spectroscopy in hemodialysis patients, J. Appl. Physiol. 100 (2006), 717 - 724. 